\title{
EFFECTS OF A COMPREHENSIVE ARRAY OF DROPOUT-PREVENTION INTERVENTIONS: RESPONDERS VS. NON-RESPONDERS
}

\author{
A Dissertation submitted to the faculty of \\ San Francisco State University

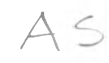 \\ 35 \\ 2017 \\ .866 \\ In partial fulfillment of \\ the requirements for \\ the Degree \\ Doctor of Education \\ In
}

Educational Leadership

by

Joshua Wing-Yun Pong

San Francisco, California

August 2017 


\section{CERTIFICATION OF APPROVAL}

I certify that I have read Effects of a Comprehensive Array of Dropout Prevention Interventions: Responders vs. Non-Responders by JoshuaWing-Yun Pong, and that in my opinion this work meets the criteria for approving a thesis submitted in partial fulfillment of the requirement for the degree Doctor of Education in Educational Leadership at San Francisco State University.

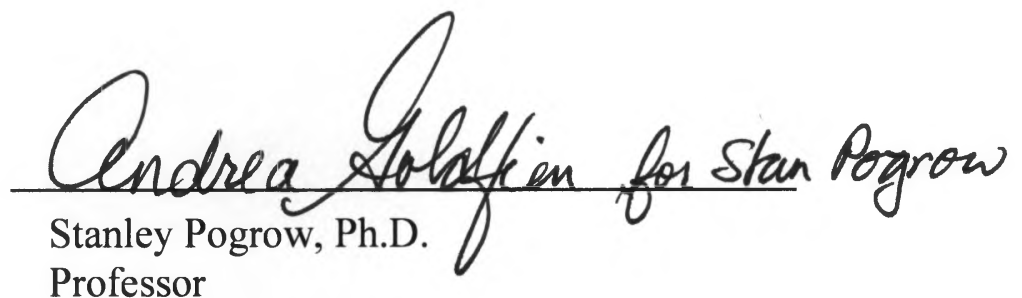

Professor

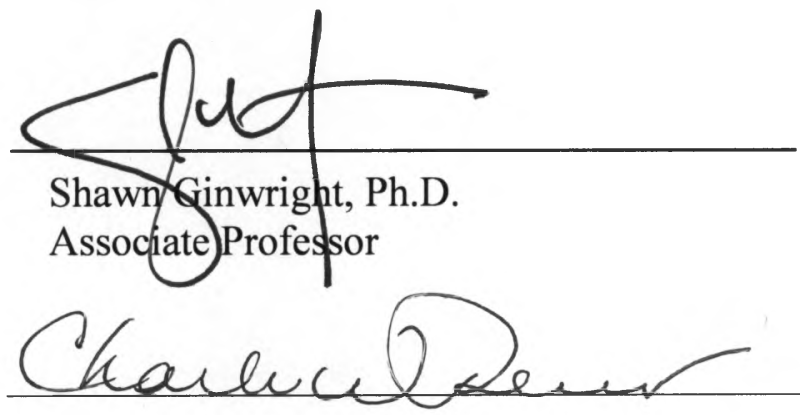

Charles Plant, Principal at MetWest 


\title{
EFFECTS OF A COMPREHENSIVE ARRAY OF DROPOUT-PREVENTION
} INTERVENTIONS: RESPONDERS VS. NON-RESPONDERS

\author{
Joshua Wing-Yun Pong \\ San Francisco, California
}

2017

A plethora of dropout-prevention interventions exist, many as standalone programs and some as ecological approaches that wield many programs at once. The effectiveness of these programs are widely variable. While there is some knowledge of which interventions seem effective for the short term, little is known about those students for whom the interventions did not work or what happens to those who continue to struggle. Intervention effectiveness research has traditionally ignored students who dropped out after the interventions ran their course. It is likely that either the interventions failed to sufficiently differentiate amongst the target populations or they failed to take some unknown element into account.

This research examines why students in grades 10-12 were struggling to respond, or not responding, to one of the strongest arrays of interventions available. I conclude that students' mental health plays a key role in dropping out despite intervention. I make several practical suggestions surrounding student mental health and other strategies that site administrators can use to improve their intervention effectiveness, and ultimately prevent their least responsive students from dropping out and graduating. It is likely that if a site experiences success with this subpopulation, all its struggling students will be helped.

I certify that the Abstract is a correct representation of the content of this dissertation.
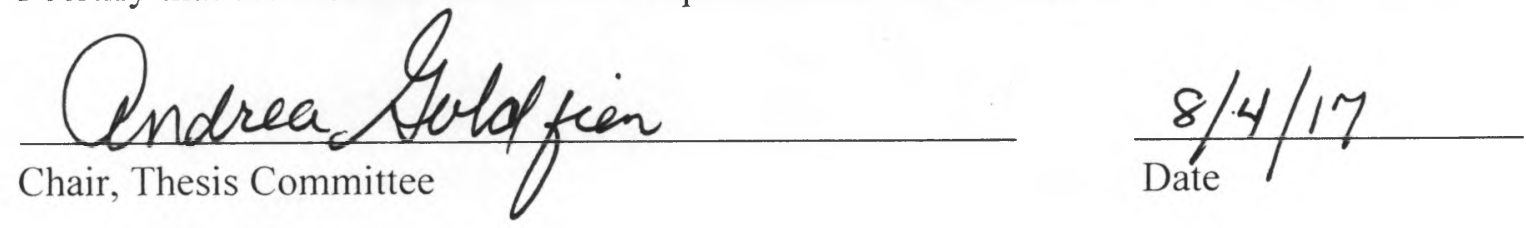


\section{ACKNOWLEDGEMENTS}

The candidate would like to first and foremost thank his wife because she forbore four years of husband absenteeism with grace. Thanks are also due to (a) Maia Steward for being a guiding force in this research, (b) Mimi-Page Broughton for being a staying force within this program, and (c) Andrew Kwong and Kevin Chisaki for working far below their worth.

The candidate extends thanks to (a) Charlie Plant for letting him be immersed in MetWest for two years, (b) Dr. Stan Pogrow for enduring with great patience the process of turning him into a decent writer, and (c) Dr. Shawn Ginwright for turning his mind to areas of research he had not considered.

Finally, the candidate dedicates this study to his father, who passed away believing that his son would finish. 


\section{TABLE OF CONTENTS}

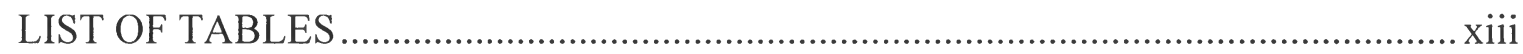

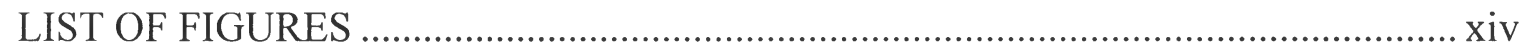

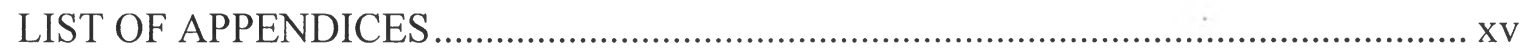

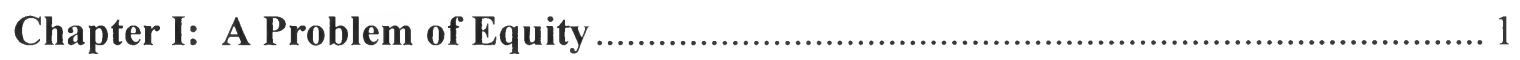

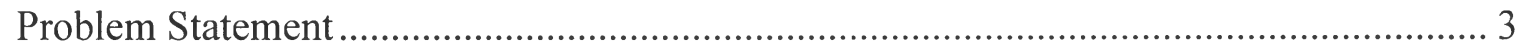

MetWest as Context for Proposed Research................................................................... 7

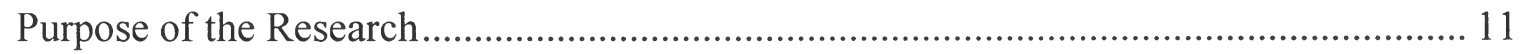

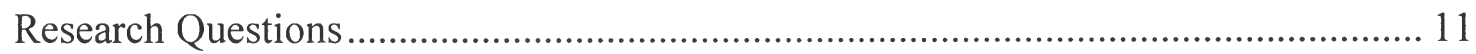

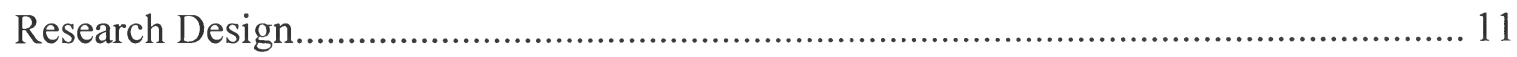

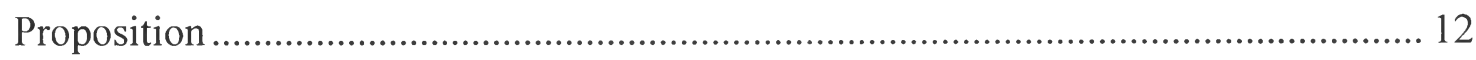

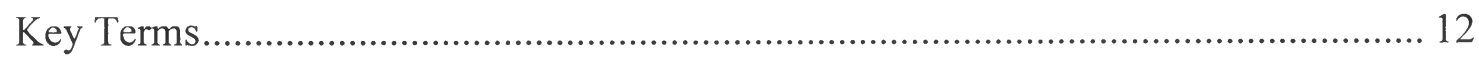

Significance of the Proposed Study ............................................................................ 13

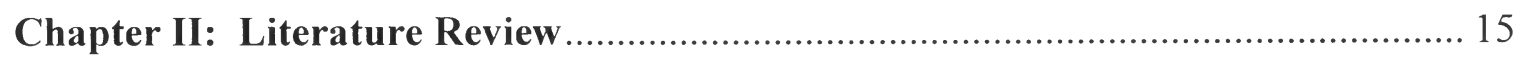

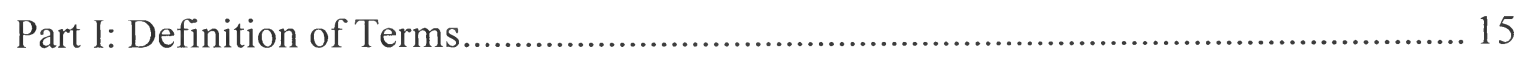

Part II: Methodology of the Literature Review............................................................ 17

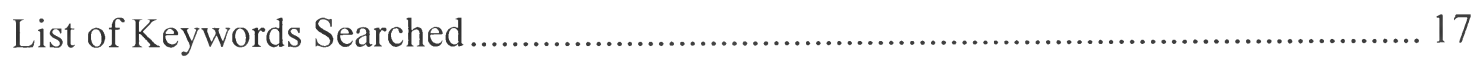




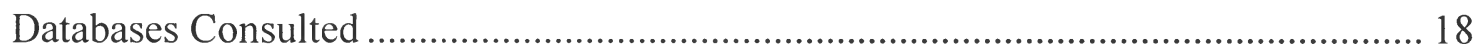

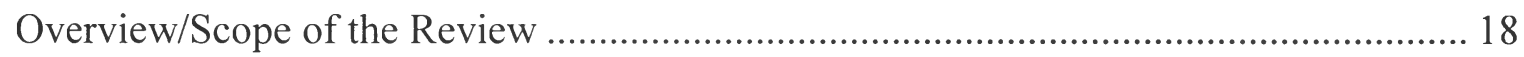

Criteria for Selecting Sources for the Review ……….............................................. 18

Key Constructs/Sub-Constructs Guiding the Review.................................................. 19

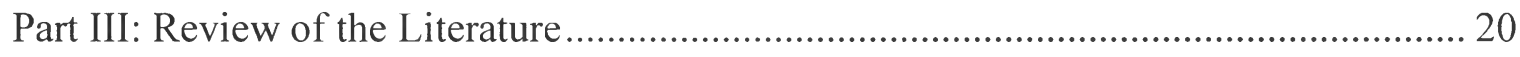

General Characteristics of Dropout Students................................................................ 20

Individual Student Factors That Predict Dropout ........................................................... 20

Students' experiences as a predictor of dropout. ........................................................ 20

Academic attitude as a predictor of dropout. ............................................................. 22

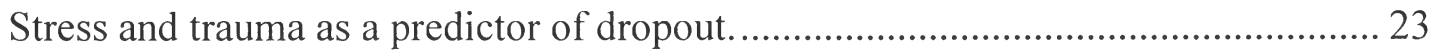

Predictive validity of individual student factors for dropping out ............................. 27

School Factors That Predict Dropout Events............................................................... 29

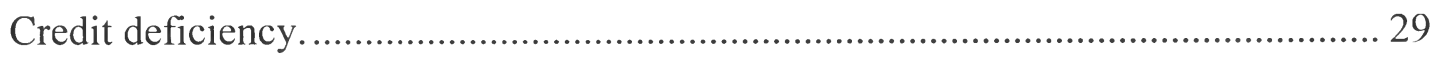

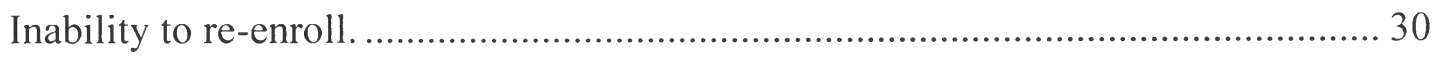

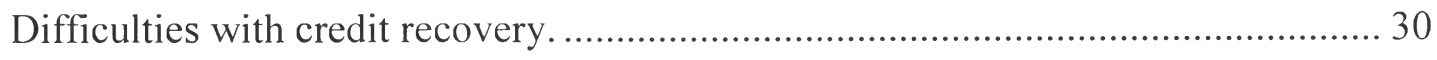

Predictive validity of school factors for dropping out.............................................. 31

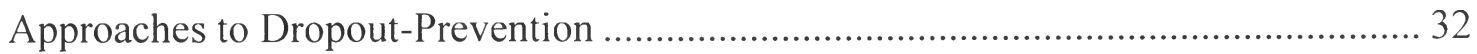


Meta-analysis of Effectiveness of Dropout-Prevention Interventions

Limitations of the meta-analysis.

Standalone Approaches to Dropout Prevention..................................................... 36

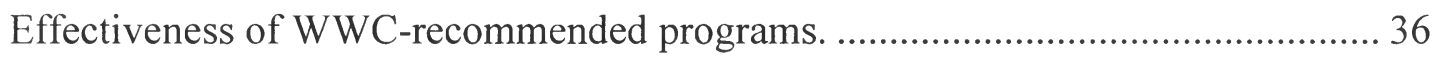

Effectiveness of truancy prevention programs ................................................. 42

Effectiveness of trauma interventions.......................................................... 43

Summary of effects of standalone approaches.................................................. 47

Ecological Approaches to Dropout-prevention ..................................................... 48

Effectiveness of Community schools........................................................ 48

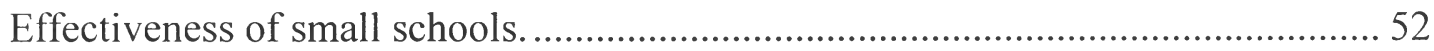

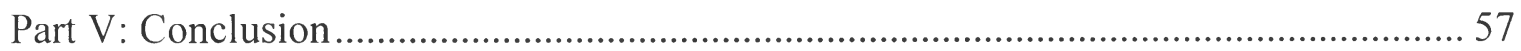

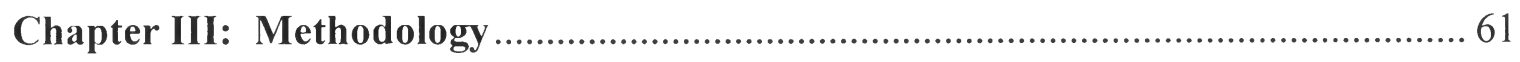

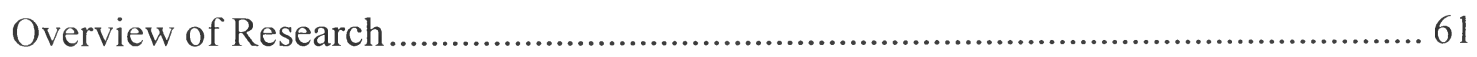

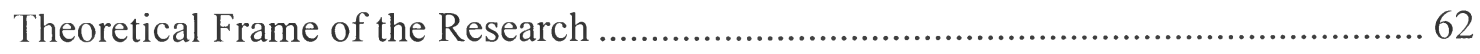

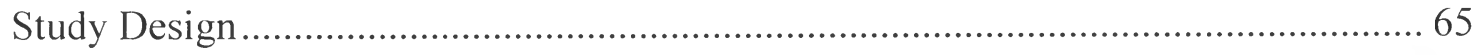

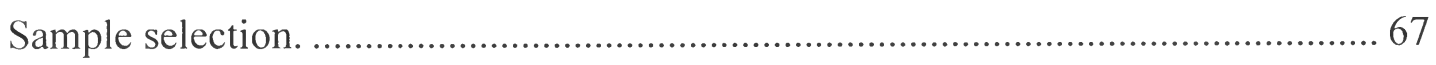

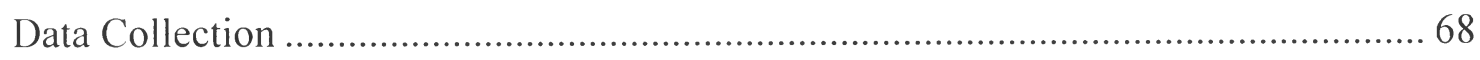


Role of the researcher.

Consideration of ethics. 70

Participant recruitment. 71

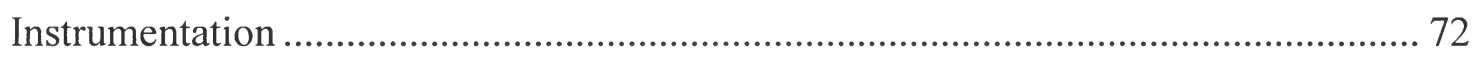

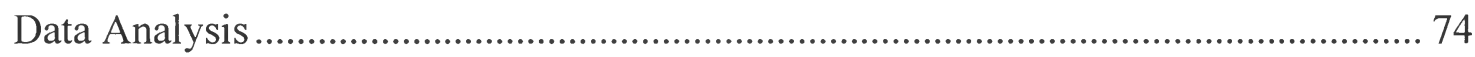

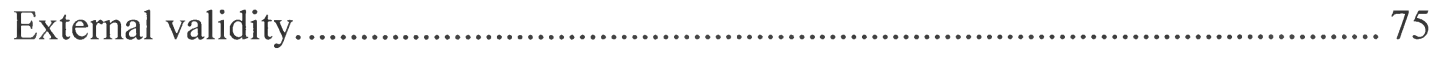

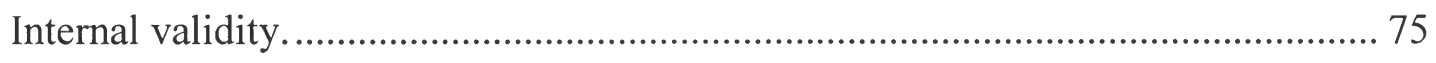

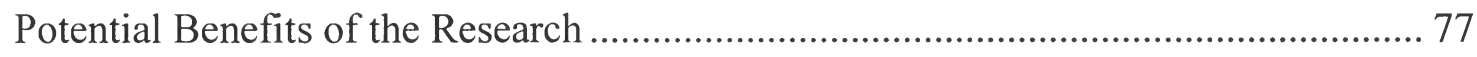

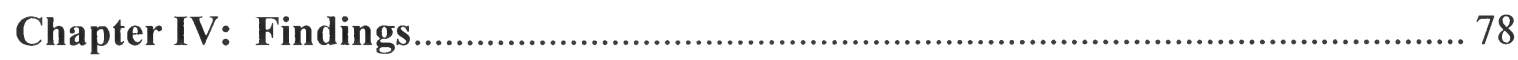

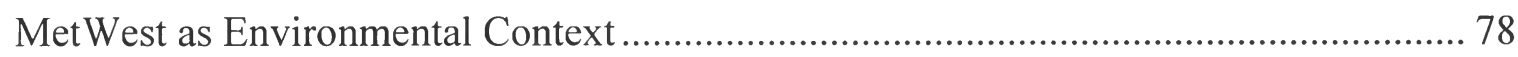

A Description of the School Microsystem ...................................................................... 79

Partnership With The Community Microsystem ......................................................... 80

Cooperation With The Home Microsystem .................................................................. 81

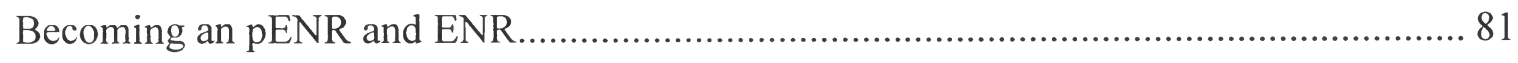

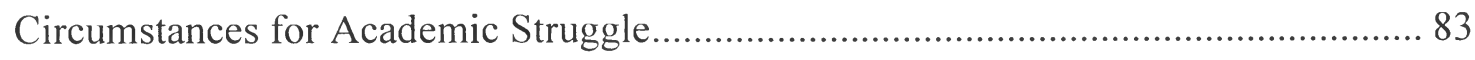

Personal trauma

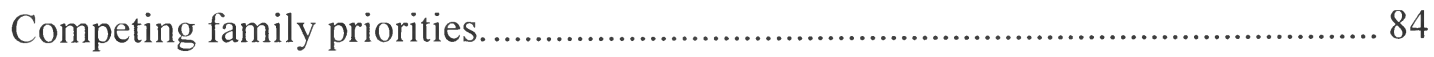




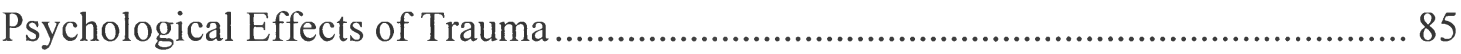

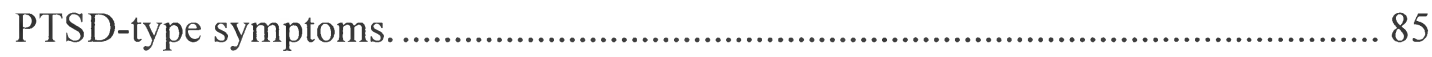

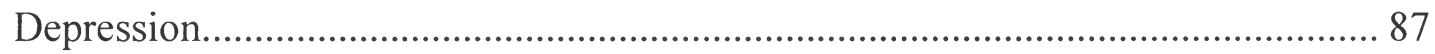

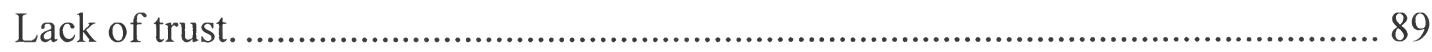

Psychological Effects of Competing Family Priorities.......................................... 90

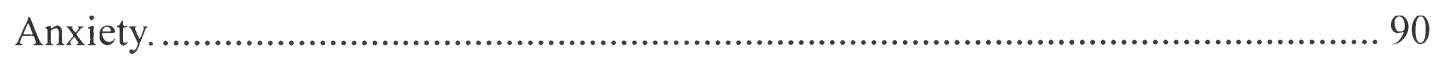

How past trauma exacerbates academic struggle............................................. 93

Psychological Effects and Becoming a pENR ................................................... 95

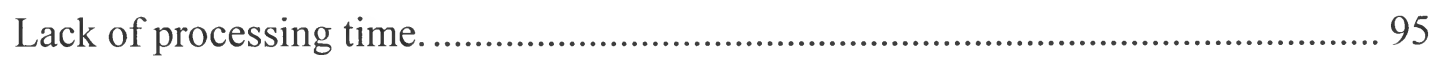

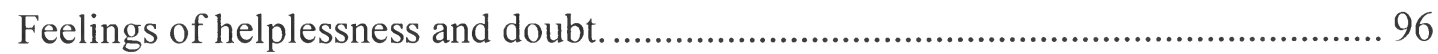

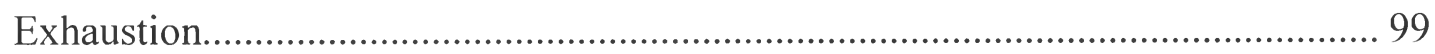

Conditions That Exacerbate Becoming pENR/ENR ............................................ 100

Volatile Home Microsystems ................................................................... 100

Cultural differences can facilitate volatility............................................... 101

Intergenerational trauma can facilitate volatility......................................... 103

Families' Sole Dependence on the Student ...................................................... 105

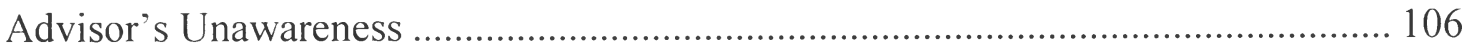




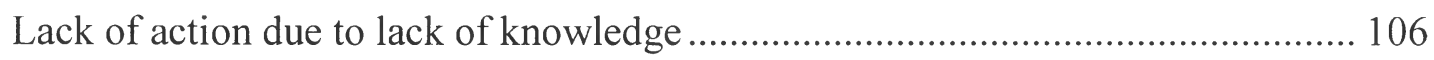

Uninformed actions facilitate becoming ENR ..................................................... 110

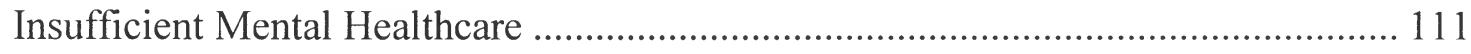

Summary Of The Process Of Becoming An ENR..................................................... 113

Protective Factors From Dropping Out........................................................................ 113

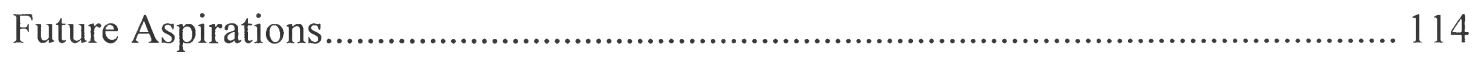

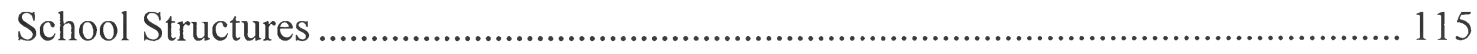

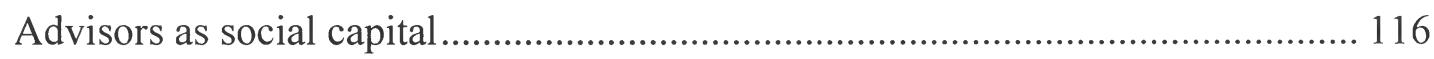

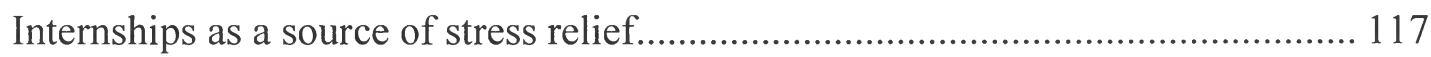

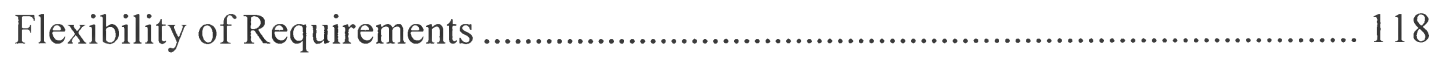

The Difference Between pENRs and ENRs ………….............................................. 120

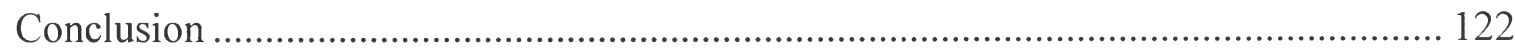

Chapter V: Significance of the Findings and Recommendations.......................... 125

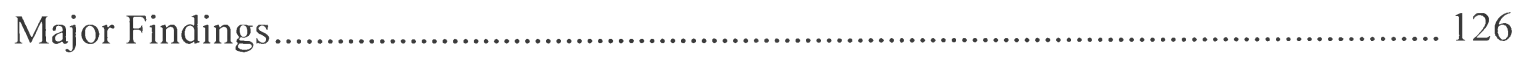

Why Some Students Do Not Respond to Intervention ............................................ 126

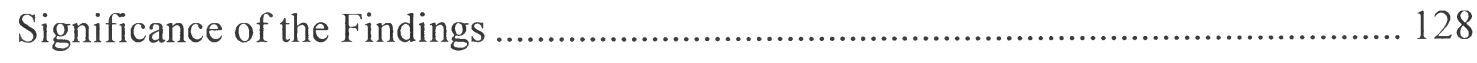

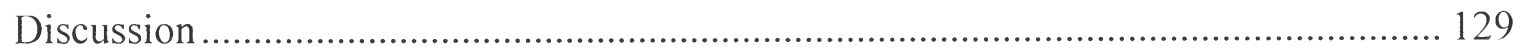




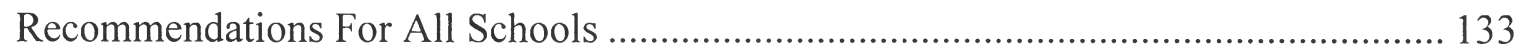

Recommendations For Traditional High Schools....................................................... 135

Recommendations for Improving MetWest Services ................................................. 137

Recommendations Surrounding Student Mental Health............................................ 138

Recommendations Surrounding Competing Family Priorities .................................... 140

Recommendations For Further Research................................................................ 142

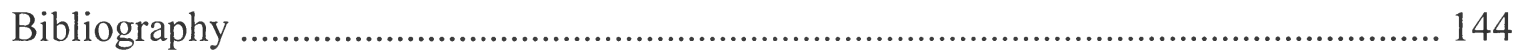

Appendix A: Permission to Perform Research at MetWest Oakland .............................. 154

Appendix B: General Recruiting Script for Students .................................................... 155

Appendix B2: General Recruiting Script for Staff Members ........................................ 156

Appendix C: Assent Form for Students ………………........................................ 157

Appendix D: Parent/Guardian Permission Form .......................................................... 161

Appendix E1: Semi-Structured Interview Protocols for Students .................................. 164

Appendix E2: Semi-Structured Interview Protocols for Staff ....................................... 164

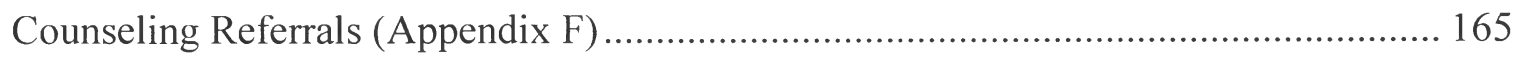




\section{LIST OF TABLES}

Table

Page

1. MetWest and OUSD student populations, 2014-2015...................4

2. MetWest and OUSD performance metrics, 2013-2014 .....................5

3. A Summary of pENRs'/ENRs'characteristics..........................................82-83 


\section{LIST OF FIGURES}

Figures

Page

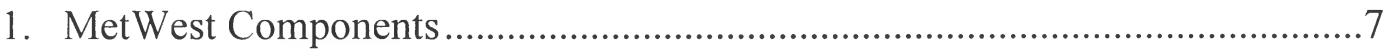

2. Bronfenbrenner's Theory Applied to Schools.................................................64 


\section{LIST OF APPENDICES}

Appendix Page

1. Permission to Perform Research at MetWest Oakland.........................154

2. General Recruiting Script for Students ................................ 155

3. General Recruiting Script for Staff Members ............................. 156

4. Assent Form for Students ..........................................157-158

5. Consent Form for Staff Members............................... 159-160

6. Parent/Guardian Permission Form..................................161-163

7. Semi-Structured Interview Protocols for Students......................... 164

8. Counseling Referrals................................................. 165 


\section{Chapter I: A Problem of Equity}

Many students attending schools within low-income neighborhoods in the United States are marginalized by a long-existing opportunity gap (Wilson, 2009; Ginwright, 2004; Ladson Billings, 2006), defined as "the accumulated differences in access to key educational resources" (Darling-Hammond, 2010, p.28). Their higher-income counterparts have substantially greater access to educational resources such as welltrained teachers, modern facilities, engaging curriculum, and extracurricular activities (Darling-Hammond, 2010).

Students of higher-income families also tend to have access to external education aids associated with academic success, such as tutors, college-educated parents, their parents' friends, and coinciding professional networks that provide knowledge, futureoriented perspective, and guidance (Erickson, McDonald, \& Elder, 2009; Roska \& Potter, 2011). In contrast, low-income youth must learn to navigate the academic world hindered by variables associated with poverty, such as run-down and underfunded schools, single-parent homes, neighborhood violence, a lack of college-educated parents or role models, chronic poverty-related stress, and past or persistent trauma experiences (Herrera, DuBois, \& Grossman, 2013; Parks-Yancy, 2012, Wadworth, Raviv, Reinhard, Wolff, Santiago, \& Einhorn, 2008).

Due to a confluence of historically discriminative practices, the opportunity gap manifests itself as an academic achievement gap that runs along racial and socioeconomic lines. In 2013, 38\% of Black male students and 33\% of Latino male students, all aged 0- 
17 , lived in poverty, in contrast to only $12 \%$ each of White and Asian male students (National Center for Education Statistics, 2015). In that same year, Black and Latino male students scored 20 and 10 points respectively below the national average in reading, and 22 and 13 points respectively below the national average in mathematics (NCES, 2015).

The lower gains in achievement scores for Black and Latino students are also reflected in graduation rates. In 2012, Black students experienced a double-digit gap in graduation rates from their White counterparts in 39 states, between 10\% and 33\% depending on the state (Balfanz, Bridgeland, Fox, DePaoli, Ingram, \& Maushard, 2014). Likewise, Latino students experienced a double-digit gap in graduation rates from their White counterparts in 31 states, ranging from $11 \%$ and $31 \%$ depending on the state (Balfanz et al., 2014). Only three states failed to report any data on graduation rates.

The achievement gap has narrowed over the last decade, proof that the situation is not irreversible. From 2000 - 2014, the percentage of Black male students 18-24 years old who had not completed high school decreased, from 33\% to 20\% (NCES, 2015). Likewise, similar Latino students decreased from $46 \%$ to $28 \%$ (NCES, 2015). As of 2013 , college attendance increased from $25 \%$ to $31 \%$ for Black students, and from $18 \%$ to $29 \%$ for Latino students (NCES, 2015). While the achievement gap fluctuates year to year, data disaggregated by both socioeconomic status (SES) and race/ethnicity show it has moderately narrowed overall since 1975 (Chapman, Laird, Ifill, \& KewalRamani, 2011). 
The nation's progress on narrowing the achievement gap is also reflected in California. California currently uses the federally developed Adjusted Cohort Graduation Rate (ACGR) as its graduation formula, defined as the number of students who have obtained high school diplomas within four years divided by the number of students that make up a given year's cohort. The cohort includes dropout students, and is "adjusted" by adding or subtracting transfers, deaths, and so on. Under this system, graduation rates for Black and Latino students have both risen by 3\% between 2011 and 2014. Within that same period, graduation rates for White students rose only $1 \%$ and remained static for Asian students (NCES, 2014; Balfanz, 2014). The achievement gap in California has slightly narrowed, but much work must be done on both the state and national levels to close the achievement gap completely, especially in high-poverty urban areas such as Oakland.

\section{Problem Statement}

MetWest High School, hereafter referred to as "MetWest", was designed to help close Oakland's achievement gap by addressing the student population's opportunity gap. The site has systemically integrated a comprehensive array of dropout prevention supports and resources into its daily educational practice which successfully serve most of its student population. This study focused on the narrow group of students who remain on the precipice of dropping out despite MetWest's support systems in place. 
MetWest's Latino student population is slightly overrepresented compared to Oakland Unified School District's (OUSD) student population. MetWest's Black student population is approximately equivalent to that of OUSD's. Low-income students, which include all ethnicities in MetWest, are also approximately equivalent. Table 1 juxtaposes MetWest's student population with OUSD's.

Table 1 MetWest and OUSD student populations, 2014-2015

Race/Ethnicity demographics

\begin{tabular}{|c|c|c|}
\hline Race/Ethnicity & MetWest (\# of students) & $\underline{\text { OUSD }}$ \\
\hline Asian/SE Asian & $6.3 \%(10)$ & $13.9 \%$ \\
\hline Black or African American & $27.3 \%(44)$ & $26.7 \%$ \\
\hline Hispanic or Latino & $59.6 \%(96)$ & $43.8 \%$ \\
\hline White & $5.6 \%(9)$ & $9.8 \%$ \\
\hline Two or more races & $0.6 \%(1)$ & $2.7 \%$ \\
\hline \multicolumn{3}{|l|}{ Other demographics } \\
\hline English Learners (EL) & $21.1 \%(34)$ & $32.3 \%$ \\
\hline Free/Reduced Price Lunch & $79.5 \%(128)$ & $74.5 \%$ \\
\hline
\end{tabular}

Table 1 Retrieved from: www.ed-data.org

As Table 1 indicates, MetWest is $86.9 \%$ Black and Latino (as opposed to $70.5 \%$ in OUSD) and 79.5\% low-income (as opposed to 74.5\% in OUSD). According to the site principal, most of MetWest's student body lives in East Oakland, the area with the highest poverty, most chronic health problems, and highest dropout rates. However, it should be noted that MetWest's English Learner (EL) subpopulation (21.1\%) is lower than OUSD's (32.3\%). The MetWest student population is therefore slightly more at-risk of dropout compared to their OUSD peers in some, but not all, categories. 
Despite its approximately-equivalent higher-risk student population, MetWest's students do very well in comparison to the whole district. Table 2 juxtaposes MetWest student academic measures with OUSD's student academic measures. Incomplete data sets, those which did not report both school and district data for comparison, were omitted.

Table 2 MetWest and OUSD performance metrics, 2013-2014

\begin{tabular}{|c|c|c|}
\hline Performance metric & MetWest & OUSD \\
\hline CAHSEE $10^{\text {th }}$ English (\% Passed) & $75.0 \%$ & $63.0 \%$ \\
\hline CAHSEE $10^{\text {th }}$ Math ( $\%$ Passed) & $78.0 \%$ & $68.0 \%$ \\
\hline AGCR & $71.4 \%$ & $60.5 \%$ \\
\hline Graduates meeti & $81.8 \%$ & $49.1 \%$ \\
\hline
\end{tabular}

Table 2 Retrieved from www.ed-data.org

As Table 2 shows, tenth-grade MetWest students outperformed the district average in English (75\% compared to 63\%) and Math (78\% compared to $68 \%)$. Twelfthgrade MetWest students experienced higher graduation rates than the OUSD average ( $71.4 \%$ compared to $60.5 \%$ ). Further, $81.8 \%$ of those graduates were UC/CSU ready, compared to $49 \%$ of graduates from OUSD.

MetWest's success extends past high school. A longitudinal study between 20062011 showed that $74 \%$ of students enrolled into postsecondary education within one year of graduation, compared to the national average of $31 \%$ for schools with similar demographics (MPR Associates Inc., [hereafter MPR] 2013, p.1). Within MetWest's body of postsecondary enrollees, $53 \%$ of MetWest graduates enrolled into 4-year institutions, compared to the national average of $41 \%$ (MPR, 2013, p.10). After 2 years of postsecondary enrollment, $70 \%$ of MetWest graduates were still enrolled, $8 \%$ higher 
than the national average (MPR, 2013, p.11). Many MetWest graduates worked while enrolled.

All told, MetWest has done very well for its traditionally-marginalized student population, due to its comprehensive array of interventions and supports. However, MetWest still has students who fail to respond to all sustained efforts to engage them from the comprehensive array of academic supports and drop out. Hereafter, such students will be referred to as "extreme non-responders" (ENRs). Another narrow band of students (a) have only sporadically responded to sustained efforts by MetWest's supports, (b) are low achieving or underachieving, and (c) are consequently perilously close to dropping out. Hereafter, these students will be referred to "probable ENRs" (pENRs). The key delineation both groups share is that both groups have experienced the full array of services offered to them.

A ninth or tenth grade student will occasionally drop out, but this occurs at less than a rate of one per school year. This research will not examine students who dropped out of MetWest during their ninth and tenth years because (a) it is recognized that almost all ninth and tenth grade students have a high chance of remediation prior to their eleventh year, and (b) ninth and tenth grade students have not experienced full, sustained exposure to the comprehensive supports.

MetWest appears to have learned how to consistently realize academic success for most of its marginalized student population, but doing so for its ENR and pENR student subpopulations remains an unsolved problem. This research intends to (a) listen to both 
groups' voices to understand why they struggled to respond after exhausting the existing array of interventions, and (b) propose suggestions for new interventions or alterations to existing programs, to ensure that no MetWest students are "left behind".

\section{MetWest as Context for Proposed Research}

MetWest's unique comprehensive array of academic helps for dropout prevention allows the school site to serve as an excellent research context. This array operates at every level, starting with on-site social-justice practices by school staff and extending outwards towards on-site wraparound services performed by community-based partners. All of these are a direct result of MetWest's organizational structure and supportive district policy. Below is Figure 1, a visual representation of MetWest as an educational site.

\section{Figure 1: MetWest components}

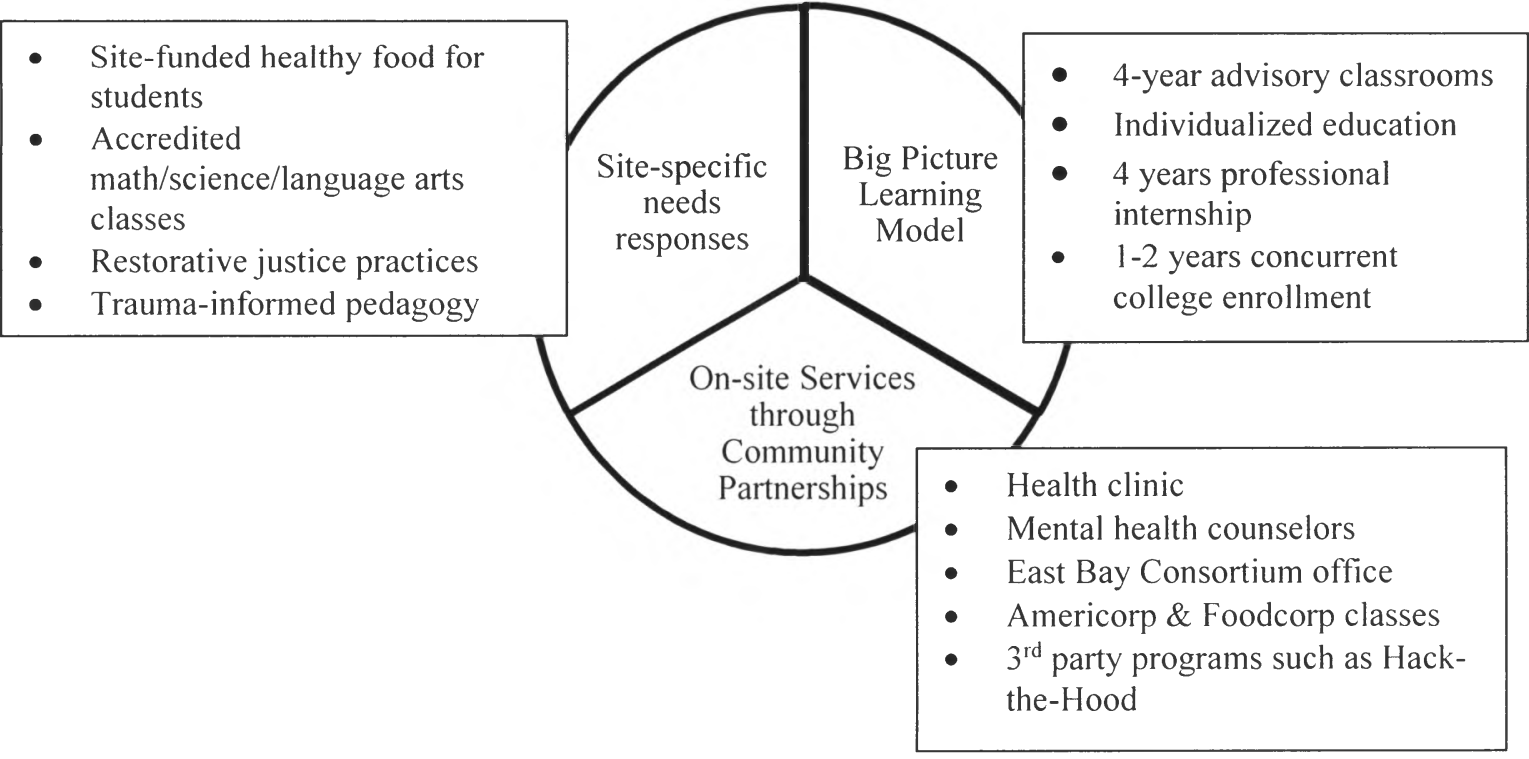


Four aspects of MetWest Oakland High School (MetWest) distinguish its array of supports to prevent students from dropout. First, MetWest is classified as a small school of choice (SSC), one of only three (Lifehouse and Coliseum College Prep Academy are the others) within OUSD. All three are choice schools for students who felt they could not flourish in a traditional secondary school. To date, all the small schools have consistently outperformed the district in graduation rates and test scores.

Second, MetWest is a Full Service Community School (FSCS), one FSCS of 27 in OUSD. Its FSCS designation indicates that (a) students have access to communitybased services that MetWest itself cannot readily provide, (b) community-based services are often, but not always, provided on-site, and (c) services provided by MetWest were chosen in partnership between the school district, the student population, and the surrounding community (Valli, Stefanski, and Jacobson, 2014). OUSD has 53 more schools not classified as FSCS.

Every FSCS is unique in types and extent of services offered, each with its own set of locally-formed partnerships democratically selected to meet the needs of its student body (Castrechini \& London, 2012; Valli et al., 2014). Some of MetWest's offerings include a youth health center connected to the school, on-campus tutors, admissions counselors, scholarship helps, writing/research tutors, on-site job fairs, interest-based offerings from community-based organizations, partnerships with the local community college, and more. 
Third, MetWest is also a Big Picture Learning (BPL) affiliate. All BPL Schools utilize a three-pronged approach to realizing academic success for traditionallymarginalized student populations. The first prong consists of individualized education via advisories. BPL advisories differ from traditional advisory periods in both function and scope. BPL advisories are accredited, social-justice oriented courses that comprise a mixture of history, ethnic studies, and writing composition. BPL advisories also have dedicated teachers who act in the capacity of case managers: mentor, academic advisor, family liaison, and life coach for twenty students throughout their four years. For clarification, these teacher advisors are credentialed teachers, but not credentialed casemanagers. The teacher advisors (hereafter known simply as "advisors") coordinate between parents, internship advisor, college counselors, admissions counselors, and students throughout the students' tenures.

The second and third prongs are placed within the local community but proctored by a student's advisor. The second prong is a mandatory interest-based professional internship every year of high school enrollment. The third prong is mandatory concurrent enrollment in at least one community college course during the $11^{\text {th }}$ and $12^{\text {th }}$ years. In each of these areas, students are allowed to pursue whatever subject matter they wish, so long as they can meet baseline knowledge and skill competencies.

To be clear, even though OUSD's other small schools share aspects of the Big Picture Model they differ in format and programming. Further, the small schools are unaffiliated with BPL. Colisseum College Prep Academy utilizes traditional classes the 
first two years and requires internships in the last two years, whereas MetWest utilizes advisors and internships throughout all four years of high school. Life Academy utilizes a two-component system similar (if not identical) to MetWest's but with a limited focus of empowering low-income Oakland youth to join the healthcare industry. MetWest has no such specialization, effectively taking on all students regardless of career aspirations.

Finally, MetWest goes beyond the BPL model and provides extra, site-specific attempts to meet the needs of its students. For example, the school twice daily provides healthy and nutritious food for its students in place of the high-calorie/high-sugar food the district distributes to all its schools. Consequently, MetWest's food costs are all paid through school funds instead of district funds. Every teacher has professional development in trauma-informed pedagogy in order to help teachers correctly perceive and respond to disruptive classroom behaviors often manifested by low-income students who have experienced trauma commonly associated with low-income environments.

To sum up, MetWest serves as an ideal environmental context for the proposed research. It has a wider and more intensive array of supports and services than any other schools in Oakland or in the research literature. Most of its marginalized students respond very well to the array presented. That said $25-30 \%$ of its student population, hereafter known as pENR's, still struggle to respond and are on the verge of dropping out. Some of these pENRs will drop out and become ENRs. 


\section{Purpose of the Research}

Regardless of MetWest's high amount of success, one can reasonably expect that any given intervention will work better with some than others because marginalized students are a heterogeneous conglomeration of students. The pressing question is, "What more can MetWest do to improve the response of its pENRs and ENRs?" The purpose of this study is to better understand why the pENR and ENR subpopulations are not responding as well to MetWest's wide array of services compared to the rest of MetWest's student body.

\section{Research Questions}

1. Why do some students not respond well despite a wide array of services that successfully helps most?

2. What differentiates extreme non-responsive students who drop out in years 3 or 4 from students who sporadically struggle to respond but do graduate?

3. How can schools better reduce dropout rates at the different stages of students' struggles?

\section{Research Design}

This research was a qualitative study comprised of thirteen case studies, seven pENRs, one ENR, and five school staff who worked closely with them. A series of interviews with both current students and former students who dropped out sought to establish their current world and perspectives to better understand the process of 
becoming an ENR. These interviews were triangulated against staff interviews, and student transcripts to allow for a more objective and comprehensive understanding of the hurdles that ENRs face and consequent needs. Analysis was expected to draw out strengths, challenges, and needs to better understand ENRs as a subpopulation and make recommendations to MetWest regarding their services to them.

\section{Proposition}

This research is largely exploratory so no propositions were presented in advance. The exploratory interviews and data analysis utilized grounded theory to find emergent themes to answer the research questions.

\section{Key Terms}

- Extreme non-responder (ENR): any student within a school site's marginalized student subpopulation that failed to respond to all sustained efforts from the provided comprehensive array of academic supports and consequently dropped out in their third or fourth year.

- Probable Extreme Non-Responder(pENR): any student within a school site's marginalized student subpopulation that has only sporadically responded to all sustained efforts from the provided comprehensive array of academic supports, is low achieving or underachieving, and on the verge of dropping out in their third or fourth year. 


\section{Significance of the Proposed Study}

Students in low-income urban districts still drop out despite access to the strongest array of interventions, but no research has attempted to understand why. This research will provide a more fine-grained understanding of the nature of students who drop out; particularly those who drop out after all known effective interventions have been exhausted. It will also provide a new way to understand the process of dropping out.

This study will provide a new perspective on the study of dropouts in the following respects:

1. This study examined dropout students at a highly successful, high-poverty urban school.

2. This study examined students at a school that has a more comprehensive array of supports and services than most other schools in Oakland or in the research.

3. This study established a more precise differentiation of marginalized student populations using a concept of responsiveness over time.

Improved differentiation of marginalized student subpopulations will enable site administrators to target students with appropriate interventions most suited to their needs. Site administrators will be able to improve key elements on their already-existent intervention arrays, and add more appropriate interventions not yet on the array. Additionally, it is likely that providing interventions to improve pENRs' responsiveness will also improve all students' responsiveness to comprehensive intervention arrays. 
By understanding the process of student dropout better, site administrators will be able to improve the cost-effectiveness of interventions. Improved differentiation will allow for a tiered response of intervention. Tiered responses are more feasible because they only apply to a select target audience rather than everyone.

Finally, site administrators will be able to add elements specifically to help prevent dropout of their pENRs. By definition, pENRs are those students who are struggling to not drop out after all other known interventions were applied, sustained, and ultimately failed. Providing characteristics of ENRs will help site administrators develop programs appropriate to their own pENR subpopulations.

\section{Conclusion}

This research explored pENRs'/ ENRs' microsystems through their experiences to understand what hindered their academic progress regardless of MetWest's largely successful practices. This exploratory study provides insight on characteristics of pENRs / ENRs and recommendations to help improve their responsiveness to the comprehensive array. In this way, MetWest may well prevent pENRs from dropping out. 


\section{Chapter II: Literature Review}

The purpose of this research is to understand (a) what circumstances lead to students becoming probable extreme non-responders (pENRs), a previously undefined student subpopulation, and (b) to learn what factors prevent pENRs against non-response and consequent dropout (ENRs). I intend to explore pENRs' and ENRs experiences to better understand what disrupted their academic progress despite the presence of a comprehensive array of supports that effectively helps most of their traditionally marginalized, at-risk peers. This literature review focuses on two specific subject areas that are closely related to the process of becoming an ENR: predictors of dropout students, and dropout-prevention interventions.

\section{Part I: Definition of Terms}

Extreme non-responder (ENR): any student within a school site's marginalized student subpopulation that failed to respond to all sustained efforts from the provided comprehensive array of academic supports and consequently dropped out in their third or fourth year.

Probable Extreme Non-Responder(pENR): any student within a school site's marginalized student subpopulation that has only sporadically responded to all sustained efforts from the provided comprehensive array of academic supports, is low achieving or underachieving, and on the verge of dropping out in their third or fourth year. 
Case-management: A cross-disciplinary model of service, typically for students in distress, that includes student advising, advocacy, and guided negotiation of institutional systems when students' academic progress is slowed or halted (Adams, Hazelwood, \& Hayden, 2014).

Trauma-informed Practices: An approach to education that conceptualizes the cause of problematic classroom behaviors as psychological and physiological reactions to trauma or stress rather than simple defiance or lack of respect. Trauma-informed practice has more of a restorative, rather than punitive, focus. Further, it includes social-emotional development, emotional processing, coping skills, and problem-solving skills (Anderson, Blitz, \& Saatamoinen, 2015).

\section{Types of Interventions}

- Standalone. Any interventions that target specific subpopulations of students and are not school-wide.

- Ecological. Any school-wide intervention open to all students enrolled at the site.

\section{Types of Schools}

- Small school. A school with a small student population and small class sizes.

Small schools are designed as an ecological intervention in themselves. The more intimate learning environment is meant to promote learning opportunities not found in schools with larger populations and class sizes (American Institutes for Research \& SRI International [AIR \& SRI], 2003). 
- Community school. Community schools emphasize integrating local community-based services into their daily operations (Valli, Stefanski, \& Jacobson, 2014). Specifically, community schools (a) form partnerships with community-based organizations (CBOs) that meet the needs of their student bodies; (b) increase access to services for their student bodies by hosting CBOs on site; (c) embed services and support structures into daily operation.

\section{Part II: Methodology of the Literature Review}

\section{List of Keywords Searched}

Preliminary searches began with "dropout" AND "secondary students" AND "predictors" OR "factors". Intervention effectiveness research in this literature included two general search terms, "dropout prevention" OR "truancy prevention" AND "outcomes" OR "effectiveness". Ecological interventions, which are a class of dropout prevention programs, were differentiated into "small schools" and "community schools".

A repeated theme, "trauma", was consistently brought out during preliminary qualitative data analysis. This finding led me to review one more topic domain, "trauma". This researcher consequently searched for "trauma intervention" AND "outcomes" AND "secondary schools", but the databases provided no results. The next search was "trauma intervention" AND "secondary students" AND “meta-analysis" OR "outcomes". This yielded a bit more, but school-based trauma interventions so far seem sparse. 


\section{Databases Consulted}

$\underline{\text { Indexed sources }}$

Proquest

ERIC (EBSCO)

Google Scholar

Non-indexed sources

National Education Association (www.nea.org)

National Center for Education Statistics (https://nces.ed.gov/)

Ed-data

(www.ed-data.org)

OUSD

(www.ousd.org)

Big Picture Learning

Coalition for Community Schools

(www.bigpicture.org)

John W. Gardner Center

(www.communityschools.org/)

(https://gardnercenter.stanford.edu/)

\section{Overview/Scope of the Review}

\section{Criteria for Selecting Sources for the Review}

All research sources, with the exception of the research surrounding small

schools, date between 2010-2016. Small schools research is an exception for this review as the primary research on the effectiveness of small schools was written well before

2010. Thus, most of the articles regarding small schools are sourced prior to 2012 .

When possible, all research was retrieved from peer-reviewed journals in indexed education databases. Outcomes research on community schools and small schools could not be located on the indexed databases and were consequently retrieved from foundations that funded outcomes research. Such sources-are not peer-reviewed.

Research on dropout students, the subpopulation of students most similar to the pENR and ENR subpopulations, was restricted to factors that predict which students will drop out. Other factors-such as student motivation, grit, engagement, social capital, and 
cultural capital are relevant to both groups, but the goal of holistic understanding of pENRs and ENRs makes in-depth review of these factors impractical.

Only research directly relevant to MetWest as a school site was included. For example, research on dropout-prevention programs was restricted to secondary students because MetWest is a secondary school. Searches on small schools and community schools was included as was research covering both standalone and ecological dropout preventions.

The number of standalone and ecological dropout prevention interventions are too numerous to count, and many more have never been studied for outcomes research. For that reason, outcomes research for both standalone and ecological interventions were restricted to meta-analysis or program evaluations covering multiple school sites, as these tend to offer a broad view of program effectiveness. Standalone interventions that cover multiple school sites were included in this review in order to give an example of what types of programs exist or have been attempted in the past.

\section{Key Constructs/Sub-Constructs Guiding the Review}

The review covers common characteristics of drop-out students, the population closest to ENRs. The review will also cover factors that predict or cause student dropout. The dropout-prevention interventions section will review (a) some existing standalone interventions, (b) school-based trauma interventions, and (c) small schools of choice and community schools, along with research on the effectiveness of each. 


\section{Part III: Review of the Literature}

\section{General Characteristics of Dropout Students}

Dropout students are most often male, people of color, and lower SES (DarlingHammond, 2010; Fantuzzo et al., 2012, Ginwright, 2004; Skiba, Michael, Nardo, \& Peterson, 2002). Dropout students tend to face many poverty-related obstacles to their academic success, such as homelessness, parents without a high school education, and neighborhood violence (Darling-Hammond, 2010; Fantuzzo, LeBoeuf, Rouse, \& Chen, 2012, Ginwright, 2004; Skiba, Michael, Nardo, \& Peterson, 2002). Further, the relationship between the dropout event and the above factors are at least partially mediated by a lack of academic engagement (Bowers \& Sprott, 2012; Fantuzzo et al., 2012; Gregory, Skiba, \& Noguera, 2002, Hodis, 2011).

\section{Individual Student Factors That Predict Dropout}

For the purposes of this research, individual student factors are here defined as internally-located factors of dropout attributed to individual students.

Students' experiences as a predictor of dropout. Fantuzzo et al. (2012) showed that increasing students' cumulative experiences with risk factors markedly decreased academic performance. Fantuzzo et al. studied students along six risk categories: child maltreatment, low maternal education at birth, homelessness, inadequate prenatal care, preterm/low birth weight, and lead exposure (Fantuzzo et al., 2012, p. 564). They found that academic achievement for all students decreased as number of risks 
increased, to a maximum of three risks (Fantuzzo et al., 2012, p. 564). No effect sizes were offered. Though Fantuzzo et al. (2012) did not link risk factors to dropout, they speculated that the reason so many dropout-prevention interventions failed low-income students was due to their lack of differentiation according to cumulative risk experiences.

Herrera et al. (2013) designed a system that disaggregated risk factors as a way to assess the potential benefits of mentoring at-risk youth. Specifically, Herrera et al., (2013) differentiated risk into two separate concepts, "environmental risk" and "individual risk". Environmental risk was defined as challenges from the surrounding environment that can lead to negative outcomes, and included "economic adversity", "family risk/stress", and "peer difficulties" as subdomains (Herrera et al., 2013, p.111). Individual risk was defined as challenges in the youth's behavior, social, or academic functioning or health that could lead to negative outcomes, and included the subdomains "academic challenges", "problem behavior", and "mental health concerns" (Herrera et al., 2013, p.111). The researchers theorized that youth with the highest cumulative number of individual and environmental risk experiences would benefit more from being mentored than youth with lesser amounts of risk-experiences in either categories. The results of that research reported no differentiation in benefit, indicating that predicting ENRs through disaggregated risk is not likely to be very helpful.

Bowers and Sprott (2012) proposed the following typology of dropout students based on differing educational experiences: (a) not disaffected from school but felt they could not succeed, (b) not disaffected but dropped out for discipline reasons, and (c) 
entirely disaffected by school, and their academic and discipline records substantially exacerbated their decision to drop out. All three groups generally agreed that they dropped out because they did not like school based on their experiences, though each group differed in their reasons (Bowers \& Sprott, 2012). Bowers and Sprott (2012) concluded that dropout students developed different attitudes based on their school experiences.

Academic attitude as a predictor of dropout. Dropout students could also be differentiated according to academic attitude (Bridgeland, 2010; Hodis, Meyer, McClure, Weir, \& Walkey, 2011, p. 315). Students who self-reported to "do just enough to pass" (a) often attained academic credits at a lower rate, (b) attained less academic credits overall, and (c) were more likely to drop out or be inelegible for secondary school than those who self-reported to "do their best" (Hodis et al., 2011). Bridgeland (2010) reported that $50 \%$ of dropout students cited "boredom" and uninteresting classes as principal reasons for dropping out. $70 \%$ of dropout students reported a lack of motivation to work or work hard, and $80 \%$ reported only doing one hour or less of homework per night (Bridgeland, 2010, p. 103).

Much of what negatively affects students' academic attitudes can be external to the students. Low expectations from teachers and parents, low engagement from parents, and a lack of connection between classroom leaning and students' lives and aspirations frequently contributed to poor academic attitude (Bridgeland, 2010). Other events that students cited for leaving were needing employment and funding, becoming a parent, 
acting as caretaker for family members, missing too many days of school, poor grades, being behind on credit accrual, stress, and traumatic experiences (Bowers \& Sprott, 2012; Bridgeland, 2010, Burchizelli, Mackey \& Bausmith, 2011; Mann, 2013). Students dropped out if the competition between academic and external demands became too unmanageable and no extensive intervention was offered.

Stress and trauma as a predictor of dropout. Both internal and external stressors can have deleterious and even long-lasting effects on students' motivation and/or ability to academically progress. Stress is a mental and emotional response to perceived adverse situations (Shanks \& Robinson, 2012). Common symptoms of stress include depression, bouts of generalized or acute anxiety, social withdrawal, lack of appetite, and insomnia. Sources of stress can be either single occurrence (e.g. natural disaster) or chronic (e.g. family fragmentation or poverty). In addition, sources of stress can range from the mundane (e.g. overwork) to the traumatic (e.g. watching a friend die).

Trauma is considered both an experienced event that evokes a negative stress reaction which "persistently impede[s] well-being and functioning" as well as the negative stress reaction itself (Crosby, Day, Baroni, \&Somers, 2014, p. 347; see also Little, Akin-Little, \& Somerville, 2011; Wright, 2014). Further, traumatic events can be single occurrence, multiple discrete occurrences, or persistent exposure (Felitti et al., 1998; Nixon, Sterk, \& Pearce, 2012). The most common sources of trauma are sexual abuse, especially towards females, substance abuse, mental illness, and exposure to 
violence in the family or surrounding neighborhood (Felitti et al., 1998; Johnson \& Pryce, 2013; Kataoka et al., 2009; Wright, 2014).

Trauma symptoms can greatly vary in type, intensity, and duration (Felitti et al.,1998; Foltz et al., 2013; Jaycox, Kataoka et al., 2011; Kataoka, Stein, Langley, \& Wong; 2012; Kataoka et al., 2011; Nixon, Sterk, \& Pearce, 2012; Shanks \& Robinson, 2012; Wadsworth et al., 2008). A person who experienced trauma will not only manifest general stress symptoms but also more acute trauma symptoms, such as changes in mood or cognition. For example, trauma can induce hyperactivity disorders, emotional dysregulation, maladaptive behaviors, and substance abuse. Symptoms lasting up to a month are diagnosed as Acute Stress Disorder, whereas symptoms lasting longer than a month are diagnosed as Post Traumatic Stress Disorder (PTSD; DSM-V, 2013).

A person's ability to cope with stress and trauma determines the severity of the long-term effects (Shanks \& Robinson, 2012; Wadsworth et al., 2008). Sufficient social capital, funds for effective therapy, or innate resilience may ameliorate the long-term effects to a good degree; what Shanks \& Robinson (2012) call "tolerable stress". Conversely, if the person either does not have those ameliorating factors or does not utilize them, stress can become "toxic". "Toxic stress" is so named because untreated extreme and/or prolonged stress can have permanent negative physiological effects on the brain and brain function, such as hypervigilance, emotional numbing, and decreased IQ (Kataoka et al., 2011; Shanks \& Robinson, 2012; Wadsworth et al., 2008). 
There is reason to believe that persistent stressors can cause toxic stress. The full extent of toxicity, as measured by health outcomes and mortality rates, often depends on the severity of the stressor and amounts of stressors (Felitti et al., 1998, Shank \& Robinson, 2012). Tellingly, Felitti et al. (1998) found a "strong and cumulative" positive relationship between breadth of exposure to "adverse childhood experiences (i.e. types of abuse, family dysfunction) and leading causes of death in adults such as such as substance use/abuse, unprotected sex with numerous partners, and crime (p. 251).

Persistent stressors disproportionately affect impoverished communities, both in types and number (Fantuzzo et al., 2012, Nikulina et al., 2011; Shanks \& Robinson, 2012; Wadsworth et al., 2008). Wadsworth et al. (2008) recognized poverty as a chronic stressor and called the stress response "poverty-related stress". Blacks and Latinos thus more often live with persistent poverty-related stress than Whites and Asians (Shanks \& Robinson, 2011). Blacks were twice as likely as Whites to have three categories of adverse childhood exposure and Latinos were 1.9 times as likely as Whites to have four categories of exposure (Felitti et al., p.251). Fantuzzo et al. (2012) found that Blacks were 3.6 times more likely than Whites to have three or more categories of "cumulative risk experience" (p. 572).

Even though Fantuzzo et al. (2012) and Herrera et al. (2014) did not explicitly consider trauma when disaggregating risk, many of the risk factors they list in their research are codified as traumatic stressors by trauma researchers. It is thus plausible to 
conclude that trauma and its effects (a) can be accumulated over time, (b) are a source of persistent stress, and (c) put students at risk of dropping out.

By extension, persistent and extreme stress stemming from traumatic experiences is also potentially toxic. The memory of a single, intense traumatic event can cause persistent and extreme stress (Kataoka et al., 2011). For example, hospital admission from accidental injuries is a particularly significant risk of PTSD for children (Nixon, Sterk, \& Pearce, 2011). Further, the toxicity of trauma-induced stress is likely to be high because trauma events are perceived to be so severe. Criterion B for a PTSD diagnosis requires one of the following: (a) "recurrent, involuntary, and intrusive memories, (b) traumatic nightmares, (c) dissociative reactions (e.g., flashbacks), and (d) intense or prolonged distress after exposure to traumatic reminders (PTSD; DSM-V, 2013). PTSD is often co-morbid with social withdrawal, poor health, and academic problems, all evidence of the toxicity of trauma (Nixon et al., 2011).

To be clear, long-term negative results from trauma are not a certainty though the symptoms and problems described above are common. Trauma responses vary by the individual who experienced it. Only $15 \%$ of those who have experienced trauma are diagnosed with PTSD, although ongoing debate exists on sufficient criteria for diagnosis (Gutermann et al., 2016). The more resilient among those who experienced trauma not only restored function quickly, but also improved in function in a process known as "post-traumatic growth" (Little, Akin-Little, Somerville, 2011; Shanks \& Robinson, 2012). 
Wadsworth et al. (2008) and Shanks \& Robinson (2012) proposed that stress is a strong mediator between poverty and academic outcomes. Low-SES students daily face multiple poverty-related stressors that exist in every environmental system, such as mental illness, family fragmentation, lead exposure, and urban decay. Low-SES students also tend to be witness to more traumatic events, such as domestic abuse and neighborhood violence (Fantuzzo et al., 2012; Nikulina, Wisdom, \& Czaja, 2011; Shanks \& Robinson, 2012; Wadsworth et al., 2012). Further, low-income students tend not to receive the mental help they need in order to process and cope with their stress or trauma (Goodkind, LaNoue, \& Milford, 2010; Nadeem, Jaycox, Kataoka, Langley, \& Stein, 2011; Johnson \& Pryce, 2013). These findings can inform Fantuzzo et al.s' (2012) inverse relationship between reading and math outcomes and cumulative risk experiences.

Low-SES students have higher rates of (a) academic disengagement, (b) learning disabilities, (c) suspension, (d) truancy, and (e) dropout. Additionally, low-SES students more often display decreased social competence, lower IQ, and lower math and ELA proficiency than their higher-income peers (Foltz et al., 2013; Jaycox, Kataoka, Stein, Langley, \& Wong; 2012; Kataoka et al., 2011; Shanks \& Robinson, 2012; Skiba, Nardo \& Peterson, 2002; Wadsworth et al., 2008; Wright, 2014).

Predictive validity of individual student factors for dropping out. To date, no previous body of research has adequately differentiated ENRs from the larger body of traditionally-marginalized students to allow for prediction. Fantuzzo et al. (2012) and 
Herrera et al. (2013) attempted to differentiate among the body of marginalized student populations, but could not adequately do so. Fantuzzo et al.s' (2012) system is inadequate because the risk experiences used were almost all pre-childhood or early childhood, and not necessarily applicable to teenagers struggling to graduate. Further, almost every student at MetWest presents more than three of the risks categorized by either Fantuzzo et al. (2012) or Herrera et al. (2013), but most are doing well.

It is also difficult to adequately predict dropout students by traumatic experiences. Felitti et al. (1998) noted that about $50 \%$ of the participants in their research had at least one traumatic event during their childhood, and about $25 \%$ had two. It is reasonable to believe that at least half of MetWest's students have experienced a traumatic event, and at least a quarter have faced two such events. If $70 \%$ of MetWest students are graduating despite the widespread prevalence of trauma within traditionally-marginalized communities, then exposure to traumatic events is not adequate on its own to predict or differentiate ENRs. At least part of the graduating student body would have been exposed to trauma, and a good many of them would not have received professional treatment. It is likely that ENRs have experienced trauma, although how their experiences may differ in quantity, type, and intensity from the larger student population is unknown.

Finally, no data could be found on the predictive validity between (a) experiences and dropout, (b) stress and trauma and dropout, or (c) academic attitude and dropout. It is consequently impossible to predict or differentiate their pENR and ENR 
subpopulations according to any of these measures at this current time. At best, these are helpful concepts to begin examining and better differentiating the pENR and ENR subpopulations.

\section{School Factors That Predict Dropout Events}

For the purposes of this research, school factors are here defined as factors used by schools to predict dropout students.

Credit deficiency. Credit deficiency was a leading cause for dropping out (Barrat, Berliner, \& Fong, 2012; Allensworth \& Easton, 2007). A factor closely linked to credit deficiency was a lack of student engagement via absenteeism. Absentee students tended to fall behind on course credits, delaying their ability to graduate on time as well as having a negative impact on their grades (Gregory et al., 2010; Mac Iver, 2011; Maynard, McCrea, Pigott, \& Kelly, 2012; Maynard, Kjellstrand, \&Thompson , 2014; Tanner-Smith \& Wilson, 2013). Common key factors either causal or correlative of absenteeism as reported by truant students were unengaging curriculum, unengaging instructional style, negative relationships with teachers, large class sizes, and threats to safety such as bullying (Gase, DeFosset, Perry, \& Kuo, 2016; Havik, Bru, \& Ertesvag, 2015; Maynard et al., 2012). The school practice measures most strongly correlated with student absence were (a) teacher-student trust [-.40], (b) teacher personal support [-.36], (c) importance of high school for the future [-.45], (d) schoolwide academic press for the 
future [-.43], and (e) teacher collaboration and shared sense of responsibility [-.31] (Allensworth \& Easton, 2007).

Inability to re-enroll. Systemic barriers existed after students dropped out, making reenrollment and eventual graduation more difficult to obtain. School leaders reported disincentives for helping dropouts re-enroll, thus pushing dropout students towards permanent dropout status (Barrat et al., 2012, Darling-Hammond, 2010). For example, schools lose money on re-enrollees because they are not considered stable attenders and school funding is based on "average daily attendance" (ADA). Spotty attendance and test-taking by dropout students also negatively impact a school's record on testing, graduation, and accountability, which often leads to sanctions against the school (Barrat et al.,2012; Darling-Hammond, 2010). If a reenrolled student drops out again, the school will have another dropout event on its record (Barrat et al.,2012). Since dropout students lower a school's income, tarnishes its record, and possibly brings sanctions against it, school leaders have very strong disincentives to let them back in.

Difficulties with credit recovery. Another systemic barrier to reenrollment was that continuation and adult schools often had a minimum age requirement, thus closing off credit recovery as an option for $9^{\text {th }}$ and $10^{\text {th }}$ grade dropouts (Barrat et al., 2012, p.228). Any students who dropped out in $9^{\text {th }}$ or $10^{\text {th }}$ grade are therefore at increased risk of permanent dropout status. The problem has traditionally been compounded by the social promotion of content-deficient $8^{\text {th }}$ graders, resulting in them becoming credit deficient by 
the end of their $9^{\text {th }}$ grade (Allenworth, 2013). As a consequence, content-deficient $8^{\text {th }}$ graders also share an increased risk of permanent dropout (Allensworth, 2013).

Credit recovery was possible through enrollment into the community college system, but many obstacles existed there too. For a dropout student to successfully make up credits in time, many must schedule a hodge-podge of courses from several different colleges simultaneously, usually without the help of a consistent graduation advisor (Barrat et al., 2012). The end result was a probable loss of valuable time and money for no gain, as the credits accrued were either insufficient in amount or type for graduation.

Predictive validity of school factors for dropping out. Dropout predictors are a key instrument for identifying which students should be referred into intervention programs. Recent research in Chicago's public school district found that GPA and ontrack measures served as very accurate predictors of on-time graduation, at $80 \%$ for graduation and 73\% for dropout (Allensworth, 2013, p. 69). Background characteristics stereotypically associated with dropout students, such as 8th grade test scores, race, gender, school transfers, and low-income neighborhoods, were less robust predictors, predicting graduation with only $65 \%$ accuracy and dropout with $48 \%$ accuracy (Allensworth, 2013, p. 70). Prediction accuracy increased only 1\% for graduation, and zero for dropout, when aggregating both data sets together (Allensworth, 2013, p.71).

While on-track indicators are the best predictors of graduation outcomes, more immediate indicators are more helpful for determining which students should be targeted 
for intervention. On-track indicators are only available at the end of a year, and waiting a full year to assess which students could benefit from intervention can be harmful. Allensworth and Easton (2007) found that students' attendance and effort served as good, immediate measures of whether a student needed intervention, accounting for $73 \%$ of the variance in failure rates (Allensworth \& Easton, p. 16). The implication is that school staff should monitor and assess students on a weekly basis. Students should be consistently monitored and considered for intervention enrollment according to these two measures (Allensworth, 2013; Fantuzzo et al., 2012; MacIver, 2011).

\section{Approaches to Dropout-Prevention}

Dropout prevention can be sorted into two main approaches: standalone and ecological. Standalone interventions are aimed at individual student subpopulations and tend to exist as silos of practice that operate alongside, but apart from, daily school operations. Ecological interventions work at reforming the whole school, in its services offered, culture, power/leadership structures, and processes. Both the Community Schools Movement and Big Picture Learning are prominent examples of ecological interventions. MetWest, as a whole entity, is an ecological intervention.

All interventions vary widely in terms of methodology although all have a common goal of preventing student dropout and improving student performance. For example, some interventions focus on community service while others focus on mentoring and counseling. Interventions can also utilize multiple-methods, such as 
pairing mentoring/counseling with skills training or case management (Wilson, TannerSmith, Lipsey, Steinka-Fry, \& Morrison, 2011).

Interventions also vary widely in terms of location. Many dropout-prevention interventions regularly take place off-campus in community settings. In contrast, community schools, which will be discussed later, usually work to bring interventions directly onto school grounds. In such cases, dropout-prevention interventions can happen in the classroom or another designated area on-campus that is not a classroom.

\section{Meta-analysis of Effectiveness of Dropout-Prevention Interventions}

Wilson, Tanner-Smith, Lipsey, Steinka-Fry, and Morrison (2011) performed a meta-analysis of 167 dropout prevention programs. Both standalone and ecological interventions were included. Participant characteristics were 50\% male, 33\% White, 39\% Black, 22\% Latino, and 9\% "Other minority". Participants' SESs were not reported, but the authors noted that most of the interventions targeted at-risk populations.

Overall, they claimed that dropout prevention interventions were effective, though all results were reported as mean-odds ratios and no effect sizes were given. Mean oddsratios are a relative measure, in this case determining how much more probable it was for a student undergoing intervention to avoid dropout compared to peers who were not.

Within those 167 programs, nonparticipants were 1.72 times more likely to drop out than participants (Wilson et al., 2011). Since the average dropout rate over all studies was $21 \%$ for the control groups, they speculated that any participation in a dropout prevention 
intervention would result in an average 13\% dropout rate for experimental group participants (Wilson et al., 2011, p.32). That said no evidence was provided as to actual dropout rates for participants.

All intervention methodologies, except for attendance monitoring, had roughly equal influence on outcomes (Wilson et al., 2011). Attendance monitoring programs experienced the least reduction in dropout ([MeanOR $=1.4]$ Wilson et al., 2011, p.38). The most effective intervention methodologies were community service (MeanOR = 3.53), vocational training $(\mathrm{MeanOR}=2.64)$, and mentoring/counseling $(\mathrm{MeanOR}=$ 2.62), cutting dropout events between $46 \%-66 \%$. Notably, at least for this meta-analysis, all students undergoing intervention improved over their non-intervention peers regardless of methodology.

Of all the varied location characteristics, school-based interventions were most effective when placed in the classroom during school hours. This result makes sense, given that students' access to intervention is greatly expanded when student travel and time demands are minimized. Using regression analysis, Wilson et al. (2011) reported moderate relationships between successful intervention and classroom programming $(b=$ $0.45 ; 95 \%$ CI $0.2,0.69 ; p<0.01$ ), and interventions that combine classrooms with offsite experience $([\mathrm{b}=0.29 ; 95 \% \mathrm{CI}-0.02,0.60 ; p<0.05]$ Wilson et al., 2011, p. 34). On the other hand, the confidence intervals reported are too wide to comfortably assert a relationship. For example, the fact that $95 \%$ of repeat trials relating classrooms programming and offsite experience to academic outcomes falls between a miniscule 
negative effect (-.02) and a moderate positive effect $(0.6)$ renders the confidence interval somewhat uninformative. Further, no effect sizes were given so effectiveness is inconclusive.

Lastly, "implementation quality", classified by the researchers as proper support of interventions from site administers and sound infrastructure, was also moderately related to intervention success $(b=0.30 ; 95 \% \mathrm{CI} 0.18,0.41 ; p<0.01)$, (Wilson et al., 2011, p. 34). This held true regardless of methodology or program location. Wilson et al. (2011) found that almost all prevention programs have equal outcomes despite widely varied methodologies and characteristics. They concluded that site administrators may be served better by choosing interventions based on how effectively a school site can implement them rather than how well-tailored the programs are to target populations.

Limitations of the meta-analysis. First, the meta-analysis by Wilson et al., (2011) did not disaggregate programs' graduates or dropouts by any metric. A regression disaggregating responsiveness by race/ethnicity was performed, but a regression is primarily predictive rather than descriptive. The meta-analysis is consequently useful for understanding the efficacy of dropout-prevention interventions but ineffective for bringing light to why students did or did not respond to the given interventions.

Second, despite Wilson et al., (2011) including both standalone and ecological interventions in their meta-analysis, they did not disaggregate outcomes based on whether interventions were standalone or ecological. Consequently, it is impossible to know from this meta-analysis how the reported positive results are distributed between the two 
approaches, even if the overall outcomes are minimal. The following sections will examine research on both standalone and ecological approaches in order to better understand the achievement differences between the two approaches.

\section{Standalone Approaches to Dropout Prevention}

The standalone approach to dropout-prevention covers several different types of dropout-prevention interventions. The first are interventions that What Works

Clearinghouse (WWC) recommends, exemplifying a range of methodologies to improve student outcomes. A second group targets chronic truancy. A third type targets students who experience trauma. The effectiveness of each will be reported below.

Effectiveness of WWC-recommended programs. WWC purports to use goldstandard research methodology to recommend to practitioners which educational interventions work. WWC seeks to act as a primary federal arbiter of what is effective, including standalone dropout prevention interventions. The following are some of the dropout prevention interventions WWC deemed most successful.

Achievement for Latinos through Academic Success (ALAS) utilized mentors or counselors as unofficial case-managers. They monitored students classified "Comprehensively At Risk" (CAR) for attendance, classroom behavior, and academic achievement. ALAS was tested in one middle school that was $96 \%$ Latino and performing around the $17^{\text {th }}$ percentile of all California schools (Gandara, Larson, Mehan, $\&$ Rumberger, 1998). The counselors/mentors met with the student regularly, gave 
feedback, and coordinated interventions and resources to the student, the student's family, and teacher(s). Intervention started in $7^{\text {th }}$ grade and continued through $9^{\text {th }}$. Students were trained in life skills, and the parents were trained in education participation skills.

Check \& Connect $(\mathrm{CaC})$ is another highly recommended intervention that utilized adult case managers who work with students and their families for the intervention's duration. $\mathrm{CaC}$ was evaluated in a random effectiveness trial covering 14 urban middle and high schools (Maynard, Kjellstrand, \& Thompson, 2014). The case managers focused on student engagement by teaching them how to build and maintain relationships, monitoring their progress weekly, and implementing personalized interventions based on the data presented. The program was targeted towards youth with learning, behavioral, and/or emotional disabilities.

WWC also listed programs that did not utilize mentoring and case management. Financial Incentives for Teen Parents to Stay in School (FITPSS), also known as CalLearn in California, awarded increases or decreases in family support (between $\$ 100$ and $\$ 500$ ) for course grades, and a $\$ 500$ completion bonus for graduation or GED. Twelve Together (TT) utilized adult-volunteer led peer support groups. As the name implies, each group consisted of twelve participants, intentionally mixed according to academic risk assessment. Group discussions were based on the students' interests, and usually focused on support while undergoing personal issues. TT also offered tutoring, trips to college campuses, and an annual weekend camp. 
Finally, four recommended programs were based around vocational training: Job Corps, JOBSTART, New Chance, and Talent Search. WWC notably described them as alternative education, with a stated goal being to obtain a GED and job skills. These interventions were for continuation school students who had already dropped out of traditional high school.

There is reason to question whether the standalone programs recommended by WWC are effective. Under WWC's rating system an effect size equal or above +0.25 is classified as a "substantively important positive effect" (WWC, 2015). This classification is a bit optimistic because an effect size of 0.25 means that the change was, at best, "difficult to detect" (Pogrow, 2015).

At the end of the $9^{\text {th }}$ grade $98 \%$ of ALAS students were still enrolled in school, compared to $83 \%$ from the control group, a $15 \%$ difference. Further, $72 \%$ of ALAS students were considered on track, compared with $53 \%$ of the control group. The positive results held true to a lesser extent two years later; $75 \%$ of ALAS students were enrolled in school as opposed to $67 \%$ of the control group. However, ALAS students' on-track status had dramatically decreased over the two-year period, though the percentage ontrack (33\%) was still greater than their control-group peers (26\%). That said these results were not statistically significant. ALAS raised retention rates of its at-risk population by 42 percentile points and progression rates by 19 percentile points (Gandara et al., 1998).

Sinclair, Christenson, \& Thurlow (2005) performed a 4-year longitudinal study of $\mathrm{CaC}$, examining two consecutive $9^{\text {th }}$ grade cohorts receiving special education services 
for emotional or behavioral disabilities. The participant sample comprised $64 \%$ Black, $84 \%$ male, $70 \%$ low-income. The average participant was 14 years of age. According to the study, dropout rates and attendance improved very slightly for 4-year students, ES = 0.18 for dropout rates. School attendance also increased annually between years 3-5 (ES $=0.22,0.32,0.48$, respectively). Of 71 participants, $45 \%$ of CAC students graduated at the end of 4 years if they attended regularly, as opposed to $26 \%$ CAC of students who attended sporadically (Sinclair et al., 2005, p. 474).

While CAC's outcomes are substantially higher compared to the control group, the overall result for 4 -year graduation is not high. Though $61 \%$ of CAC students graduated in four years as opposed to $43 \%$ in the control group, the result was not significant and the effect size was low $(E S=0.14)$. Student persistence was still low for both groups overall after the first year, and declined steadily over the remaining years (Sinclair et al., 2005).

In contrast, $\mathrm{CaC}$ 's $5^{\text {th }}$-year students experienced great improvement for dropout reduction $(\mathrm{ES}=0.58)$ and moderate improvement for attendance $(\mathrm{ES}=0.32)$ though overall results are still low. $26 \%$ of fifth-year students graduated, as opposed to $6 \%$ of their control group peers. Further, $33 \%$ of the $5^{\text {th }}$-year cohort kept attending, compared to $0 \%$ of the control group (Sinclair et al., 2005, p.475).

Overall none of the other WWC interventions listed in this review produced benefits that had practical significance, defined as holding an ES=0.39 (Pogrow, 2015). No intervention listed held an ES $>0.25$ for persistence, progression, or school 
completion except for $\mathrm{CaC}$. None of the standalone interventions were really effective despite WWC's voucher of confidence.

Critique of effectiveness research on WWC-recommended programs. WWC's efficacy is questionable, given its endorsement of failed programs such as Success for All (Pogrow, 2000). ALAS reported the most successful measures according to WWC's improvement index but it should only be considered slightly successful at best. First, the review only had a sample size of around 80 students. While the percentage of ALAS students on track to graduate at the end of a given grade was between $10-20 \%$ higher than its comparison group, none of these differences were statistically significant past the end of 9th grade. Further, while ALAS students experienced a 5\% improvement over their control-group peers, the intervention has little practical value for a school with a graduation rate of $27 \%$.

Outcomes research on FITPSS and TT similarly reported no practical significance. Researchers reported that $29.1 \%$ of FITPSS participants graduated compared to $24.2 \%$ of non-participants (WWC, 2006). However, the researchers noted that the improvement in completion numbers came almost entirely from GED receipt, rather than graduation on time (WWC, 2006), indicating that this intervention might be good for continuation schools but not traditional high schools. Researchers on TT also reported a $5 \%$ reduction in dropout, but the reduction was not statistically significant. Further, TT participants experienced zero improvement on school completion (WWC, 2007). 
$\mathrm{CaC}$ also reported barely detectable change. Maynard, Kjellstrand, and Thompson (2014) performed parallel research on $\mathrm{CaC}$ and found that students participating in $\mathrm{CaC}$ performed only $3 \%$ higher, and had 0.363 fewer disciplinary referrals, than their control-group peers (Maynard et al., 2014, p. 303). In brief, the change between experimental and control is negligible, almost non-existent, for both academic success and behavior.

With the exception of $\mathrm{CaC}$ for the category of student persistence, WWC reported each standalone intervention listed within this review as only having "potentially positive" results. Administrators who desire to implement standalone interventions in their school sites should give careful consideration to these interventions prior to implementing them. None of the standalone interventions have produced substantial results that merit implementation, what Pogrow (2015, in press) deems as "practically significant".

Further, there seems to be no single intervention characteristic that stands out as a common thread for future research. The most common goals across these interventions were improving academic performance (95\%), decreasing truancy $(66 \%)$, transition support (60\%), increasing school attachment (59\%), and addressing behavioral challenges (50\%). Accordingly, the most utilized core strategies were advocating for students' needs (64\%), family engagement and support (57\%), monitoring school attendance (53\%), and mentoring (43\%) (Burchizelli et al., 2011, p.5). Findings on their efficacy are currently inconclusive. 
Effectiveness of truancy prevention programs. Students who miss more days of school are more likely to fail than those who regularly attend (Allensworth, 2007; Allensworth, 2013; Maynard et al., 2012). Maynard et al. (2012) completed a metaanalysis of 15 chronic-truancy-prevention programs and found that overall, the programs work as intended $[\mathrm{ES}=0.46]$, (p. 35). Moderator analyses found no significant difference in outcomes based on location, modality, or duration (Maynard et al., 2012, p. 7). Similar to Wilson et al.'s (2011) study, one might conclude that the presence of a program is sufficient so long as it can be implemented well.

Some programs specifically dual-targeted dropout-prevention and chronic truancy, but Tanner-Smith and Wilson (2013) found that these dual-target interventions do not effectively combat student absenteeism. Participants were 50\% male, primarily minority, and primarily secondary students. Overall the mean effect size of randomized controlled trial (RCT) programs was small, 0.23 , roughly a $4 \%$ reduction in student absence, or 1 extra day of attendance (Tanner-Smith \& Wilson, 2013, p. 477). On the other hand, mean effect size of quasi-experimental design (QED) programs was a negligible 0.03 and non-significant. QED dropout-prevention programs had practically no effect on student absenteeism. Further, no data was reported on how well dual-target programs reduced dropout rates.

Critique of Effectiveness Research on Chronic Truancy Programs. Studies that chronic-truancy prevention programs are effective should be viewed with skepticism. First, Maynard et al. (2012) only had a small sample size of fifteen studies due to: a) the 
lack of programs that solely targeted chronically truant youth, and b) the lack of concrete definitions of truancy. Second, moderator analyses could not be run for race/ethnicity, age, or background characteristics because the studies themselves were barren on those details. Third, even though the average program participant attended an additional 5 days in a school year, chronic truancy levels remained unacceptably high across all studies. In conclusion, programs that target chronic-truancy are ineffective in combating truancy.

Effectiveness of trauma interventions. Trauma interventions are centered on the specific subsection of students who were identified as being exposed to trauma. Even though trauma experiences disproportionately occur among low-income students, no ecological interventions for trauma treatment exist in the literature for low-income schools, except in cases of natural disasters or school shootings.

Most low-income students exposed to trauma or chronic stress do not receive proper and timely treatment (Kataoka et al., 2011). One common reason for this is that practitioners may not recognize the behaviors as symptoms of trauma (Foltz et al., 2013; Goodkind, LaNoue, \& Milford, 2010). Another possibility for a lack of proper treatment is a cultural resistance to, or mistrust of, therapeutic interventions (Ngo et al., 2008).

Lack of access to services, either by schedule, transportation, or infrastructure, can also result in lack of treatment. Schools often find a lack of adequate administrative support, ongoing implementation support, solid community partnerships, or funding, to be barriers to proper implementation of trauma treatment (Kataoka et al., 2009; Langley, Nadeem, Kataoka, Stein \& Jaycox; 2010; Nadeem, Jaycox, Kataoka, Langley, \& Stein, 
2011). Nationally, $75 \%$ of children who receive services do so at school than elsewhere precisely because school is the only place for which they have ready transportation (Jaycox et al., 2012).

The modalities and type of trauma care can matter. For example, foster youth who come from fragmented families might find a relationship-based intervention, such as therapeutic mentoring, more useful than other clinical methods (Johnson \& Pryce, 2013). Psychological debriefing seemed to have little effect, or even negative effect, on symptoms of single-incident trauma (Wei, Szumilas, \& Kutcher, 2010). Cognitive behavioral therapy (CBT), a therapy centered on changing dysfunctional thinking and behavior from trauma triggers, works particularly well for survivors of traumatic events, and is both the most documented and successful of the interventions [ $\mathrm{n}=85, \mathrm{ES}=0.99$ ] (Guntermann et al., 2016; Nixon et al., 2011).

CBITS is an example of a CBT intervention designed to work in a school setting during normal school hours. A complete program includes 10 one-hour group sessions, 1-3 individual sessions, 2 group meetings for parents, and one education session for teachers (Jaycox et al., 2012). The program teaches cognitive behavioral skills to combat PTSD, anxiety, and depression including social problem solving, relaxation training, and identification of anxiety triggers, among others (Jaycox et al., 2012).

Researchers have claimed that it has decreased symptoms for PTSD, depression, and psychosocial dysfunction in low-income populations in general. Importantly, CBITS has been modified for use with different cultures while still retaining fidelity to the 
curriculum. It works equally well in Latino populations, and slightly less so in Native American populations (Goodkind, LaNoue, Milford; 2010). Stein et al., (2003) ran a 126-participant randomized control trial, here reported as adjusted mean differences and 95\% CI, and found that CBITS reduced (a) PTSD, -7.0 (-10.8 to -3.2); (b) depression, $3.4(-6.5$ to -0.4$)$; (c) psychosocial dysfunction -6.4 (-10.4 to -2.3$)$ (p. 607). However, no effect sizes were given so it is difficult to evaluate what true impact CBITS had (Goodkind, LaNoue, \& Mildofrd, 2010; Kataoka et al., 2003; Ngo et al., 2008; Stein et al., 2003). Notably, CBITS did not significantly affect classroom behavioral issues even as it positively affected trauma symptoms.

The overall effects of trauma interventions are largely positive, though some are more effective than others. Gutermann et al. (2016) performed a comprehensive metaanalysis of trauma interventions for PTSD, depression, and anxiety. Generally, interventions specifically targeting PTSD are highly effective (ES=0.89), while interventions targeting depression and anxiety are moderately effective $(\mathrm{ES}=0.62,0.64$ respectively).

Age is a moderator between interventions and outcomes. Studies with older participants reported larger effect sizes (Guntermann et al., 2016). A possible reason is that some interventions require cognitive components that younger children have difficulty mastering (Guntermann et al., 2016) Contrarily, another finding reported that delaying interventions for young children exposed to trauma until they are older "often 
require greater effort to overcome initial delays, and typically at greater expense" (Shanks \& Robinson, 2016, p.155).

Research on academic outcomes of trauma interventions is rare. This researcher could only locate one such study, Kataoka et al. (2011), concerning the use of CBITS in two middle schools in Los Angeles during 2001-2002 academic year. 123 sixth-grade students, primarily low-income, Mexican American participated in the study. $40 \%$ lived in extreme poverty conditions, and $74 \%$ had witnessed or been victim to knife or gun violence in the previous year (Kataoka et al., 2011, p.5).

The findings on academic outcomes in Kataoka et al., (2011) were mixed. The students were randomized into an early-intervention cohort and a delayed-intervention cohort. The research centered around standardized math and ELA test scores, presented as unadjusted mean effect sizes. The early-intervention cohort reported an unadjusted math score mean of 2.0, and the delayed group reported a 1.6, a mean difference of 0.4 (p.12). The early-intervention cohort also outperformed the delayed cohort in ELA, 2.2 as opposed to 1.9, although the improvement was not significant (p.12). No other academic measures were taken or reported in this research. Ultimately, the research can only be taken as preliminary due to the lack of a non-treatment group and a larger, more diverse sample.

Critique of effectiveness of trauma interventions. The effectiveness of trauma interventions on treating trauma symptoms seems well established. Though CBITS is a promising program, it is difficult to make a positive conclusion regarding its 
effectiveness due to the lack of reported effect sizes. It is also impossible to draw conclusions regarding the effect of trauma interventions on dropout reduction due to the lack of extant research.

Summary of effects of standalone approaches. Overall, standalone dropout prevention interventions seem ineffective. While ALAS and $\mathrm{CaC}$ both showed early promising gains in persistence and progress, none of the programs promoted by WWC had any noticeable improvement on dropout reduction. Programs targeting both dropoutprevention and chronic truancy were ineffective in curbing truancy, and dropoutprevention rates were unreported. Programs targeting chronic truancy did somewhat improve truancy rates, but the improvement was not sufficient to improve dropout rates.

Trauma interventions for PTSD were strongly related to improved mental health among students, and interventions for depression and anxiety were moderately so. Yet, academic improvement resulting from trauma interventions is mixed and inconclusive. In conclusion, based on the samples in this review, standalone interventions are inadequate to keep students from dropping out. At best, program effectiveness can be said to be inconclusive.

It is unknown why these programs did not work. None of the programs investigated why their dropout students did not respond to the interventions as designed. Thus, none of the research on standalone approaches in this review give any indication of who pENRs are, what they are responsive or unresponsive to, and why. 


\section{Ecological Approaches to Dropout-prevention}

Ecological approaches are an umbrella covering all school-wide interventions.

They are based on the idea that students may best thrive in a comprehensive ecosystem of interventions rather than in a normative school utilizing some number of standalone programs.

Two types of ecological approach, community schools and small schools, are reviewed here. Community schools are sites that form partnerships with communitybased organizations in their surrounding communities to collaboratively provide services for students. Small schools are sites that restrict the size of the student population. Typically, a small high school will host 100 students per grade level.

Effectiveness of Community schools. Dropout reduction outcomes for community schools was inconclusive. ICF concluded that dropout reduction increased as thoroughness of model implementation increased (Castrechini \& London, 2012; ICF International 2010). ICF (2010) reported small effect sizes (ES) of "high implementers" for dropout reduction and graduation, $\mathrm{ES}=0.36$ and $\mathrm{ES}=0.31$ respectively (p.4). No information was given regarding the qualifications for "high implementers", and no dropout reduction was reported for "partial implementers". Despite that, dramatic increases occurred among the case-managed population. Fewer 9th-graders dropped out in their first year over their non-CIS peers [ES =0.70] (ICF International, 2010, p. 5). Dropout reduction was not reported for either Oakland or Redwood City. 
Community schools also showed inconclusive results for disciplinary referrals and out-of-school suspensions, two measures related to dropout. CIS students were referred more often than their control group counterparts for disciplinary referrals and out-of-school suspensions, although the researchers could not establish whether the CIS programming was causative (ICF International, 2010, p.5). On the other hand, the Oakland study showed a 33\%-66\% decrease in student suspension. All but one experienced a 20\%-33\% decrease in chronic truancy. In all cases, Oakland's community schools were at or below the district average in both measures (Fehrer \& Leos-Urbel, 2015, p.32)

Achievement outcomes of community schools were inconclusive. No schools could report more than small improvements in mathematics and mixed results in English/Language Arts (ELA) for their mainstream student bodies. On the other hand, Castrechini \&London (2012) found that ELLs particularly benefited from community schooling. Community-schooled ELLs reported higher California English Language Development Test (CELDT) scores than their non-CIS peers for every year of participation. A student with 3-4 years' involvement in CIS averaged 3.5 points gained per year more than non-CIS students, resulting in a 12 point gap at the end of the $2010-11$ school year (p.18).

None of the data on community schools was disaggregated in a way that would be helpful to predict ENRs. Neither graduates nor dropouts were disaggregated in a way that showed how and why students did or did not respond to community schooling. It is 
impossible to conclude how students can become ENRs from the community schools data.

Critique of effectiveness research on community schools. None of the articles in educational journals regarding student-learning outcomes of community schools participants were peer-reviewed. Further, this researcher was unable to obtain any absolute data of the ICF study (2010), CIS reports (2014; 2015), or the Castrechini \& London (2012) report, despite requests to the authors and organizations underwriting the evaluations.

Of the outcomes data found, three reports offered helpful, but ultimately biased, information. Two of the three were CIS annual reports from 2014 and 2015, which only reported high success rates for their case-managed students. Of the $1.5 \mathrm{M}$ students served nationally, no data is given regarding, a) what percentage of them are case-managed, b) how prevalent case management was between "low" and "high" implementers, and c) participant demographics. These are problematic omissions, since then the only certain thing is that case managing (Tier 2 services) worked particularly well. Even in the highest implementing community schools, case-managing all students is a herculean task, so the report left no clear insight as to how well the CIS model works for all other students.

In that same vein, ICF's choice to report solely on 9th graders was a curious one, and left far too much room to question community school programming efficacy for later grades. That said ICF's data on case-managed 9th graders was very noteworthy. Student 
case management at the 9th grade level seems to be a worthwhile intervention to implement considering that (a) credit deficiency is the leading cause of student dropout (Barrat et al., 2012; Bowers \& Sprott, 2012; Bridgeland, 2010; Burchizelli et al., 2011), and (b) on-track credit status should be ascertained earlier than later (Allensworth, 2013). ICF also failed to account for other possible mediating or causative factors in their results. For example, no mention was made of familial influence, peer influence, sociocultural differences, and the like. Additionally, no data was disaggregated by gender, race, programming, or participation. The end result is that while methodologically sound, the research questions were too narrow in scope to justify ICF's implications of causation between programming and positive student outcomes.

Castrechini's \& London's research (2012) was methodologically sound, but their research was focused on answering for whom and how community schools benefit through disaggregation of district data. The research did not focus on the students' surrounding microsystems and how they interacted with community schools programs and student outcomes. Just as with ICF, ignoring the environmental contexts of the students under examination does not help to disprove or eliminate alternate causes of positive student outcomes.

OUSD's community schools data should be taken with some skepticism. First, the researchers were carrying out a qualitative study on schools that evidenced thorough FSCS implementation and definite downward trends in suspension and chronic truancy. The purposive sample is therefore better fitted to inform principles of best practice rather 
than inform for overall progress, since 22 other FSCS's are not examined. Second, it is difficult to judge practical significance without disaggregated data over several more measures and a larger sample size. Third, it is difficult to completely establish OUSD's FSCS policies as causative of a school site's success without including student voice.

In conclusion, community schools academic outcomes are mixed at both national and local levels. At the national level community schools only do markedly well with $9^{\text {th }}$-grade case-managed students in "full-implementer" schools. In Redwood City community schools programming has really only benefited the ELL subpopulation in terms of academic achievement. In Oakland, student suspension and chronic truancy are down in the community schools, but none markedly lower than the district average. Much research has yet to be done to begin to understand why these results are so disparate and mediocre.

Because the schools had not examined why students were not improving despite improved school environments, there is no way to understand what the students were or were not responding to. Likewise, since the schools had not examined why students became non-responsive to the point of dropout there is no way to know how they became ENRs.

Effectiveness of small schools. Most of the effectiveness research on small schools reported inconclusive results for academic achievement. Overall academic outcomes were weak in both English language arts (ELA) and math against their controlgroup peers (AIR \& SRI, 2006, p. 114-118, Bloom et al., 2010). Indeed, some 
researchers found that academic achievement was actually positively associated with larger school sizes (Leithwood \& Jantzi, 2009; Wainer \& Zwerling, 2006). Wainer and Zwerling (2006) found zero relationship between enrollment in small schools and academic achievement. Further, they found a moderately positive relationship regression between $11^{\text {th }}$-grade math scores and enrollment in larger secondary schools. Leithwood and Jantzi (2009) conducted a meta-analysis on the effects of school size and academic achievement and concluded that at least middle-sized schools are more beneficial than large schools, and perhaps more beneficial than small schools.

The only school district to report an increase in graduation, and thus imply a decrease in dropout, was New York City's small schools of choice (NYC SSCs). Graduation rates for the first three SSC cohorts were $8.3-11 \%$ higher than their control group peers. Even six years after enrollment, SSC students were still $8.2 \%$ more likely to graduate than their control group peers (Unterrman, 2014, p.4).

NYC SSCs also seemed to benefit marginalized student populations more than traditional schools. Low-income students experienced an improvement in their graduation rates of $11.2 \%$ over their control group counterparts, and a slightly smaller improvement of 7.0\% for non-low-income students (p.12). Black females and Latinas benefited the most from the SSCs, an increase in graduation rates of $7.2 \%$ and $8.7 \%$ respectively over their male counterparts (p.12). Black males graduated $13.5 \%$ more than their control group counterparts, and Latino males graduated 7.3\% more than their control group counterparts (p.12). That said no disaggregation was performed on 
students who dropped out, so the nature and reasons for dropouts' non-response is unknown.

Benefits from attending an NYC SSC held up into college. More SSC students were ELA college-ready than their control-group peers (40.2\% as opposed to $33.4 \%$ ), though both groups were approximately equal for math college-readiness. More SSC students $(68.4 \%)$ were enrolled in post-secondary education the year following on-time graduation than control group students (65.4\%) (Unterrman, 2014). Further, more SSC low-income students enrolled into post-secondary than their control group peers, $47.7 \%$ to $38.1 \%$ respectively, a $9.6 \%$ difference (Unterrman, 2014, p.6). Of those enrolled in post-secondary, SSC students maintained higher persistence through all 4 years, between 5.7\%-6.8\% (Unterrman, 2014, p.8).

New York City's success with SSCs should be considered in light of two noteworthy conditions. First, much of the SSCs' success was disproportionately found in new small schools rather than redesigned ones. Small schools were either newly made or redesigned from larger, failing schools. Redesigned schools were most often nonselective and located in low-income areas. New schools were usually located in more affluent areas and usually required a threshold test score for eligibility (Rodgers, 2014). Thus, new small schools generally favored higher-income families who could pay for test preparation (Rodgers, 2014). Often, new schools not only showed higher gains in math and ELA, but redesigned schools reported deleterious effects on academic achievement 
(AIR \& SRI, 2006). It is possible that the students' responsiveness is dependent on the school environment and the students' peer environment.

Second, the SSCs had less experienced staff than control group schools. Of the SSC teaching staff, $62.2 \%$ had four or more years of teaching experience, and only $21.7 \%$ of them held an M.A. or Ph.D in education and 30 unit-hours (Bloom et al., 2010, p.37). In comparison, $77.2 \%$ of the traditional schools' teaching staff had four years or more experience, and $30.9 \%$ held some form of advanced degree. Unfortunately, Bloom did not disaggregate the teacher data by new or redesigned schools. The fact that SSCs outperformed the control schools despite the gap in teacher experience implies that the ecological approach had a positive effect not necessarily related to teacher quality.

Overall, the results of the small schools movement are inconclusive. No small schools reported more than negligible improvement in math and ELA scores. No small schools except New Yorks's reported dropout reduction or increases in graduation. New York City's SSCs increased their graduation rates by approximately $10 \%$ over their nonSSC peers, and did in fact benefit Black and Latino students over their more affluent White-peers. However, no attempt was made to (a) disaggregate the dropout students by any metric, and (b) disaggregate the graduates by a metric other than race/ethnicity. It is impossible to conclude how NYC SSCs' dropout students responded and why they ultimately failed to respond.

Critique of effectiveness research on small schools. A large problem with much of the small schools research is that is that they all presented findings using correlation 
coefficients instead of effect size (AIR \& SRI, 2006; Bartlett el al. (2011). Knowing effect size, disaggregation of data by student sub-population, and reporting on common or special practices would have made the findings more helpful in determining "what works" or not. For example, the fact that enrollment in a small school is positively and significantly related to academic improvement for low-income students (Bartlett et al., 2011) says nothing about the size of the improvement, which might be very small.

NEP's evaluation on OUSD small schools reported success, but that too should be taken with some skepticism. First, presence of so many benefits coincidental with school size makes attribution of improvement to school size impossible to distinguish. For example, a larger community school with similar innovations save decreasing student population may have performed just as well. Second, even though the most schools in low-income areas improved, most were still under California's proficiency standards.

The findings in New York City's SSCs have some gaps in the data that would have helped prove their success. Additional data on student dropout within Cohort One would have helped the dataset's thoroughness (Bloom et al., 2010). Also, given the almost negligible difference between SSC and control group in attendance and credits earned for Cohort 1, the choice to omit such data for Cohorts Two and Three is curious, especially as on-track indicators are the most accurate predictors for graduation (Allensworth, 2013). Such data would have been very helpful in understanding how the SSC students consistently graduated on time at higher rates than their control group 
counterparts, especially since both groups experienced similar increased graduation rates over time ( $8 \%$ for SSCs as opposed to $6.8 \%$ for control group schools).

The benefits of small schools are questionable without more data, such as effect size, dropout rates, school practices prevalent in successful school sites, and the like. Certainly, without more sources of funding or a change in funding formulas, small schools are not a viable intervention to scale upwards, since funding was already a major barrier to implementation (AIR \& SRI, 2006; Bartlett et al., 2011, Bloom et al., 2010; Rodgers, 2014). As of 2009, OUSD ran 26 small secondary schools. OUSD presently only runs three small secondary schools: Life Academy, Coliseum College Prep Academy, and MetWest. Notably, these three small schools are the highest performing in OUSD according to several different metrics, but they are also all FSCSs.

\section{Part V: Conclusion}

Standalone dropout-prevention programs had only a small effect on academic achievement and dropout reduction. High dropout and truancy rates still remained after the programs completed (Maynard et al., 2012; Tanner-Smith \& Wilson, 2013; Wilson et al., 2011). Trauma interventions, especially CBITS, reduced PTSD-symptoms for students who were victims or witnesses of traumatic events, and worked well to ameliorate some of the poverty-related stress/trauma that marginalized students often face. Currently unknown is whether or not trauma interventions reduce dropout rates or improve academic performance. 
Stronger results were reported from interventions that sought to reduce dropout rates by designing whole school approaches, what is referred to as the ecological approach. Introducing small schools was insufficient to close the gap, and in fact redesigning large schools into several smaller schools was detrimental to many lowincome students. Community schools also experienced difficulties closing the gap for non-ELD students, who only showed minimal improvement in math and ELA test scores over their non-CIS peers. Further, no evidence was shown that community schools reduce overall dropout rates. On the other hand, community schooling seemed to be moderately able to close the gap for ELD students, especially as it pertains to CELDT scores. Further, fully case-managed ninth graders had marked improvement in attendance, credit accrual and dropout. The lack of peer-review unfortunately means that these results are, at best, promising.

None of the interventions of either approach brought light on (a) who the dropout students were, (b) the nature of their response or non-response, (c) why they ultimately failed to respond and dropped out, (d) whether those who dropped out did so due to an absence of support or despite the presence of support. Consequently, it is also impossible to understand and differentiate pENRs, and ENRs within the current body of literature.

Below are some reasons why the interventions covered in this literature review might fail ENRs. First, it is possible that interventions have not yet sufficiently differentiated marginalized student subpopulations. Since none of the evaluations attempted to disaggregate programs' graduate or dropout populations, little is known 
about why the students were unresponsive. Many interventions disaggregated their participants by very common metrics such as age, gender, race/ethnicity, or SES, but more personalized differentiation may be needed. Certainly, the minimal results of each dropout-prevention approach suggest that most of the interventions under review have been unable to differentiate marginalized student populations well.

Second, it is possible some disconnect in understanding exists between ENRs who receive the intervention and the designers/implementers of the intervention. For example, the intervention is not necessarily applicable to the intervention targets, or the ones implementing the intervention did not account for a key element common to the target subpopulation. This would especially be the case if subsequent researchers did not attempt to find out what caused the students to drop out even if the intervention improved outcomes for most participants.

In conclusion, the research shows that dropout students (a) are only moderately differentiated by race/ethnicity, gender, and SES, (b) can be somewhat differentiated by other metrics such as academic attitude, cumulative risk experience, credit accrual, or trauma, (c) experience an inverse relationship between SES and stress, risk factors, and trauma, (d) experience an inverse relationship between academic achievement and cumulative risk experiences.

The research also shows that dropout students respond best to ecological approaches that are comprehensive in scope and well-implemented. However, no 
research yet shows how effective certain combinations of supports are, or what individual pieces of an intervention array are most effective.

As yet unknown is (a) what characteristics predict sporadic response or nonresponse, (b) what factors facilitate becoming a pENR, (c) what factors protect against becoming an ENR. There is reason to believe that high levels of stressors from sources such as trauma or poverty play a role in dropping out. Further, there is reason to believe that increasing amounts of stressors and risk factors also increase dropout rates. 


\section{Chapter III: Methodology}

\section{Overview of Research}

Despite MetWest's success, a small subpopulation of students exists who have not responded as well. The students have dropped out due to non-response despite the sustained efforts of a comprehensive array of supports are hereafter referred to as "extreme non-responders" (ENRs). A second subpopulation consists of students who have only sporadically responded to sustained efforts of a comprehensive array of supports and are consequently near dropout. Such students are hereafter referred to as "probable ENRs" (pENRs).

ENRs appear to be an ignored student subpopulation within education research on dropouts. Large-scale dropout-prevention interventions, even successful ones, have students who "fall through the cracks". Due to the dearth of research on the topic, little is known why students drop out despite going through both simple and comprehensive intervention arrays. Nothing is known of pENRs' struggles or their decision-making processes that lead them towards dropping out. We only know who dropout students are after the fact. .

I conducted an exploratory, qualitative analysis of pENRs' and ENRs' academic and life experiences in an effort to ascertain what more MetWest can do to help ENRs graduate. The in-depth descriptions provided were intended to inform site administrators elsewhere how to identify, and design better differentiated interventions for, their own 
ENR subpopulations. The study then provided MetWest information to help improve the performance of its pENRs and a new perspective on the study of dropouts

\section{Theoretical Frame of the Research}

This research used Bronfenbrenner's ecological theory as a framework to guide qualitative exploration. MetWest, and all community schools in general, are founded on the assumption that the ecological theory is true. It makes sense to make inquiries along the same premise since this study is designed to understand where MetWest's breakdown in services is. The ecological theory is here explained below.

Bronfenbrenner's ecological theory posits that a growing person's motivation and abilities of engagement are shaped by their environment (Bronfenbrenner, 1979). Bronfenbrenner (1979) further posited that five concentric circles make up a given environment: the microsystem, mesosytem, exosystem, macrosystem, and chronosystem. A "microsystem" is a student's most immediate environments in which the student interacts daily. Some examples of microsystems are the classroom, the home, and the surrounding neighborhood. The mesosystem consists of lateral connections between microsystems. The exosystem is the environment with which a student has little contact but is crucial to supporting the smaller systems. The macrosystem describes the cultural and economic conditions of society, and the chronosystem situates the current state of society in time, showing historical shifts. The last two systems lie outside the scope of this research and will not be examined. 
If any of a student's diverse microsystems do not function in a way that encourages learning that student's academic potential will most likely be unfulfilled (Bronfenbrenner, 1979). MetWest students, primarily comprised of marginalized student subpopulations, navigate life with many obstacles that are not optimal for learning. Students' microsystems may be disrupted due to any number of possible reasons: a single parent household, conflicting work schedule, babysitting, neighborhood violence, systemic racism, and trauma, amongst others. Strong family dysfunction can have a severe impact on academic progress despite an ideal classroom microenvironment. Conversely, academic progress may be hindered if the classroom microsystem is compromised by bullying or a bad student-teacher relationship. On the other hand, if students' microsystems are undergirded by strong support from mesosystems such as the MetWest advisors, and those mesosystems could connect students to exosystems they would otherwise not have access to, then full potential may be reached.

Below is Figure 2, a chart illustrating Bronfenbrenner's theory as it applies to MetWest. At the center is the student, surrounded by the family, neighborhood, and school microsystems. On the outer ring are exosystems, environments surrounding the student that affects the student's trajectory without directly being a part of the student's life. Heavily connecting the two rings are the mesosystems, students' advisors and other school staff.

On the right side is the same theory applied to a traditional high school. The student at center and the three microsystems remain the same. However, in traditional 
schools far less staff are available to connect students to surrounding exosystems.

Further, connection more often than not depends on students' initiative rather than staff initiative.
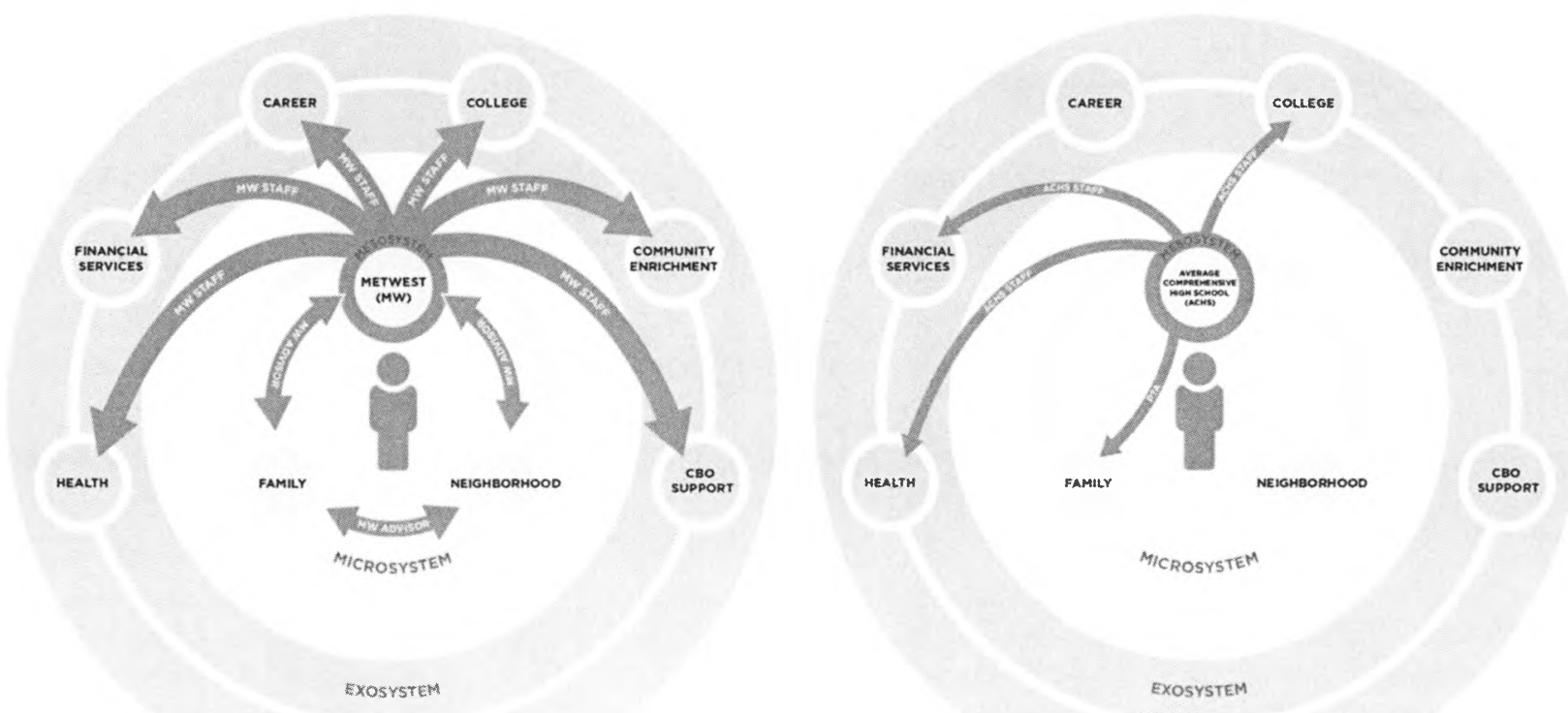

Figure 2: Bronfrenbrenner's Theory applied to schools. This figure illustrates Bronfenbrenner's ecological theory to MetWest (left) and a traditional comprehensive high school (right). All systems are labelled.

A school developed according to Bronfenbrenner's theory seeks to build a strong interconnected set of environments, from microsystems to exosystems, to support student learning (Leonard, 2011). One way that MetWest meets this responsibility is to provide mesosystems in the form of teacher-advisors and community volunteers. The teacher- 
advisor acts as a liaison between students' microsystems: parent(s)/guardian(s), the school site, and the student's internship. The teacher-advisor is thus a mesosystem that links and supports the students' home, school, and job microsystems. Site and district administrative staff ideally act as exosystems that support the mesosystems. The principal sets up school policies and structures to enable the teacher advisors to do their jobs. The principal may also act as a microsystem in disciplinary and advocacy roles. District policies for funding, staffing, and expert support directly affect the school's performance and all its partnerships. MetWest's comprehensive array of supports includes microsystems (e.g. community-based classes), mesosystems (e.g. the teacheradvisors), and even exosystems (e.g. internships, college admissions help, and student health, among others). MetWest and OUSD have worked to ensure that students' microsystems are sufficiently supported to make learning, and thus graduation, probable.

Using this framework I explored students' past and present lives in their home, school, and neighborhood environments. Students' histories were also examined to understand both the causative circumstances of dropout and the processes that led to their failure to respond.

\section{Study Design}

I chose qualitative methods because ENRs were a previously unresearched phenomena with undefined parameters (Denzin \& Lincoln, 2010; Miles, Huberman, \& Saldaña, 2014). This study examined pENRs' and ENRs' realities, both in and out of 
school, to understand the factors that contributed to non-response despite the sustained efforts of a comprehensive array of supports at their disposal.

In-depth qualitative student interviews were analyzed and supplemented by interviews with faculty members. All participants' teacher-advisors (hereafter referred to as "advisors") were interviewed. I also interviewed both the principal and the restorative justice coordinator because they were knowledgeable about most of the student participants. Advisors and school staff who had only minimal contact with the student participants did not participate in this research.

This research defined MetWest High School as the single case under study. MetWest was specifically chosen because it hosts a comprehensive array of services and supports for all its students. Further, the MetWest student body was ideal for delineating the ENR subpopulation from among the student body. First, the majority of MetWest students come from historically marginalized student subpopulations that have traditionally underperformed within education literature and OUSD in particular. Second, most of its students graduate in four years due to the comprehensive array of supports that every student receives. It was therefore reasonable to expect that conducting research at MetWest would provide the most accurate way to delineate ENRs from within an overall subpopulation of traditionally marginalized students.

The case study approach was ideal because it allowed me to explore the lived experiences of participants with a great degree of depth through observations, field notes, interviews, and reflective memos (Miles, Huberman, \& Saldaña, 2014). This collective 
body of data brought the necessary detail regarding the school environment, extent and intensity of interventions used for students, characterizations of students, characterizations of interaction between students and MetWest staff. Further, case studies facilitate exploration of causality (Miles, Huberman, \& Saldaña, 2014). A grounded theory analysis of the collective body of qualitative data resulted in a holistic and systemic understanding of how factors present in participants' lives put their academic progress at risk.

Sample selection. This study utilized a purposive sample according to three striations based on responsiveness to intervention. The first striation, quick dropout, was not considered for this study. This consideration will be explained below. The second striation are pENRs, those students on the verge of dropout despite long sustained efforts from all possible interventions. The last striation are ENRs, those students who have dropped out despite long sustained efforts.

Advisors identified and referred each student participant in the second and third striations. Students qualified to participate if the advisors deemed the student's graduation was at risk due to (a) large amounts of missing assignments, (b) chronic truancy, and (c) multiple suspensions OR if they had already dropped out. Only one criterion was necessary.

Ninth and tenth grade students were not considered eligible for this study. First, MetWest has fewer than one dropout student per year from the ninth and tenth grades. Those few students who dropped out in their first or second years were considered to not 
have exhausted every part of MetWest's available supports. Since this study is meant to determine what supports MetWest lacks or needs to improve upon, it made sense to begin the research where all sustained efforts in the array were exhausted. Second, students who are initially non-responsive usually become responsive after some acclimation time. Third, MetWest's array of supports is designed to address much of the credit deficiencies that many of the incoming ninth and tenth grade students have. There is consequently no way to anticipate which ninth and tenth grade students will become ENRs to or three years later.

The sample comprised thirteen MetWest students in their eleventh and twelfth grades. Advisors nominated nine current eleventh and twelfth grade students and three former students who dropped out previously for this research. From within this sample

pool seven current students and one former student agreed to participate. The study also included each participant's teacher advisor, the site principal, and the restorative justice coordinator.

\section{Data Collection}

Role of the researcher. I am the primary researcher for the collection and analysis of the data. My credibility comes from my experience as a teacher, considerable experience at MetWest building trusting relationships with the students, and doctoral coursework in educational research at SFSU. SFSU's educational leadership program was designed to address issues of equity through research. Coursework relevant to this 
study includes structural inequality, theories of learning, organizational accountability, performance, and reform, transformative leadership, and qualitative research.

I was an "outsider" to MetWest's students and staff. In order to gain the trust of teachers and students I (a) negotiated for consistent access to the school, (b) built rapport and collegial respect with the advisors and site administrators participating in the research, (c) worked out an agreement with participating advisors to allow me to spend time in their classrooms, and (d) established a rapport with students to whom I have had no previous exposure.

Negotiating access involved preliminary meetings with Mr. Plant, the site principal. He supported the research design and purpose, and authorized me to carry out research at MetWest (appendix A). I then attended several staff meetings and met with several advisors and site administrators that I became a familiar face to them.

Participating advisors allowed me free access to their classrooms and encouraged me to help students with their work projects. Such an arrangement is not unusual in MetWest because adult volunteers come into the classrooms weekly to help students with their individual work. The advisors introduced me to the students they believed qualified as participants, and encouraged them to partner with me to complete assignments. It was crucial that the students perceived me to have no authority over them to avoid the possibility of perceived coercion. Most students were not aware of my role at the school. I anticipated that potential participants in the study might perceive my request as coercion because most adults in MetWest have some form of authority over them. I 
verbally assured all participants that participation was voluntary for the duration of the study during recruitment. A clause noting only voluntary involvement was included in the informed assent forms and informed consent forms (Appendix C). A stipend was offered to each participant as an incentive. Student participants could choose $\$ 50$ upon completion of their interviews or up to $\$ 150$ worth of semester textbooks and supplies if they graduated and enrolled into postsecondary education. Staff participants were offered $\$ 50$ upon completion of the interviews. All participants were allowed to decline the stipend if they desired.

Consideration of ethics. All participants in this study faced some risk of loss of privacy. Identifying circumstances and details reported in the research may have jeopardized participants' anonymity. Student participants were informed that details of their experiences may be in the final document and they signed an agreement in advance of the interviews. They were also informed that they would be able to review and approve findings for their own testimonies prior to publication.

Discomfort or anxiety during interviews was another consideration given the personal nature of the questions. To maximize comfort all interviews were held in spaces the students suggested. Interviews were always at students' and staff members' convenience. Typically, I interviewed students during school hours and advisors after school let out. I also sought to limit interviews to one topic domain per interview. This was subject to change based on the pace and willingness of participants to continue. I provided a list of counseling resources to any participants who desired it (Appendix F). 
Also, choosing to answer (or not answer) a question was voluntary. No penalty was associated with choosing not to answer, and all participants could stop participation in the research at any point.

In order to prevent data theft all audio recordings and observations/data memos were digitally stored on a laptop. Only the researcher was allowed access to the data collected. All research data was stored with full disk encryption and password-protection. All recordings and transcripts will be destroyed one year after the completion of the study.

Participant recruitment. The following was the general procedure for recruitment of student participants:

1. I personally approached students eligible to participate and inquired if they were interested in joining the study. A general script for verbal recruitment is included in (Appendix B). If students assented to participate in the study after I approached them, I handed them the informed assent form (Appendix C) and visually and verbally reviewed it with them.

2. If the participant was underage I asked for their parent(s)'/guardian(s)' email address. If no email address existed, I gave the participants informed consent forms (Appendix D) to take home and be signed by their parent(s)/guardian(s).

3. Students and parent(s)/guardian(s)' returned their respective forms for the student to participate in research. Upon receipt, I gave each participant a photocopy of all applicable forms for recordkeeping. 
4. Interviews were scheduled based on participants' convenience (i.e. during lunch, after school, open block periods). Most interviews took place somewhere on school grounds of the participants' choosing. Student interviews usually occurred near the main atrium or a quiet classroom. Staff interviews usually occurred in their workspaces.

The recruitment procedure for MetWest staff participants was identical except that (a) advisors received informed consent forms instead of informed assent forms (Appendix C2), and (b) advisors were only interviewed twice.

\section{Instrumentation}

I used phenomenological interviews to uncover the detail and depth of pENRs' and ENRs' lived experiences (Roulston, 2009). The interview instrumentation (Appendix E) was researcher-designed and covered three topic domains: (a) students' backgrounds and experiences, (b) past and current struggles and coping strategies, and (c) future aspirations and reflections on their experiences at MetWest. The intent of the interviews was to establish their current world and perspectives to better understand (a) their characteristics, and (b) the process of becoming an ENR.

Interviews with students were compared against interviews with school staff. Staff interviews included participants' advisors, the restorative practices coordinator, and site principal. These interviews were broken up into two topic domains: (a) their experiences with student participants, and (b) self-reflections on their practice and 
experiences at MetWest. The intent was to establish (a) their understanding and perceptions of the present pENRs and past ENRs in their care, (b) the challenges they face teaching their pENRs, (c) perspective on what the participants testified about themselves, (d) the gap in knowledge between staff and students regarding students' lives, and (e) perspective on MetWest's daily operations and support structures.

All interviews followed a semi-structured format. The exploratory nature of this research prohibited a preformed matrix of inquiry usually found in fully structured interviews (Fontana \& Frey, 2008). A semi-structured format allowed participants' to better clarify their unique lived experiences (Roulston, 2009). See Appendices E1 and E2 for interview instrumentation. The researcher piloted the interview questions on several other consenting students of similar background (but are not on the verge of dropout) at MetWest to verify validity and reliability of the instruments.

My own observations and data memos supplemented interviews from both student and staff participants. These qualitative tools differ in that observations are primarily descriptive while data memos are primarily reflective (Miles, Huberman, \& Saldaña, 2014). Observations and data memos were made anytime I was on campus. I observed and recorded the general school environment, classroom environments, interactions between advisors, students, and myself, and notable occurrences related to this research. Data memos were written after all interviews and notable observed occurrences. If I was unable to write my observations or data memos down in the moment I recorded them at the earliest opportunity. 


\section{Data Analysis}

This was exploratory research into the lives of students within a previously unresearched student subpopulation. Therefore, no prior analysis instrumentation or code lists were created to avoid imposing my own assumptions or values onto the interview data. All coding, patterns, and themes emerged from the interview data in accordance with grounded theory. Transcript data were limited to school attendance, classes enrolled, and grades.

Initial coding of all interview data included (a) descriptive coding to understand the circumstances of students' struggles, (b) process coding to understand how students and staff are adapting to those struggles, and (c) values coding to understand students' and staffs' understanding, perceptions, beliefs, and attitudes regarding students' lived experiences (Miles, Huberman, \& Saldaña, 2014). As patterns and themes emerged in the data, secondary codes defined general thematic or topical domains that applied to multiple participants. Finally, comparison of coded themes from the various sources of data allowed for stronger verification of participants' claims.

\section{Limitations of the Research}

The immediate aim of this research was to explore the worldviews and lives of pENRs/ENRs and how their lived experiences affected their academic progress despite MetWest's comprehensive array of interventions which were found to help most of their peers. 
External validity. While this research has uncovered some common threads for MetWest's pENR and ENR subpopulations, the small pool of participants (nine students and five staff) and the personal nature of phenomenological interviews does not provide enough of a cross-section to allow for generalizability. Instead, the depth of qualitative analysis is meant to inform future ENR's academic support structures without assuming similar outcomes. It is possible that the narrative of each student participant is so unique such that the findings could not be replicated at other sites. Other schools' ENR subpopulations may include students that do not share the common threads found in MetWest's ENRs.

Further, the low number of participants allows for the possibility that the findings in this research are not exhaustive. Other events and processes not found in this research may also be factors in causing students to become ENRs. Similarly, other protective factors not found in this research may keep ENRs from dropping out.

Internal validity. All claims of this research were based on students' answers from interview data. It is possible that student participants exaggerated interview answers for the sake of social desirability, which can skew the data. To avoid this, students' qualitative data was triangulated against staff participants' qualitative data and student participants' academic records. Academic records were restricted to student transcripts held at the school site office. Transcripts were taken for each participant and compared to students' interview data. Not only are students' claims verified, by doing so 
provided a richer understanding of the world that pENRs/ENRs live in and how their academic progress was affected by their lived experiences.

I as the researcher was also a possible challenge to the internal validity of this study. First, my familiarity with students was a possible source of bias. Second, it is possible that I made favorable conclusions regarding the students that they did not have in mind because I as the interviewer co-create understanding with the interviewee (Denzin \& Lincoln, 2005). To prevent my own bias from affecting the data I contacted each participant post-analysis to proofread their own qualitative data and make corrections (Miles, Huberman, \& Saldaña, 2014).

It is impossible to assume that any one of the factors that protected students from dropping out is entirely causative. Microsystems and mesosystems within MetWest's ecological approach provided many more protective factors surrounding the students than they were aware of. For example, school culture, academic freedom, and administrative support all directly supported the teacher-advisors or supplemented their work. Therefore, it was beyond the scope of this study to parse the interplay between all these factors to determine specific causation.

Also, this research did not expansively explore protective factors against becoming a pENR/ENR. The common factors linking each research participant may also have happened among the wider MetWest student body to some extent. The findings do not address why those students did not become pENRs, so it cannot be assumed that the strategies offered in this research will prevent all students from becoming ENRs. 
Finally, this research was an exploratory case study of a previously unresearched student subpopulation. The research was thus descriptive, but not predictive of student behavior. For example, many pENRs/ENRs in this study experienced some form of trauma but not all students who experience trauma will become pENRs/ENRs.

\section{Potential Benefits of the Research}

The findings of this research can inform future educational leaders about a heretofore unresearched subpopulation located within the larger pool of traditionally marginalized students. This research serves to distinguish ENRs from other at-risk students who do respond to a comprehensive array of supports.

District administrators will gain some insights regarding what more resources should be added to already existing exosystems to benefit ENRs. Second, district administrators will gain some strategies on how to improve access to these exosystems, to maximize utilization of the comprehensive network provided.

Site administrators and staff acting as mesosystems will be empowered to identify their own ENR subpopulations. Staff acting as mesosystems will gain helpful insights into the ENRs they work with, and build new pathways into students' microsystems that will act to ameliorate hindrances to their academic progress. This research may provide insights for interventions and supports that help ENRs pull back from the edge of dropout. 


\section{Chapter IV: Findings}

This research attempted to answer the following questions:

1. Why do some students not respond well despite a wide array of services that successfully helps most?

2. What differentiates extreme non-responsive students from students who sporadically struggle to respond but do graduate?

3. How can schools better reduce dropout rates at the different stages of students' struggles?

Using Bronfenbrenner's ecological theory as a framework, I examined pENRs' and ENRs' lives to uncover what hindered their progress. I intended to use grounded theory coding and then place the codes within their appropriate microsystems or exosystems. As data was gathered it became apparent that Bronfenbrenner's ecological theory was insufficient to explain their struggles to progress academically.

\section{MetWest as Environmental Context}

MetWest and its daily operations are more fully explained here to contextualize the findings of this research concerning its pENR and ENR subpopulations. A portrait of MetWest's daily operations and programs is described below to plainly show how comprehensive the site's support system is. 


\section{A Description of the School Microsystem}

MetWest shares characteristics of an independent studies school, where students and advisors work according to individual agreements. Graduation is based on a portfolio of culminating projects that must conclude with an end-of-semester exhibition that demonstrates proficiency of knowledge in the areas of study. Projects are always aligned with students' interests and monitored by the advisors (hereafter known as advisors). Some examples include the uses of music and graffiti as outlets for creativity, the importance of honeybee preservation, and the effect of gentrification on police brutality rates in student neighborhoods. The traditional letter-grade system is not used and teacher assessment is always performed with the intent of improvement. Absent students have their workload and requirements adjusted as necessary dependent on what the advisor and student agree upon and graduation requirements.

MetWest also shares characteristics of a traditional school. On Mondays, Wednesdays, and Fridays students attend single-subject classes in math, science, foreign language, literature, or the arts. MetWest also contracts with community-based third parties for single-subject elective classes such as community gardening or Maker's Lab. On the other hand, every day begins with advisory, a 1.5-hour affair that includes some combination of (a) daily announcements, (b) class-community check-in, (c) lessons on composition, rhetoric, ethnic studies, or history, (d) sustained silent reading, and (e) independent work on student projects. 
MetWest seeks to build and foster a young-adult community. Advisory rosters remain the same for two years so students and teachers bond together. Students sit at workgroup tables of four to encourage collaborative work. Sofas are present in the classroom to enhance student comfort, giving the classroom a living-room feel. Students are encouraged to address all faculty and classroom volunteers by their first names in order to minimize relational distance. Student self-advocacy is highly encouraged, though this can sometimes lead to public airing of grievances, even against the teachers. Interpersonal grievances between students can and usually are resolved in the restorative justice offices at the students' initiative.

\section{Partnership With The Community Microsystem}

Preparation for adult life within the local community is an important cornerstone of MetWest practice. On Tuesdays and Thursdays, students practice professional internships based on their interests, such as mechanic garages, veterinary offices, or food establishments. Concurrent college enrollment is mandatory in eleventh and twelfth grades, and students can attend whichever colleges and classes they wish. Advisory classes will occasionally participate in community events or community activism.

Per its FSCS designation, MetWest provides students access to necessary services by contracting with community-based organizations to operate in its space. Health, finance, and college admissions services are all on-site. Students can set their own appointments as the need arises. Some sessions, especially college admissions 
preparation, are scheduled into the academic calendar. MetWest also hosts a communitybased psychiatric service, but students must be referred by an internal team that arbitrates on a per-case basis.

\section{Cooperation With The Home Microsystem}

MetWest seeks to ensure that students' home microsystems are meaningfully engaged and connected with their school microsystem. Advisors personally contact parents whenever students perform poorly, fail to turn in work, or are absent. It is also not uncommon for advisors to call parents to compliment the student for exemplary work, though this is not mandatory. Parents are always encouraged to attend and participate in students' end-of-semester exhibitions. As an incentive, parent-teacher-student conferences are usually scheduled directly after the exhibition.

While more can be said of this site and its practices, this portrait is sufficient for establishing the backdrop for this research. MetWest's array of services is comprehensive and largely effective for most of its at-risk student body. What needs remain unmet define this site's ENR subpopulation.

\section{Becoming an pENR and ENR}

Below is Table 3, a visual aid to remind the reader which letters correspond to which students. Students names' were all switched to letters because letters are both gender and ethnic neutral. The substitution was deemed to be the most effective method of ensuring participant anonymity. 
Table 3: A Summary of pENRs'/ENRs' characteristics

\begin{tabular}{|c|c|c|c|c|}
\hline$\underline{\text { Student }}$ & $\frac{\underline{\text { Cause of }}}{\underline{\text { Struggle }}}$ & $\begin{array}{l}\text { Psychological } \\
\underline{\text { Effects }}\end{array}$ & $\begin{array}{l}\text { Exacerbating } \\
\underline{\text { Factors }}\end{array}$ & $\underline{\text { Protective Factors }}$ \\
\hline $\begin{array}{l}\text { A } \\
(\text { ENR) }\end{array}$ & $\begin{array}{l}\text { Violent deaths } \\
\text { in the family }\end{array}$ & Depression & $\begin{array}{l}\text { No mental } \\
\text { healthcare, advisor } \\
\text { actions } \\
\text { No sense of self, } \\
\text { lack of future } \\
\text { aspiration }\end{array}$ & $\begin{array}{l}\text { Advisor as social } \\
\text { capital, flexibility of } \\
\text { requirements }\end{array}$ \\
\hline $\begin{array}{l}\text { B } \\
(\mathrm{pENR})\end{array}$ & $\begin{array}{l}\text { Witnessed } \\
\text { death of close } \\
\text { friend }\end{array}$ & $\begin{array}{l}\text { PTSD, } \\
\text { Depression }\end{array}$ & $\begin{array}{l}\text { No mental } \\
\text { healthcare, } \\
\text { Volatile home }\end{array}$ & $\begin{array}{l}\text { Future aspirations, } \\
\text { Sense of self, } \\
\text { Internship, Advisor } \\
\text { as social capital, } \\
\text { flexibility of } \\
\text { requirements }\end{array}$ \\
\hline $\begin{array}{l}\mathrm{C} \\
(\mathrm{pENR})\end{array}$ & $\begin{array}{l}\text { Witnessed } \\
\text { abuse of family } \\
\text { member }\end{array}$ & $\begin{array}{l}\text { PTSD, } \\
\text { Depression }\end{array}$ & $\begin{array}{l}\text { No mental } \\
\text { healthcare }\end{array}$ & $\begin{array}{l}\text { Future aspirations, } \\
\text { Sense of self, } \\
\text { Internship, Advisor } \\
\text { as social capital, } \\
\text { flexibility of } \\
\text { requirements }\end{array}$ \\
\hline $\begin{array}{l}\text { D } \\
(\mathrm{pENR})\end{array}$ & $\begin{array}{l}\text { Witnessed } \\
\text { dismemberment } \\
\text { of family } \\
\text { member }\end{array}$ & PTSD & $\begin{array}{l}\text { No mental } \\
\text { healthcare, } \\
\text { Advisor lacked } \\
\text { knowledge, } \\
\text { Advisor Actions, } \\
\text { Volatile home }\end{array}$ & $\begin{array}{l}\text { Future aspirations, } \\
\text { Sense of self, } \\
\text { Internship, flexibility } \\
\text { of requirements }\end{array}$ \\
\hline
\end{tabular}




\begin{tabular}{|c|c|c|c|c|}
\hline Student & $\frac{\text { Cause of }}{\underline{\text { Struggle }}}$ & $\frac{\text { Psychological }}{\underline{\text { Effects }}}$ & $\begin{array}{l}\text { Exacerbating } \\
\underline{\text { Factors }}\end{array}$ & $\underline{\text { Protective Factors }}$ \\
\hline $\begin{array}{l}\mathrm{E} \\
(\mathrm{pENR})\end{array}$ & Divorced & $\begin{array}{l}\text { Depression, } \\
\text { High anxiety }\end{array}$ & $\begin{array}{l}\text { Volatile home, } \\
\text { Family's sole } \\
\text { dependence, Lack } \\
\text { of mental } \\
\text { healthcare, } \\
\text { Advisor lacked } \\
\text { knowledge }\end{array}$ & $\begin{array}{l}\text { Future aspirations, } \\
\text { Sense of self, } \\
\text { Internship, Advisor } \\
\text { as social capital, } \\
\text { flexibility of } \\
\text { requirements }\end{array}$ \\
\hline $\begin{array}{l}\text { F } \\
(p E N R)\end{array}$ & $\begin{array}{l}\text { Competing } \\
\text { family } \\
\text { priorities }\end{array}$ & High anxiety & $\begin{array}{l}\text { Volatile home, } \\
\text { Family's sole } \\
\text { dependence }\end{array}$ & $\begin{array}{l}\text { Future aspirations, } \\
\text { Sense of self, } \\
\text { Internship, Advisor } \\
\text { as social capital, } \\
\text { flexibility of } \\
\text { requirements }\end{array}$ \\
\hline $\begin{array}{l}\text { G } \\
(p E N R)\end{array}$ & $\begin{array}{l}\text { Competing } \\
\text { family } \\
\text { priorities }\end{array}$ & $\begin{array}{l}\text { High anxiety, } \\
\text { Acute anxiety, } \\
\text { Anger, lack of } \\
\text { trust }\end{array}$ & $\begin{array}{l}\text { Volatile home, } \\
\text { Family's sole } \\
\text { dependence, No } \\
\text { mental healthcare, } \\
\text { Advisor lacked } \\
\text { knowledge }\end{array}$ & $\begin{array}{l}\text { Future aspirations, } \\
\text { Sense of self, } \\
\text { Internship, Advisor } \\
\text { as social capital, } \\
\text { flexibility of } \\
\text { requirements }\end{array}$ \\
\hline $\begin{array}{l}\mathrm{H} \\
(\mathrm{pENR})\end{array}$ & $\begin{array}{l}\text { Competing } \\
\text { family } \\
\text { priorities }\end{array}$ & $\begin{array}{l}\text { High anxiety, } \\
\text { lack of trust }\end{array}$ & $\begin{array}{l}\text { Family's sole } \\
\text { dependence, no } \\
\text { mental healthcare, } \\
\text { Advisor lacked } \\
\text { knowledge }\end{array}$ & $\begin{array}{l}\text { Future aspirations, } \\
\text { Sense of self, } \\
\text { Internship, Advisor } \\
\text { as social capital, } \\
\text { flexibility of } \\
\text { requirements }\end{array}$ \\
\hline
\end{tabular}

\section{Circumstances for Academic Struggle}

Personal trauma. Of eight students interviewed, five began to struggle academically due to persistent effects of past trauma. Four students reported the source of trauma to be death or violence of people close to them. Student A experienced two 
deaths in his family a year apart, one due to gang violence and the other to police violence. Student B witnessed the death of his mentor due to a heart attack. Student C witnessed the attempted trafficking and beating of a family member in the process of forced emigration. Student D witnessed the videotaped dismemberment of a family member by drug cartel members. Student $\mathrm{E}$ was forced to divorce his wife by his fatherin-law.

Competing family priorities. Three students reported that competing family priorities were their primary source of academic struggle. Student F served as unofficial caretaker for her diabetic head-of-household and siblings. Student G was the sole income-earner and English translator for her family. Student $\mathrm{H}$ served as caretaker for a diabetic relative and supplementary income-earner for her family.

Interaction of causes. The academic struggles for students F, G, and H were somewhat exacerbated by past traumatic experiences. Student F reported a long series of broken relationships, beginning with parents and eventually several client/therapist relationships. Students $\mathrm{G}$ and $\mathrm{H}$ were sexually assaulted. In all cases, longstanding effects of trauma seemed to negatively affect each student's abilities to cope with competing family priorities. Their traumatic experiences also affected their coping behaviors. These will be expanded on in the following sections.

Student E reported that competing family priorities greatly exacerbated his academic struggle even though a traumatic divorce was the primary cause. He often served as the liaison between public services and his family and family-friends. The 
strain of serving in that role prevented him from "getting back on track" even though he was beginning to academically recover from his traumatic experience.

\section{Psychological Effects of Trauma}

Traumatic experiences are so-named because they have lasting negative psychological effects. Below are the negative psychological effects of trauma experienced by the students, and how each is related to students' academic struggles.

PTSD-type symptoms. Students B, C, and D all developed PTSD-type symptoms from their traumatic experiences. To be clear, only Student $\mathrm{C}$ had been officially diagnosed with PTSD. That said many of the symptoms they speak of fall within the post-traumatic stress scale. What is notable in the students' testimonies is the wide variability of trauma sources in terms of recency, cause, and nature of the trauma.

Student B's causative trauma experience occurred in his second year. An adult close to Student B died of natural causes in his presence. Student B consequently experienced recurring, intrusive images as nightmares that would eventually cause sleeplessness and exhaustion. Significantly, he noted that these episodes were causing daily dysfunction resulting in a prolonged period of truancy. He speaks:

(Student B, personal communication, n.d.):

It messed me up so bad, where I didn't go to school for 3 weeks, because it was just like... I was waking up in the middle of the night sweating, 
because I was seeing him choke on his own saliva. I ain't never seen that... like someone overdosing right there in front of you.

Contextual anxiety triggers developed concurrently with the intrusive images. Student B eventually became unable to function at his internship. Student B dropped his internship and chose another one that would not act as a traumatic trigger for him.

(Student B, personal communication, n.d.):

After my dude died, it was kind of hard working [at the internship]... You end up saying his name, asking if he can hand you a tool, and then right when you realize nobody's there but you...it just hits you all over... [So] I gave up.

Student C's causative trauma experience occurred four years prior, just before entering high school. He spoke of suffering from recurring and intrusive images of his experience with human trafficking.

(Student C, personal communication, 05/04/2016):

My family suffered the persecution from the government and so I was very young. And I saw those images of my mother getting beaten by the police and just the terror that I had. Those occurred to me as a nightmare when I was in [redacted]. [Redacted] was kinda peaceful, but my past has been haunting me. And it started since then, those have been in my mind, I should say.... It still appear to this day. 
Student C consequently suffered from severe depression throughout his time at MetWest. He also attempted suicide at least once since immigrating to the United States. His depression will be addressed in the following section.

Student D watched a videotaped torture and execution of a family member by a drug cartel in another country. She consequently experienced recurring and intrusive images. Student D also developed multiple panic triggers from audio and visual cues. She speaks:

(Student D, personal communication, n.d.):

When a person is angry and they reach for their backpacks I start freaking out a lot. Like if you were mad right now and you started reaching for your backpack I would definitely just panic. Sounds like gunshots. Definitely... chainsaws I don't like the sound of chainsaws. When you cut something like say...onions? I can't hear that sound. Just like stuff like little stuff that I can't deal with.

Student D displayed the fewest symptoms (relative to B and C), and to her credit was never truant multiple days in a row. That said she did experience a total lack of motivation for academic work that will be expanded on in a following section.

Depression. Students A, C, E, and F each experienced a debilitating depression. Each student's struggle with depression is uniquely individual in terms of consistency, duration, and behavioral responses. Students $\mathrm{C}$ struggled with occasional depression comorbid with PTSD over the last four years, ever since his relative was abused by 
traffickers. He confessed that his depression was a key reason for several stints of prolonged truancy:

(Student C, personal communication, n.d.):

It's not consistent, but... When I do get the depression again, it really strikes me. It hit me very hard. I just fell down that I can't get up... Sometimes I won't even show up to school for two, three months. I thought it has been improving, and I have been improving in those. I have been seeking a lot of support, but the past three months or so I became a little bit depressed again.

Student $\mathrm{E}$ experienced a deep depression as a consequence of divorce during the last semester of his twelfth grade. He was truant for three months, during which he mourned "with Sam Smith and tequila" (Student E, personal communication, n.d.). Interestingly, Student E ran away from home causing him to miss tenth grade entirely, effectively making him an ENR. Student E returned in his eleventh grade and had steadfastly worked himself out of pENR status with a unique schoolwork arrangement between him, his advisor and the principal during his eleventh year and the first half of his twelfth. The divorce and consequent truancy put him squarely back into pENR status.

Student A fell into deep depression after losing two family members, the first to gang violence in his tenth grade, and the second to police violence in his eleventh grade. Unlike Students C and E, Student A mostly attended class but reported that he could not focus sufficiently to complete work. He speaks: 
(Student A, personal communication, n.d.):

Like around the time, a lot was happening around me; my mind was clogged up. I didn't realize I didn't have peace...I love the work. I love MetWest. It allows you to have your own mindset... But just at that time, things I was expressing was negativity. It was bad. It was horrible... I felt like I was done. Like I was in a hole that you can't jump out of so I just kept digging, like, "Forget it."

Student A eventually did begin to be increasingly truant. Ultimately, Student A failed to turn in a sufficient number of assignments and he dropped out of MetWest at the end of this eleventh year.

Lack of trust. Students $\mathrm{G}$ and $\mathrm{H}$ both reported that their experiences with sexual assault resulted in an inability to trust others. Student G reported an inability to form close bonds with all males except her brother. Student G speaks:

(Student G, personal communication, n.d.)

I don't have relationship with men. It's really hard for me because I feel like every single man just wants something from you... [so my advisor is] just my teacher. To be honest, I don't see him as anything else. I don't see him as a friend I could come talk to...I feel like it's really hard to just even try to build a relationship.

Student H's experience with sexual assault resulted in social isolation. It is plausible that her isolation exacerbated her academic struggle through a lack of support. 
Student H noted, "I need help but like I said I don't like to ask people for stuff...I don't want people to know that I need stuff. I don't want them to know what I'm going through" (personal communication, n.d.). Student H worked several jobs per day to support her family, precisely because she would not or could not depend on others.

It is hard to discern how much either student's inability to form close bonds with those around them exacerbated their academic struggles. Unlike other participants of this research who similarly did not have a close bond with their advisor, Students $\mathrm{G}$ and $\mathrm{H}$ consistently informed their advisors why they had been absent or not completed work.

On the other hand, it is plausible an increase of social capital in both students' lives could have somewhat ameliorated their academic struggles.

\section{Psychological Effects of Competing Family Priorities}

Anxiety. Students E, F, G, and H attributed part or all of their academic struggles to competing family priorities. Notably, all students felt that their families solely

depended on them for every need. Each student consequently reported experiencing high, and even debilitating, anxiety as they sought to balance academic work and family priorities.

Student E experienced severe anxiety regarding his family's needs which caused him to remain an ENR after emotionally recovering from his divorce. His anxiety led to insomnia and sleep paralysis. Whenever Student E awoke paralyzed, he would typically think, "Am I dead? Is this what death feels like? Is this gonna happen for like eternity?" 
(personal communication, n.d.). Eventually, Student E would, "ask myself questions and panic myself back to sleep" (personal communication, n.d.). On days when he experienced severe sleep interruption he opted to stay home and attempt rest instead, family needs permitting.

Student E's anxious thoughts were divided between his own future and his family's future. Specifically, Student E believed that it was impossible for him to work towards his own future while also working for his family's future.

(Student E, personal communication, n.d):

I care for their immigration services and statuses and everything. I help them with their job documents they have to fill out. So it's like "take all of those away"... Everything just else falls apart from then forward...In my head I'm playing scenarios of how to make things better and sadly all of those scenarios end terribly.

These scenarios played through Student E's head every night alongside questions regarding his own future. He fully realized that (a) his family's needs were severely interfering in his ability to make up his three missing months, and (b) his future rested on his academic progress.

Student H similarly had anxiety-induced insomnia, though hers was more based on current needs rather than her long-term future. Student H would frequently sleep through advisory as a result. She believed her late-night anxiety made her too tired to function well at school. Student H said, "I can't concentrate. In my head I am like, 'I am 
going to get all this done,' and then I get [to MetWest] and I am like, 'I can't concentrate. Why am I here?' (personal communication, n.d). To her credit, Student H always kept her appointments with her advisor. That said her exhaustion and anxiety kept her from turning in much of her work.

Student $\mathrm{F}$ was particularly susceptible to stress and anxiety due to a combination of congenital disorder and constant life in a high-stress household. She had learned how to mostly manage her anxiety and stress-related diabetes through an arrangement between her, the advisor, and MetWest staff. At the time of this research her relative had started ailing due to old age and diabetes. When Student F returned home she reported never having time to do work because she was "helping [her diabetic and ailing relative] 24/7" (personal communication, n.d). Student F also reported being in the role of peacekeeper in her household daily. These daily stresses "[left] pressure inside her body" that caused her to lapse on several key assignments for graduation (Student F, personal communication, n.d).

Student G experienced anxiety because she was the family's sole income-earner as well as English-speaking liaison with the general community. She reported having panic attacks in the MetWest bathrooms. Student G partially ameliorated her anxiety through journaling. She noted that she needed to be cautious because her own writing could become an anxiety trigger. Student G said "If I [put] so much out, that creates an anxiety "cause you start seeing everything you've gone through" (personal communication, n.d). 
How past trauma exacerbates academic struggle. Students $G$ and $H$ were both sexually assaulted some years prior to entering MetWest. Both students reported that the experience happened too long ago to be causative of their current academic struggles. However, Students $\mathrm{G}$ and $\mathrm{H}$ acknowledged that the experience played a part in the way they responded to the pressures they faced.

Student G's experience with sexual assault fueled her temper, which Student G acknowledged to be her biggest challenge to academic success and continued employment. She said, "[My temper was] not a result of [the assault], because like I said I've been having anger issues since I was little... but I feel like [the assault] played a part of it." This result is notable because Student G's growing anger was one reason she missed so many days of school. Her anger was growing as a result of (a) the constant stress of providing income and services for her family, (b) her inability to work towards her own future, and (c) consistent immersion in a toxic home environment.

Student $\mathrm{H}$ was sexually assaulted seven years prior to this research and reported two primary consequences from the experience. First, she reported occasional mood swings that caused a lack of motivation in her work and school life. Student H said, "Sometimes I just think about it and I... start tripping out, and...I dont want to do anything anymore, but that lasts for like a day or two... I try for it not to get to me, you know?" (personal communication, n.d.). It is notable that Student H's mood swings were a major cause for her social isolation. Whenever Student $\mathrm{H}$ had a mood swing she would 
"yell at her mom and stuff" (personal communication, n.d.). More drastically, Student H's mood swings caused her to avoid befriending fellow students. Student H speaks: (Student H, personal communication, n.d.):

I felt lonely and I felt like out of place. Like I don't want to talk to these people you know? That's how I felt, “They don't know me.”... I push everybody away. I don't want to be like that but... I wanna make friends, but sometimes like I said I have mood swings.

Second, it seems that Student H's trauma compelled her to take on an exhausting workload, which was a major contributor to her academic struggle. Student $\mathrm{H}$ speaks:

Student H, personal communication, n.d.):

I don't wanna let myself go to the point of where I am depressed and don't want to do anything, because I have been there you know? So I have to keep myself busy; I have to keep my mind running... Like whether I am happy or mad or whatever. I have to keep doing something. So I just don't give up.

As can be seen, it is possible that Student $\mathrm{H}$ used her exhaustive work schedule to keep herself preoccupied from thinking on her sexual assault. At the time of this research Student $\mathrm{H}$ worked several jobs and would often return home late at night. Student $\mathrm{H}$ was often too exhausted and unfocused to complete her assigned work or to wake for advisory classes the following morning. 


\section{Psychological Effects and Becoming a pENR}

The rigors of the academic calendar compounded with psychological struggles put sufficient pressure to cause each student to become a pENR. All eight participants experienced a severe lack of motivation for academic participation when they felt overwhelmed by the demands put on them. Each student subsequently went through long periods of academic disengagement when faced with high academic pressure. Certain other conditions, which will be discussed in a later section, will be shown to exacerbate students' academic struggles to the point of becoming pENRs.

Lack of processing time. Students A, B, G, and E felt that the pace of the academic calendar did not provide them the space and time they needed to mentally and emotionally process. Students A, B, and E all experienced grief from their traumatic experiences, and the academic pressures overloaded them for at least one protracted length of time. Student A's statement best encapsulates what Students A, B, and E experienced as they simultaneously attempted to cope with grief and navigate the academic calendar:

(Student A, personal communication, n.d.):

Yeah. I didn't have no time at all. We had lunch and all that... but that wasn't enough time... It was so much pressure and stress, [which] were necessary, but I didn't have time to process. I go home and I got work to do. I didn't have space for school and myself... I didn't have peace. My brain was clogged; it was too full; my brain was going to explode; before it exploded I just shut everything down and said, "Forget it." 
To Students A, B, and E, their lack of motivation and subsequent prolonged absence(s) of academic activity were a necessary form of self-care to regain their bearings.

Feelings of helplessness and doubt. Students C, D, F, and G lost their motivation to participate in schooling due to feelings of helplessness and self-doubt. Student C's PTSD-induced depression occasionally led to overwhelming self-doubt. When Student C was faced with the high demands of the academic calendar, he said, "The pressure I put on myself to come together... that just knock[s] me out" (personal communication, n.d.). He reported missing weeks at a time because he doubted his ability to successfully graduate. Student C's self-doubt was magnified during the last semester because to him college was a monolithic concept. He said, "Since it is the last semester, I am not taking school seriously, kind of... So I have something to look forward to, but sometimes it is too heavy. 'Aw, that is too much. I can't do that...' that mentality come[s] in" (Student C, personal communication, n.d.).

After Student D watched drug cartel members dismember her relative, she reported going to school every day struggling with hopelessness. Unable to focus, Student D imagined future possibilities of losing life and limb to terrorists or drug cartel members. Student D said, "There was a certain point where I was like... "Fuck it, I'ma die anyways. Its either I'ma get killed or I'ma die naturally so why would I apply so much effort on school?" (personal communication, n.d.). As can be seen, Student D's ideations of hopelessness directly led to a lack of motivation and effort to participate in her schooling. 
Student $\mathrm{F}$ began to lose motivation to participate in schooling when she could not receive the help she felt needed to complete her assignments. Student F said, "They'll help me with a little bit, but not a lot. It'll be like minor projects and stuff, but [not] for major projects" (personal communication, n.d.). Student F consequently stopped attending advisory because she did not see the point if her advisor could not afford her the time and help she needed to succeed in the program.

Student G's motivation to participate in school began to wane when her assignments were backed up one full month. Student G was too busy helping her family economically survive. Student G's family situation was particularly stressful because they simultaneously (a) expected her to be the first to attend and graduate college, and (b) help them even at the cost of her academic wellbeing. As her assignments backed up Student G began to doubt that she could fulfill both conditions at the rate she was absent. Student G speaks:

(personal communication, n.d.)

"[My family] got so many high expectations for you, and you're getting pushed so much... and you feel like you're not making it, then it kinda starts bringing you down. You kind of start getting to this dark spot... you have all these obstacles being thrown at you and not a lot of help. It brings you down, unmotivates you. 
Student $G$ was described earlier in this chapter struggling with anxiety and anger, much of it school-related. Occasionally, whenever the family's needs and academic expectations became overwhelming, Student G would skip school as a form of self-care. Student G speaks:

(Student G, personal communication, n.d):

Yeah, so I didn't feel like stepping out of my [house].... that dark side has been growing very angry lately... 'cause that's when I don't have time to shut down, and I'm not a crier, so I can't just sit there and cry my feelings out even if I wanted to, like... my anger is like really off the charts... I feel like lately it's gotten to a point where I black out... when I get really mad.

Staying at home was a type of self-care for Student G because she noticed that as her anger grew she was irrationally short-tempered with friends and family. Student G's selfcare absences were in addition to weeks-long stretches when she would be absent helping her family.

One interesting episode that occurred in the penultimate semester can shed light on the extent of Student G's anxiety and lack of motivation. During a conference Student G had with her advisor, it came out that she (a) had to write several essays or not pass advisory class, and (b) make up a quarter of math because she was missing math credits. She was potentially ineligible for a nearby state university and most likely ineligible for any other four-year postsecondary institution. For reasons that will be discussed later in 
this chapter, Student G refused to attend the state university. In reply, she said, "Fuck it; I'll just have to let [my failures] stay on my transcript!" In that singular utterance Student G had strongly vocalized that (a) her family's health and safety were her highest priority, (b) she had neither time nor willpower to write make-up essays or learn more math, and (c) she understood it would have a negative effect on her college admissions but could not do anything about it.

Exhaustion. Students $\mathrm{E}$ and $\mathrm{H}$ lost motivation for academic participation because both students were too exhausted to participate. To be clear, Student E lost motivation to participate in school twice. He first lost his motivation due to depression directly after his divorce. After regaining his motivation, he became increasingly anxious as his family's needs mounted. Insomnia and panic attacks kept Student E from being wellrested, and he would often sleep through the day. His absences due to anxiety were in addition to the absences used for his family.

Student H's loss of motivation was directly due to a late work schedule and latenight anxiety. She often returned home at midnight or later and was usually too unfocused for homework. Student H said, "Even when I sit down and I'ma stay up from... eleven to two in the morning ... I'm like, 'I can't do this; I don't know; I can't concentrate' and I start messing with my phone" (personal communication, n.d.). Her lack of focus was exacerbated by late-night anxiety (see "anxiety" section) which was already causing her insomnia and absenteeism. 


\section{Conditions That Exacerbate Becoming pENR/ENR}

Each student in this study shared some combination of factors that caused them to become a $\mathrm{pENR} / \mathrm{ENR}$. It is notable that while none of the students had all of the factors presented, none had only a single factor either. To be clear, it seems that psychological

struggle and subsequent lack of academic motivation are insufficient to cause a student to become a pENR, or an pENR to become an ENR. Bronfenbrenner's Ecological Theory comes into sharper focus in this section because the students reported that their surrounding home and school microsystems were insufficient to support them through their times of trial.

\section{Volatile Home Microsystems}

Five of eight student participants directly attributed volatile home microsystems and consequent poor family relationships as playing a substantial part of their academic struggles. While students' experiences can be somewhat differentiated all five students felt that: (a) they did not have the support of their immediate family, and (b) their experiences at home were detrimental to their academic progress.

Student F reported that her family "argues and fights all the time, like crazy" (Student F, personal communication, n,d.). Oftentimes, her aging caretaker would implore her to act as peacekeeper, to "stand between [the two people fighting] and break it up" (Student F, personal communication, n,d.). While Student F was not worried for her safety, she noted that due to her congenital condition and high anxiety issues she 
"can't take loud noises and stuff, because it pressures me" (Student F, personal communication, $\mathrm{n}, \mathrm{d}$.). These family fights compounded the stress and anxiety Student $\mathrm{F}$ was already undergoing due to being her relative's caretaker. When anxiety became too high she could no longer function well enough to complete her assignments. Sometimes Student F would miss school due to anxiety-induced poor health.

Cultural differences can facilitate volatility. Students D and E felt that the cultural differences between themselves and their parents were a root cause for the volatility of their home microsystems. Both students come from immigrant families whose countries of origin shall remain anonymous to protect students' identities. Students D immigrated alongside his family but came of age immersed in US culture. Student E is a second-generation US citizen. Both students experienced a constant conflict between the cultural milieu they lived in and the ethnic background each had come from. Student D went so far as to say that her home environment felt "kinda oppressive". Student E sums their cultural conflict between parents and students well:

(Student E, personal communication, n.d.)

When you get home and [the arguing] is constant non-stop, day in and day out... I'd wait and I'd go, "Today we're not gonna [argue] and today we're not gonna fight; today we're not gonna fuss [like it does every day these last few months]"... [They want] Traditional stuff, like how they want me to be "culturaler" and more "traditional" [italics reflect speech emphasis]. 
To be clear, Students D's and E's perceived lack of support is more for themselves as persons rather than academics. In fact, both sets of parents encouraged the students to graduate high school and attend college. Students D and E felt that their parents' failure to support them as whole persons facilitated academic struggle despite their constant encouragement to academically succeed.

To properly explain how Student E's volatile home microsystem affected his twelfth-grade academics one must first understand Student E's pivotal tenth-grade year. Student $\mathrm{E}$ ran away in tenth grade due to conflicts with his parents and lived independently for one year. This was the original episode that caused him to become an ENR. After returning to attend his eleventh grade, Student E decided to move out and live on his own because he (a) knew he could support himself, and (b) felt that living with his parents would cause them to resume fighting. To this day he lives independent of his parents.

Student E's poor relationship with his parents had three effects. First, he could not, or would not, talk to his parents about his divorce which caused his three-month stint of truancy in his twelfth year. Second, Student E's advisor could not contact the parents regarding his truancy because Student $\mathrm{E}$ was technically independent of them. Third, Student E's parents selected him to be their liaison for services specifically because he proved he could live and function independently of them. The end result was Student E's constant anxiety, insomnia, panic attacks, and subsequent exhaustion and truancy. 
Student D's strained relationship with her parents acted as a barrier to processing with her family about her trauma issues. Even though Student D's entire family had viewed the videotaped dismemberment, neither Student D nor her parents ever inquired of each other regarding mental health. It is possible that neither Student D nor her family recognized her lack of motivation as an effect of trauma. Whenever the advisor contacted Student D's parents, they pushed her to complete her assignments but never connected the videotape to her lack of motivation. Ultimately, Student D kept her trauma and resulting academic troubles to herself, resulting in a severe lack of motivation for several months.

Intergenerational trauma can facilitate volatility. Students B and G reported that intergenerational trauma played a part in their volatile home microsystems. Both students came from single-parent homes in which the mothers had previously experienced some form of domestic abuse and later divorce. Students B and G reported a volatile home life where each individual mother's past trauma was a key cause of the arguments, fights, and stress that occurred at home. Student G connects past trauma to present hindrance well for both students:

(Student G, personal communication, n.d.)

I always try to understand where [my mom] comes from and I know she's been through a lot in her life... [but] you can't let that hold you back. And I feel like in my family, our past tends to hold us back a lot...my mom and 
my oldest brother they're really stuck in the past... they're just still there and they don't wanna move forward; then it's like [I] can't [move forward]. As can be seen, Student G felt that her mother's past trauma was keeping both Student $\mathrm{G}$ and her mother from developing a closer relationship. Indeed, Student $\mathrm{G}$ considered her home environment so toxic that she would rather enroll in the military than attend the local state university even if it was the only postsecondary institution to accept her. Between her toxic home environment, work-hours, and familial obligations, Student $\mathrm{G}$ found it impossible to complete her assignments anywhere but MetWest, which she was already reluctant to go to due to anger issues.

Student B's strained relationship with his mother was also the result of his mother's trauma experience. Arguments were more occasional than in Student Bs family but could also have much larger effects. One year after his last interview, Student B's mother forced him to move out and relocate to his relatives in San Francisco. It is unknown how extensively Student B's poor relationship with his mother affected his academic struggles, but his home life was certainly not facilitating academic success. For example, living in San Francisco considerably lengthened Student B's daily commute to school and internship. However, it should be said that Student B's mother generally supported him obtaining at least a high school degree. 


\section{Families' Sole Dependence on the Student}

Students E and G both reported that their families solely depended on them for money and/or services. Student G was the sole-income for her home. She would sometimes go as far as Sacramento to provide English services for extended relatives who required it. Student $\mathrm{G}$ eventually found her employment workload, assignment workload, and efforts on behalf of her family to be overwhelming, and she became increasingly angry and anxious. Student $\mathrm{G}$ eventually began to academically disengage as a form of mental self-care.

Student E's family solely depended on him to obtain public services and complete paperwork on behalf of his family and family's friends. After recovering from his divorce and resuming school activities, many of Student E's absences were due to helping his family. He believed that his family would refuse to use other avenues even if such were made available. Student E replied, “My parents don't like asking anybody else. Even if the school were able to [help them obtain services], I feel like they still need confirmation on whether things are right... from me" (personal communication, n.d.). The family's sole dependence on Student E for obtaining services resulted in high anxiety, insomnia, and exhaustion. Worse, because Student E believed that his family would refuse to depend on anyone else, he felt that his personal future was in jeopardy. 


\section{Advisor's Unawareness}

If advisors lack knowledge of (a) a student's life events, or (b) the ramifications of a known life event, they might increase a student's chances of becoming a $\mathrm{pENR} / \mathrm{ENR}$. This is a difficult area to address because on one hand the advisor is only responsible for what they know. If the students do not inform the advisor then the advisor cannot act. On the other hand, it is also clear that through an advisor's unawareness, actions or inactions can facilitate a student becoming an ENR,

Lack of action due to lack of knowledge. Student D's and E's advisors were incapable of addressing the students' traumatic life events because the advisors had no knowledge of them. Both Student D's video-induced trauma and Student E's divorce were directly causative of Student D's and E's pENR status, but neither Student D nor E informed their advisors of the events. Further, the advisors did not connect either Student D's lack of motivation or Student E's prolonged truancy with the possibility of trauma. Interviews with their advisors implied a lack of knowledge regarding both events.

It should be noted that the observable effects of a traumatic event are not always clearly attributable to trauma. This can significantly complicate an advisor's interpretation of observed behaviors. For example, Student D's advisor observed Student D's severe lack of motivation and attributed it more to poor family support and a general dislike for MetWest. Student E's advisor correctly guessed that Student E's prolonged absence was due to depression, but misattributed it to family obligations and overwork. Since the advisor had some knowledge of Student E's past depressive episodes the 
advisor did not connect Student E's absence with a traumatic event. On the other hand, Student $\mathrm{E}$ had never had such a prolonged absence since his return to schooling the previous year.

Since both students had not told their advisors of the traumatic events they experienced or of the psychological fallout, they had no recourse but to cope on their own. If the advisors had known they may suggested counseling or referred for on-site psychiatric help. As it stands neither student knew that MetWest offered psychiatric services at all. Neither Students D nor E could simultaneously cope with their traumatic events and complete their academic requirements. Each student consequently academically disengaged for several months and had trouble re-engaging thereafter.

Even when an advisor is well-informed of what transpires in their students' lives, incomplete information can prevent a more complete amelioration for struggling students. Advisors for Students $\mathrm{G}$ and $\mathrm{H}$ were aware of most their students' external stressors. Their advisors were also proactive in collaborating with the students to meet their academic goals while navigating those stressors. Unfortunately, the advisors were unaware of each student's psychological struggles other than in the most general sense.

Student G's advisor's lack of knowledge regarding her psychological struggle most likely facilitated Student $\mathrm{G}$ becoming an pENR. The advisor was aware that Student G (a) was the sole-income earner for her family, (b) served as the Englishspeaking liaison between the family and public services, (c) was "surrounded by [familial] trauma" (personal communication, n.d.). Despite that, Student G's advisor was 
unaware of (a) Student G's perceived toxicity of her home microsystem, (b) her internalized anxiety, and (c) her growing anger and combativeness. It is difficult to discern the primary causes of Student G's prolonged absenteeism and incomplete work because (a) mental self-care and helping her family were both reasons for absenteeism, and (b) her anxiety, anger, family needs, and employment workload were all effective barriers to completing her assignments. At the very least, Student G's psychological struggles were certainly barriers to academic success that might have been ameliorated with counseling.

Student $\mathrm{G}$ had several possible reasons for her omissions to her advisor. First, Student G's experience with sexual assault resulted in an aversion to relationships with men. She said, "I don't have relationships with men. It's really hard for me because I feel like every single man just wants something from [me]" (Student G, personal communication, n.d.). Second, due to the advisor's institutionalized position in her life, she "[didn't] see him as a friend [she] could come talk to" (Student G, personal communication, n.d.). Third, it is also possible that she simply never thought to tell anyone regarding her psychological struggles.

Similarly, Student H's advisor may have been able to ameliorate some of the barriers to Student H's academic success if he had known about her psychological stressors. The advisor knew all of Student H's external stressors, in particular her diabetic relative and her employment workload. It is unknown if the advisor was aware of Student H's history of sexual assault, but the advisor certainly did not know that 
Student H's (a) employment workload was partly due to her need to not think on her trauma, and (b) occasional periods of academic disengagement, mood swings, and social isolation were all due to trauma effects.

Student H may have had two reasons to omit these facts to her advisor. First, she admitted that she did not like to "ask people for stuff", and did not "want people to know what [she is] going through" (Student H, personal communication, n.d.). Second, it is highly possible that she believed she was too far removed from her sexual assault experience for it to negatively impact her academic success. Student $\mathrm{H}$ certainly did not believe that her trauma had anything to do with her academic struggles. On the other hand, Student $\mathrm{H}$ recognized that the experience greatly affected her relationships and ideation.

Finally, advisors lacked knowledge of outside resources that may have helped students overwhelmed with family priorities. Advisors for Students E, G, and H had no knowledge of the services made available by community-based non-profit organizations that might have helped to lighten the burden on their students. Then again, as Student E believed, it is entirely possible that the families would have refused such help regardless of availability.

It is impossible to definitively assert whether the advisors could have prevented Students D, E, G, and $\mathrm{H}$ from gaining pENR status even if they had known of their students' psychological struggles. Too many other factors intertwined together such that it is plausible that nothing would have changed even with additional knowledge. On the 
other hand, it is also plausible that (a) successful counseling could have resulted in fewer days missed due to mental self-care or exhaustion, (b) successful family counseling could have resulted in a less volatile home microsystem, and (c) successful utilization of community-based service organizations could have resulted in less family dependence on the students.

Uninformed actions facilitate becoming ENR. Advisors for Students A and D each acted in a way that unknowingly pushed each student towards ENR status. Student A had lost two relatives to violence one year apart. The advisor knew what had happened to Student A and understood that Student A was experiencing trauma. Despite that, the advisor consistently pushed Student A to turn in at least minimal work on assignments to avoid total academic disengagement. Student A reported that the advisor's action took away the space he needed to process. Student A reported that his head became increasingly "clogged" until he dropped out.

Two facts should be considered in the advisor's defense. First, Student A admitted that he could not vocalize what he needed at the time. Second, the advisor had offered to refer Student A to the campus psychiatrist but the offer was somehow lost. Student A did not know that MetWest had an on-site psychiatrist prior to his dropping out.

Student D's advisor's actions resulted in a profound lack of trust from Student D. Student D's family experienced an event that negatively affected her academic performance During her eleventh grade. After Student D confided in her advisor, the 
advisor called her parents. Student D felt betrayed. Worse, Student D's parents became upset at her because a teacher had gotten involved in a family affair.

The result of that particular event was that Student D decided not to tell her advisor about her psychological trauma regarding the dismemberment tape one year later. She reported three reasons for her omission. First, she no longer felt she trusted her advisor enough to keep it confidential, and she feared retaliation from her parents. Second, she saw it as "a family thing", not a "school and family thing" (Student D, personal communication, n.d.). Third, she knew there was nothing he could do. Student D consequently chose to cope with her trauma alone, and the resulting lack of motivation caused her to eventually become an pENR.

\section{Insufficient Mental Healthcare}

Each of the students faced some kind of internal mental/emotional struggle related to the circumstances that pushed them towards ENR status. Each student's internal struggle played a large, if not the primary, role in making each student a pENR. The lack of proper mental healthcare or therapy resulted in each student eventually becoming overwhelmed by the academic loads placed on them. Truancy and/or a lack of homework followed soon thereafter.

Of the eight students in this research, Students C, F, and G all had gone through professional therapy some years prior to their interviews with me. Student $\mathrm{C}$, who was processing through his emigration trauma, attended some psychiatric sessions but refused 
medication. Student $\mathrm{C}$ was released two years prior to this study based on improvement of his symptoms. When his PTSD symptoms and subsequent depression returned later that year he refused to resume treatment. A staff member attributed Student C's refusal to a cultural norm against psychiatric treatment.

Students $\mathrm{F}$ and $\mathrm{H}$ discontinued treatment because they did not trust their psychiatrists, albeit for different reasons. Student $\mathrm{F}$ went through several psychiatrists and counselors, but they all "left her... moved on to other jobs or just quit" (Student F, personal communication, n.d.). She eventually became wary of constantly establishing new relationships, and opted to discontinue seeking treatment. Student $\mathrm{H}$ enrolled for psychiatric treatment regarding her sexual assault but could not share with the psychiatrist because she was wary of mandatory reporting laws. Student $H$ therefore quickly discontinued treatment.

The remaining five students, Students A, B, D, E, and G, never sought treatment. Student G did not seek treatment because she believed that her undocumented status would have negative ramifications for her family. Student E did not want to pay for a therapist because "a therapist is expensive as hell" (personal communication, n.d.). Student D did not seek treatment because she did not trust her advisor, who was empowered to act as a gateway to mental healthcare. It is unknown why Students A and B did not seek treatment, but it is entirely possible that (a) they did not know they had access to psychiatric help via their advisors, (b) they believed psychiatric help was beyond their economic means, and/or (c) they were too ashamed to talk about it. 


\section{Summary Of The Process Of Becoming An ENR}

Every participant in this research shared four things in common. First, all students experienced some intense circumstance(s) that caused them some form of mental dysfunction, such as PTSD symptoms, general anxiety, acute anxiety, or depression. Second, all students faced a number of conditions that acted as barriers to academic success from their home and/or school microsystems. Third, all students either did not seek treatment or discontinued treatment some years prior to their becoming an ENR. Fourth, all students developed maladaptive coping mechanisms to ease the pressures of navigating school, healing from trauma, and/or family pressures. The coping mechanism of choice was academic disengagement through truancy and/or incomplete or missing assignments. To the students, the choice was always between academic or personal survival.

\section{Protective Factors From Dropping Out}

The students participating in this research were resilient in the face of trying circumstances. Six of eight students graduated from MetWest on time, and Student $\mathrm{H}$ finished after a fifth year. Student A did not graduate. Notably, each participant's graduation status was questionable up to the month, and sometimes week, of graduation. Nevertheless, the following factors actively mitigated the process of pENRs becoming ENRs. 
The only one to drop out was Student A, a pENR whose depression caused him to stop responding to the array and eventually become an ENR. To be clear, Student A shared many of the same protective factors as his peers. The similarities and difference between him and the other pENRs in this study will be expanded on in the following sections.

\section{Future Aspirations}

With the exception of Student A, all students (a) held some future college or job aspiration, and (b) recognized that a high school diploma was the bare minimum requirement for the desired occupations. Student B wanted to be a welder. Student C wanted to become a lawyer to eventually become a policymaker in his home country. Student D wanted to work in the police. Student E always aimed for college even though he did not know what would come after. Student F wanted to be a teacher. Student G aimed to be a curriculum writer. Finally, Student $\mathrm{H}$ planned to become a registered nurse.

The importance of having a future aspiration cannot be underestimated. Even Student B, who felt that "school was not for him", was intent on obtaining his diploma. Student B speaks:

(Student B, personal communication, n.d.)

I don't plan on going to college; I plan on going to an apprenticeship...but I can't apply now because I need my credits... I'm ready now to walk that 
stage; I'm ready to chuck up my deuces; I'm ready... but I can't because I don't have everything I need.

Students A, B, C, D, and E, all experienced trauma effects that corroded their responsiveness to intervention for the duration of their prolonged absences. What seemed to pull Students B, C, D, and E out of their prolonged absences was the knowledge that they would surmount their personal obstacles because it was necessary for them to reach their goals.

In contrast, Student A believed that he became an ENR at least partially due to his lack of future aspiration. He said, "You can't [have] no plan. No one has it completely planned out, but there was nothing written down for me, in my life, period. Without having any plan or goal, of course everything is pointless" (personal communication, n.d.). The deaths in his family "enhanced [his lack of plan] in the wrong way", meaning that no matter what plans were made "none of them would have mattered at all" (personal communication, n.d.).

\section{School Structures}

In the end, the most effective protective factor that prevented all but Student A from dropping out was MetWest itself. The structures in place, namely the internships, advisors, and independent-studies status enabled the ENRs in this study to graduate, though only barely. 
Advisors as social capital. The advisors were the most important source of social capital for the students to draw upon. With the exception of Student D, who did not trust her advisor, all students invariably respected and trusted their advisors enough to be candid about life circumstances. Due to their institutionalized capacity as case managers, advisors traditionally wield great leeway in acting on behalf of their students. The advisors in this study were heavily involved in seeking to work around students' schedules, court appointments, internships, and family obligations to keep them on-track for graduation. In contrast, such relationships in traditional schools are more coincidental than institutionalized.

The current standing advisory/advisor system was so satisfactory that it was the one aspect of MetWest no student except Student D would change. The advisors in this study had a great depth of care for the student participants. Most students, even those not inclined to view advisors as friends, greatly respected their advisors. Many students reflected Student B's sentiments about his own advisor, who said, "she's just not showing that she's only here for just work, she's showing that she actually cares... I'm more than a job to her. Like, she gonna always remember me, and that's real" (personal communication, n.d.). Even Student A, who dropped out, said of his advisor, "[My advisor] knew everything, so [he] particularly was my therapist. If I didn't have [him], it would've ended worse. Way worse" (personal communication, n.d.).

Interestingly, few of the students regarded anyone outside of their advisor as social capital. Only Students A and D listed one or two other faculty members who 
would act as social capital for them. Only Student $\mathrm{C}$ credited his internship mentor with keeping him in school. Only Student $\mathrm{G}$ attributed a close friend to her ability to stay in school. Further, Student G believed there was no one in her neighborhood who could act as social capital for her. She said, "You just see a bunch of drug addicts and it's like when you go down that street it gives you no hope. [I feel], like, 'Damn my community is really messed up"' (personal communication, n.d.) It thus seems that ENRs may have low amounts social capital. Certainly, without the advisor system each student would have had a much higher chance to drop out.

It should be said that access to social capital must lead to utilization of social capital. One of the reasons Student A dropped out was that he eventually found another group of friends. He said, "At MetWest I started hanging around the kids that didn't like going to class. So I stopped going to class with them. That's not me. I found myself in the wrong crowd" (personal communication, n.d.). Student A had access to his advisor and a supportive family, but both were replaced by friends who did not act as social capital. Likewise, Student $\mathrm{C}$ revealed at his final exhibition that every day of his truancy was spent at a friend's house less than a mile from school grounds. No one, including his parents, knew about this.

Internships as a source of stress relief. Most students participated in an internship that served as a "release valve" as stress built up. Student B renovated houses for his internship. Student $\mathrm{C}$ had a sports internship for refugee students. Student D was an intern at the local police academy. Student E enjoyed developing a mentoring 
program at his internship. Student G's internship allowed her to be a consistent participant within the Bay Area Activism community. Student F enjoyed a teaching assistant internship working with children.

The internships generally served as a protective factor because they acted as stress-relief while keeping students at least partially academically engaged. It is significant that each student always participated in their internships even during their months-long absences from school. Student $\mathrm{H}$ did not have an internship she enjoyed, but she understood its relevancy to her future job aspirations, so she always participated. On the other hand, Student A could not find an internship that interested him, and he eventually stopped going to his internship such that he became completely academically disengaged.

Flexibility of Requirements. This one protective factor was the one most necessary for the students to graduate at all. MetWest's status as an independent studies school allowed the advisors extreme flexibility in fulfilling credit requirements. For example, Student B had trouble learning math due to a learning disability and his belief that, "school was not for [him]" (personal communication, n.d.). Student B's advisor helped him to concurrently enroll in a trade class and a class that taught him the mathematics involved in that particular trade to simultaneously gain credit and work experience.

Often the change in requirements involved inventive ways to gain academic credit. For example, Student F was struggling with geometry such that she attempted and 
failed the class twice. A math teacher at the school thought Student F might be able to gain geometry credit for a quilting class she was attending. At the end of the quilting class Student F gained the geometry credit she needed for graduation, though her proficiency at geometry is questionable.

Advisors also regularly modified assignment requirements to fit students' everchanging life circumstances. For example, when Student G fell behind on her end-ofsemester exhibition, the exhibition requirements were halved and she was required to write a series of essays in their place. Student $\mathrm{C}$ would be absent for several weeks at a time, and his advisor occasionally lowered the writing requirement but increased the reading requirement. When Student A was depressed and unable to focus on academic writing, his advisor would allow him to write poetry or songs rather than essays for homework credit.

It is possible the independent studies status can be both a facilitator and barrier to dropping out. One advisor policy that all students, particularly pENRs, took advantage of was no late-penalty for incomplete assignments. A lack of late-penalties for assignments meant that it was (a) common practice for all students to defer their work for any reason, and (b) for all students to feel increasing psychological pressure as the amount of homework increased. Student $\mathrm{C}$ explains:

(Student C, personal communication, n.d.)

"I just asked [my advisor] to send me a list of missing assignment I need to get done. Apparently, it is six essays. So, now I am, to be honest, 
totally depressed. Not depressed-depressed, but I don't want to do it anymore... sometimes it is too heavy.

This sentiment was not uncommon amongst the student participating in this study. On more than one occasion the advisor would eventually pare down the make-up requirements so the students would complete them rather than give up entirely.

\section{The Difference Between pENRs and ENRs}

One main difference existed between all the pENRs who graduated and Student A, who became an ENR. All pENRs who graduated held a future aspiration, be it college attendance or occupation. The reasons vary. Student E wanted to go to college to learn how to be independent from his parents. Student G wanted to go to college to get away from her toxic home environment and learn how to empower women across the nation. Student $\mathrm{C}$ wanted to eventually go back to his home country to be a lawmaker for social change. Student D wanted to work in law enforcement because she enjoyed the occupation.

As can be seen these aspirations cover immediate needs, near-future goals and far-flung ideals. Regardless of their immediacy, these students' aspirations, coupled with their sense of self, mentally kept them from languishing in a demotivated funk. Student D showed this war between lack of motivation and aspiration best when she said, "I wasn't planning on coming [today]. I just didn't wanna come, and I was like 'Fuck it, I am 
almost done with the semester"' (personal communication, n.d.) Student D came, performed her interview, and attended class. Aspiration won out.

In contrast, Student A had no future aspiration at the time of his dropping out. No other factors were exclusively shared by all the pENRs. Student A had a supportive family, in contrast with Students B, D, E, F, and G. Student A also had a close relationship with his advisor, in contrast with Students D, G, and H. Student A had an internship that he neither enjoyed nor disliked, similar to students E, G, and H.

It is significant that four students had internships they neither enjoyed nor disliked, yet three still graduated. The difference between Student A and the others was that he ultimately saw "no point" to anything, internship or otherwise. On the other hand, Students E, G, and $\mathrm{H}$ all developed future aspirations apart from their internships. That sense of expectation turned the internships into a requirement to meet rather than a wall to surmount, even if those internships were unrelated to their hopes.

Equally significant was that at the time of this research, Student A was ready to resume his education due to an internal change. Student A speaks:

(Student A, personal communication, n.d.)

Like I realized he's gone and I have to move on. That's why I'm going back. So when I go back, I'll give my $100 \ldots$...'m willing to go back out there because I want to, not because [someone] else is telling me to, no one's on my back telling me to do this [or] that. 
While he did not have a concrete occupational aspiration, Student A had clearly developed some sense of purpose for himself that allowed him to pursue post-secondary education. The pressure of following the "plans of others", in conjunction with his hopelessness, caused him to drop out in the first place. Student A acknowledged that he was ready and would never let his eleventh grade happen again.

\section{Conclusion}

Existing research was insufficient for understanding how to prevent students from dropping out and why existing interventions are ineffective for them. This research shows that students become pENRs despite an extensive array of services when they (a) experience trauma or prolonged stressful circumstance that causes negative psychological effects and high academic pressure lead to a lack of motivation for academic participation, (b) do not receive proper mental health care, (c) develop maladaptive coping mechanisms such as truancy, (d) lack family support, and (e) lack good rapport with authority figures. It is probable that if a pENR loses their sense of purpose as they struggle to respond, they will eventually stop responding altogether and become an ENR.

Bronfenbrenner's ecological theory predicted some of the findings. As he predicted, many of the students' problems began within the home and community microsystems. Some of these issues were exacerbated by small dysfunctions in the 
school microsystem. It is plausible that if none of these issues had started, the students' academic struggles would never have arisen.

However, Bronfenbrenner's theory is insufficient to explain how students become ENRs because it does not take into account students' mental state. Several students carried negative psychological effects from trauma for months, if not years, after the traumatic experience. As an example, Student $\mathrm{C}$ enjoyed a solid, peaceful, family, school, and neighborhood microsystem, but his long battle with depression still left him on the verge of dropping out. Student $\mathrm{H}$ shared a similar situation.

On the other hand, students were still able to respond to intervention even when the home microsystems were not ideally situated until their mental health degraded. Students E and G, whose families were solely dependent on them, became less responsive to MetWest's support only after they began to experience heavy anxiety. Responsiveness decreased further as those symptoms became more acute, such as insomnia, panic attacks, and intense anger.

Students' mental and emotional condition appears to be the large mediating factor between life circumstances and ENR status. Negative psychological effects began the process of academic disengagement that resulted in prolonged absence and missing assignments. Student A summed it well: "I would sit there and listen, but the problems would still be in the back of my head. [I know] what I need to do, but I don't live at school. So once I step out of school, I am back into my reality" (personal communication, n.d.). 
Fortunately, as has been seen with the seven pENRs in this study, intensive interventions over a sustained period of time can keep pENRs from dropping out and becoming ENRs. The fact that only one dropped out even though all of them had been on the verge of dropping out is a sign that the comprehensive array mostly works.

That said the interventions necessary to remediate pENRs back into full responsiveness are neither easy nor short-term. Intense trauma causes long-lasting stress affects and often requires extensive therapy. Intense need requires a large and varied amount of resources. The next chapter will discuss policies and recommendations that schools can use to meet the needs of their pENRs and ENRs. 


\section{Chapter V: Significance of the Findings and Recommendations}

ENRs are students who have dropped out in their third or fourth years after sustained efforts from a comprehensive array of resources that help most marginalized students. The purpose of this research was to understand how to better differentiate extreme non-responders (ENRs) from the greater body of traditionally-marginalized students in order to help improve services for them and prevent them from dropping out. If we are able to help the least responsive students within marginalized subpopulations, then we will have a more complete model of intervention array to help students graduate. Further, it is likely that whatever will benefit ENRs will benefit all the other students within a site's marginalized subpopulations. To better understand this student subpopulation ignored by research, the researcher examined the lives of students who dropped out or were most likely to drop out in a school that was highly successful in helping their marginalized peers graduate.

The most striking finding of this study is that the situation for ENRs is reversible. All eight students in this research spent a prolonged on the verge of dropping out but only one became an ENR. The array of supports to reverse the course of pENRs must be comprehensive, intensive, and sustained, but if implemented properly it seems most pENRs will graduate. While it is unlikely for every high school to add MetWest's comprehensive array wholesale, every school can add services which will help them reduce dropout rates. 


\section{Major Findings}

\section{Why Some Students Do Not Respond to Intervention}

Students became pENRs when they experienced circumstances that cause prolonged negative psychological effects. Four students, (A, B, D, and E) faced a traumatic experience that caused them to develop PTSD-like symptoms and depression soon after. Student $C$ faced a traumatic experience several years prior to enrolling at MetWest, but even then he struggled with recurrent PTSD and depression. The remaining four students (E, F, G, and $\mathrm{H}$ ) struggled to be both the sole help for their families and being a student. All four students consequently experienced large amounts of general anxiety resulting in insomnia, lack of focus, and poor health. Students E and $\mathrm{G}$ also developed acute anxiety resulting in panic attacks.

Students' pENR status solidified as they operated under numerous conditions that left them feeling unsupported. Many of the students lived in home microsystems with some degree of volatility. Sometimes the volatility was based on cultural clashes between first generation families and their more westernized children, as in the cases of Students D and E. Sometimes intergenerational trauma experienced by the parents exacerbated the volatility of the household, as in the cases of Students B and G. For student F, the volatility of her household would cause her poor health that would take her out of the classroom.

The nature of being the sole point of services for their families meant that often families could not or would not academically support the students. The services varied, 
but the services invariably took each student away from the classroom. It was common to hear that Students E, G, and H were absent because they had to work, obtain public services, or translate for family members. Student F's case was much more recently developed and not as prolonged, but she also found the circumstances occasionally overwhelming.

The advisors played their own roles in their pENRs' lack of support. In their defense, each advisor had the absolute best of intentions in accordance with their jobs. Each advisor worked mightily to push each student towards graduation. For Student A the advisor pushed too hard. Eventually, Student A "shut down" and stopped attending class altogether. Student D's advisor unwittingly betrayed her resulting in a permanent lack of trust.

In most other cases the advisors were unaware of the causes behind their students' apparent lack of motivation and subsequent truancy. The advisors had no idea that Students B and D were suffering from PTSD-like symptoms, that Students E and G were experiencing acute anxiety, or that Student $\mathrm{H}$ was experiencing high general anxiety. This held true even when the advisors knew of their students' causative circumstances, such as Students G and H.

Finally, pENRs seemed to develop a lack of motivation as a result of harboring at least one negative psychological condition (e.g; depression, anxiety, PTSD). Regardless of the causative circumstances or the conditions by which students were not supported, each student developed a lasting negative psychological condition that went untreated. 
PTSD-like symptoms, depression, and high anxiety all led to the same point: a lack of motivation leading to gradual or abrupt academic disengagement. Disengagement could be either truancy or incomplete work, but often consisted of both.

Two factors ultimately allowed all pENRs except Student A graduate. First, the pENRs all held some form of future aspiration and knew that they needed a diploma to pursue what they wanted. Second, MetWest afforded each pENR extensive assignment/requirement flexibility. Both of these things empowered their resolve just enough to push pENR to graduate.

The importance of the pENRs' resolve should not be underestimated. Student A acknowledged that at the time of his dropping out he had no plan, and no hope, unlike his pENR peers. Just as with the pENRs in this study, Student A also had a tight-knit relationship with his advisor who extended as much assignment/requirement flexibility as he could afford. However, Student A never turned anything in and he consequently dropped out.

\section{Significance of the Findings}

This study is significant because it is the first to take a longitudinal look at the characteristics of students from traditionally-marginalized subpopulations struggling despite the presence of one of the strongest set of supports currently available anywhere. This study establishes a beginning to the understanding of (a) how students become 
pENRs, (b) how pENRs become ENRs and drop out, and (c) what services schools can provide to facilitate their graduation.

Students become pENRs when they (a) develop an underlying negative psychological condition caused by at least one overwhelming life circumstance, (b) perceive a lack of support from traditional structures such as teachers or family, (c) are untreated (or undertreated) for their psychological condition, and (d) lose their motivation for academic progress. Should a pENR lose their sense of purpose, they may well become ENRs. Each student in this study was responding well to MetWest until an overwhelming set of events or circumstances catalyzed the drastic change in their behaviors. Therefore, the researcher concludes that the presented set of events is most likely sequential, though not necessarily so.

The fact that pENRs and the ENR in this research experienced such a prolonged struggle despite the presence of a more comprehensive array of supports than existing literature implies either that (a) the array had either lacked breadth or depth to proactively or preventatively provide for the students, or (b) the array evinced several "holes" between the students and the supports. These conclusions will be further expanded upon in the section on implications and recommendations.

\section{Discussion}

One of the key findings of this research was that declining mental health contributed to (a) the process of a student becoming a pENR, and (b) the process of a 
pENR becoming an ENR and dropping out. Students would encounter some overwhelming circumstance, experience a decline in mental health, lose motivation for academic work, and eventually disengage. Those who lost their sense of self and purpose stopped responding to the point of dropping out.

This research gives us a more precise understanding of the process of becoming a dropout than previously found in the literature. Bowers and Sprott (2012) concluded that dropout students could be predicted by their disenfranchisement with school. Bridgeland (2010) and Hodis et al. (2011) concluded dropout students could be predicted by their academic attitudes. While true, their findings are too simplistic. Bridgeland (2010) and Bowers and Sprott (2012) each noted (a) external conditions that caused students' changes towards schooling, and (b) the end result that caused students to drop out (e.g.; lack of motivation, attitude). However, neither researcher investigated the processes that led from the causative circumstance to the end result. Hodis et al. (2011) noted that those with less rigorous academic attitudes were less likely to accrue credits. They never investigated the underlying causes for those attitudes. One consequence of the omissions was that students' mental health was overlooked in all studies.

This research probed more deeply and found a rich variety of causes that placed students at risk of dropout and eventually caused one to drop out. This research found that (a) trauma exposure leading to trauma-related stress, and (b) overwhelming povertyrelated stress are major factors in predicting dropouts. Either will lead to poor academic performance if the student develops some form of negative psychological effect such as 
depression or anxiety. It is highly possible that Bowers and Sprott (2012), Bridgeland (2010), and Hodis et al., (2011) missed this key process between causative external conditions and students' eventual dropout.

What this study contributes is a thorough understanding of the roles stress and trauma exposure possibly play in the process of becoming a dropout student. If students' problematic behaviors and attitudes are caused by trauma and/or poverty-related stress rather than pure adolescent intransigence, it has massive implications on policies regarding school discipline, pedagogy, treatment, and differentiation. For example, it seems that any dropout prevention efforts for marginalized populations should focus on mitigating poor mental health. A school therapist or district psychiatrist could be very useful for dropout prevention.

Given these findings it is highly likely that dropout prevention programs were unaware of the role that mental health plays in academic performance. Many of the standalone programs targeted students with problem behaviors. These programs provided them with case managers who taught them life skills and relationship skills. Yet, if these programs did not think to approach the students through the lens of trauma exposure, these standalone programs would not work because the underlying cause of problematic behaviors would never have been remediated.

Likewise, small schools sought to improve the academic trajectories of marginalized students using smaller, intimate learning spaces as a theory of change. However, small schools did not have many structures in place to help mitigate the 
poverty-related stress that students were experiencing and ultimately bringing with them to school. If anything, small schools had less resources than their more traditional counterparts due to a lack of funding.

The findings also identify some of the holes in MetWest's services. For example, the advisors observed the signs of disengagement such as poor academic attitude, student disenfranchisement, and truancy, but they did not realize much of it was due to declining mental health. The advisors were correct in their assessment of academic standing since most of the pENRs remained on the edge of dropping out till the week prior to graduation. On the other hand, if declining mental health indeed mediates the process of a pENR becoming an ENR, then the advisor's unawareness of the underlying cause possibly decreases the pENR's chance of academic recovery.

Advisors seemed also to lack knowledge of available third-party resources for students, particularly those whose families were solely dependent on them for services and support. The advisors did not seem aware of the organizations available to help the students' struggling families. Given that Students E, F, G, and H graduated, it is possible this point is rendered moot. Yet, it is also possible such knowledge could have prevented the families' sheer dependence on their students, resulting in less assignment alterations and stress for all involved parties.

The fact that most of the students did not speak much of their troubles to anyone indicated (a) some distrust between them and other students or faculty, (b) shame and embarrassment, (c) or both. Such was the case for Students A, B, D, G, and H. It is 
unknown how prevalent disclosure of mental health struggles is at MetWest, but Student A suspected that silence regarding mental health was far more prevalent than anyone knew.

The students also did not know about MetWest's psychiatric services. Students $\mathrm{A}, \mathrm{B}$, and $\mathrm{E}$ spoke on their mental troubles but did not know that MetWest offered psychiatric help through a third-party contractor three days per week. Interestingly, Student A's advisor did offer to refer Student A to the psychiatrist, but Student A had no memory of that particular interaction.

Finally, the fact that the seven graduating students were resolved to finish based on their future aspirations is highly significant. Setbacks, though enormous, were viewed as temporary, because they knew that school was a necessary step to arrive at the desired destination. Similarly, Student A attributed finding his own aspiration to resuming education post-dropout.

\section{Recommendations For All Schools}

Three concepts form the foundation upon which all the following recommendations rest. The first is that some students, such as pENRs, need an extraordinary mental and social/emotional support system. Such a system should not consist of a single service. Ideally, the system should be intensive, long-lasting, and cover as many of a student's microsystems as possible. Further, the sources of care within that system should be cross-disciplinary and well integrated, uniting support staff, 
teachers, administrators, and mental health specialists. A traditional school's district psychologist whose primary task is the qualification of students for special education is a far cry from what many of these students need.

The second concept is that students must trust staff. Having the most effective supports does not guarantee the supports will be used. For this reason, building relationship and care between teachers and their least-responsive students is an absolute necessity. Valenzuela (1999) argued that students entrust themselves to school staff only when they believe they are cared for as whole people. This research recommends that site administrators inculcate staff and students in a culture of "authentic caring" (Valenzuela, 1999). At the very least, school staff should be trained to not automatically discount their least responsive students as ne'er-do-wells.

Lastly, administrators' attentions should always work towards continual improvement of services. Wilson et al. (2011) found that the thoroughness of implementation was one of the driving factors of any intervention's effectiveness. Thus, intervention leaders need to be constantly involved in improving implementation of services as well as the services themselves. As a corollary, such improvement should also involve expanding the capacity of school staff to provide up to, and including, extraordinary measures of care. 


\section{Recommendations For Traditional High Schools}

Traditional schools tend to lack much of the comprehensive array that MetWest hosts for its students. In an era where constant cuts to education budgets disallows developing schools like MetWest to scale, it is impractical to adopt everything. The following five recommendations are designed to help traditional schools prioritize what additional supports are likely to have the biggest effect on preventing dropout.

First, the researcher recommends each site have some form of on-site mental health professional, preferably a trauma specialist. Information on availability and accessibility should be made available to all teachers and students in order to maximize access. Further, the researcher recommends the mental health specialist be easily accessible by students. This allows students the freedom to seek services without risking embarrassment and shame.

Second, the researcher recommends all teachers adopt a policy of personalized plans for their least responsive third and fourth year students regarding credit accrual and assignment completion. Such plans should include (a) multiple methods of obtaining academic credit (e.g. a quilting elective to gain geometry credit), (b) multiple possibilities for assignment completion (e.g. writing instead of presenting), and (c) a contractual assignment calendar replacing punitive responses for late work (e.g. student-teacher agreement on past due dates). This school policy was most responsible for ensuring MetWest's pENRs graduated. It is recognized that teachers at non-independent study schools might be unable to alter assignments to the same extent as MetWest. That said at 
least some of these things can be done. For example, some schools in Fremont Unified School District allow for contracts that extend assignment due dates into the summer months.

Third, the researcher recommends that site administrators introduce traumainformed pedagogy to all teaching staff. Trauma-informed pedagogy is a paradigm shift in understanding students' problem behaviors. It involves (a) understanding that trauma might be the cause of problem behaviors, (b) responding to problem behaviors restoratively rather than punitively, and (c) using teaching styles sensitive to trauma victims. Many teachers are unprepared to deal with problematic behaviors associated with trauma exposure. Further, many teachers are unprepared to help a student cope with the effects of trauma exposure. Being able to correctly interpret the behavioral, verbal, and effectual cues of trauma-exposed students will (a) increase the probability of mental treatment, (b) avoid punitive treatment likely to cause the student to feel unsupported, and (c) decrease the risk of students becoming pENRs or ENRs.

Fourth, the researcher recommends adopting the case management aspect of MetWest's advisory system for its least responsive students. Advisors met with students to ensure they were on-track, arranged college visits, arranged appointments with community-based organizations for services, and acted as the liaison between student, family, and school. If providing advisors for third and fourth year students is unfeasible, then the researcher recommends at least providing case-management advisors for ninth 
graders, since (a) case-management had such a profound effect on ninth grade retention, and (b) ninth grade credit accrual has such a strong predictive validity for dropout.

Fifth, the researcher recommends that schools enable students to explore their interests so they can develop career goals and aspirations that will take them past secondary school. It is true that such aspirations can easily be derailed by trauma and other intense situations. On the other hand, the future aspirations of the pENRs in this study were partially responsible for ensuring that pENRs kept responding to MetWest's interventions. Further, the one student who dropped out attributed his dropping out to a lack of aspiration. OUSD uses Learning Through Internship programs to help its students explore future occupations. If a district or school-run program is unfeasible, many nonprofits send speakers to various schools to encourage students towards various occupations (i.e. UN school speaker to encourage females in STEM careers).

\section{Recommendations for Improving MetWest Services}

MetWest's array of supports is both powerful comprehensive. Each pENR in this study would have likely dropped out in more traditional settings. That seven of eight pENRs graduated proves that given the right supports the path towards dropout is reversible. Yet even in the most proactive schools can improve breadth and depth of their services to reduce students' struggles and prevent them from dropping out.

Recommendations will be divided according to the circumstance that caused students to become pENRs or ENRs. Since the advisors were most often pENRs' 
primary source of social capital and gateway to other MetWest services, recommendations will start with the advisors and expand towards school-wide structures.

\section{Recommendations Surrounding Student Mental Health}

To fill the gaps in advisors' knowledge about pENRs' mental health struggles, work should be focused in three places. First, trauma-informed pedagogy should be reviewed. Principal Plant informed the researcher that teachers at MetWest were all trained in trauma-informed pedagogy at some point in their careers. Though an oversimplification, trauma-informed pedagogy is meant to help teachers interpret student behaviors and responses through the lens of possible trauma-exposure. While problematic behaviors are difficult to interpret accurately, especially if the subject is taboo, shameful, or embarrassing, more work could have been done in several of the students' cases.

Second, advisors should work to increase students' access to psychiatric care. Student awareness of services is one issue of access. Students A, B, and D were unaware that such services existed already. The researcher also recommends the process be streamlined if possible. Currently, obtaining psychiatric care at MetWest involved a lengthy process of meetings and referrals between teachers, site administrators, and site support staff. If students were unwilling to trust a single faculty member with their problems, involving five to six more faculty members seems more a hindrance than a solution. Additionally, though they were immensely grateful for the staffs' open-door 
policy and willingness to listen, these students believed a certified clinician would have provided more help.

The researcher recommends an in-house therapist with ease-of access. Several students wished the school had a "walk-in" therapist, perhaps at the health clinic next door. While MetWest might not find it feasible to pay for an in-house psychiatrist they might be able to design a program utilizing freshly graduated marriage family therapists (MFTs) in need of licensing hours. For example, San Francisco United School District (SFUSD) utilizes such a program. Many SFUSD Title 1 schools have a dedicated MFT to provide counseling for their low-income student populations in return for certification hours. Since MFTs in California need 3000+ hours in order to become certified it is possible to keep the MFT on-site for two years or more. The potential longevity of the position would benefit MetWest by adding relational stability for a population wary of broken relationships.

Third, the researcher recommends that MetWest develop a protocol for trustbuilding between advisors and students, or even between students of an advisory classroom. In particular, the National School Reform Faculty features several dialogue models that can inform advisors and students on how to approach certain topics together with a shared understanding. Such a dialogue might have prevented Student D's advisor from calling her parents and betraying her trust in the process, or prevented Student A from succumbing to overwhelming pressure from his advisor. A protocol revolving 
around common dialogues might help to standardize advisors' approach with students and allow for a greater atmosphere of trust to exist between students and advisors.

As a corollary MetWest might also benefit from adjusting its community-building procedures. Once per month, MetWest holds "community circles" in addition to the weekly town hall meetings. These circles are usually gender-segregated and intended to be places of dialogue. Every student except Student A reviled the circles for their artifice and banality. Indeed, several students made a noted effort to "cut" school or avoid school altogether on days scheduled for circles. Again, the National School Reform Faculty features dialogues for team-building and trust-building between students that might be used and aid in turning the circles into functional support groups for trauma victims.

\section{Recommendations Surrounding Competing Family Priorities}

Met West should provide advisors with an updated list of community resources that the advisor can give to students or their families. Student E often provided translation services and obtained immigration paperwork for family friends. Student F sometimes missed school to watch over her niece. Student $\mathrm{H}$ often missed school because her employment was necessary to pay her relative's health bills. In each case, third-party non-profit organizations exist around Oakland to help meet these specific needs and others common to low-income and immigrant families. If advisors had access to this knowledge ENRs' stress levels might have decreased significantly knowing that their families would receive the proper care. 
As the active gateway between the student and the administration, the advisor's knowledge of resources is crucial to students' access. This is problematic because advisors do not have time in their schedules to form relationships with community-based organizations or form indices of resources. The advisors' need underscores the importance of a high-quality community schools officer. A community schools officer is a coordinator from the district that helps a school connect to community-based organizations for services and collaboration. MetWest's community schools officer should be (a) actively connecting the school to community-based service providers, (b) working to integrate those services into the site (per FSCS policy), and (c) distributing that knowledge to the advisors.

Second, for students who lack the trust to share their struggles, the researcher recommends that MetWest administrators (a) release a list of resources that students can access on their own, and (b) instruct them on how and when to use that list. Students prone to distrust are most likely not to use offered school services. In such cases it is better that they are able to receive some care than none at all. One easily accessible resource is $\underline{w w w . o n e d e g r e e . c o m}$, a local Bay Area search engine for community-based non-profit organizations. The organizations are indexed according to index, need, racial demographic, distance, and cost. Further, needs include criminal law, housing, babysitting, lost-cost insurance, legal representation, tutoring, mentoring, and more. 


\section{Recommendations For Further Research}

Much more work must be done to establish the parameters of the pENR and ENR subpopulations. First, the inability to generalize due to small sample sizes necessitates attempting to use this three-tier model at similar schools. Good site candidates to replicate research are other Met schools in Sacramento, San Diego, or Rhode Island, all of which are part of the Big Picture Learning group. Replications of this research will serve to determine if trauma and family dependence on the students are good predictors of becoming a pENR. Replicated research on a wider scale can also help determine whether additional causes of becoming a pENR exist.

Second, it is likely that some non-pENRs have been trauma-exposed and that others act as the sole point of service for their families but do not struggle. Understanding why some become pENRs and other not will help improve schools' ability to make tiered responses for their own traditionally-marginalized populations. Such additional research might also yield additional detailed categories of student responsiveness that will help add understanding to the process of dropping out as a whole.

Third, more research is needed to establish the relationship between (a) trauma effects and academic achievement, and (b) trauma interventions and academic achievement. This researcher found several articles mention in passing that trauma was related to truancy and other measures relating to dropout, but no quantitative data was given. This researcher also found many articles on the efficacy of trauma interventions. 
If school systems are to begin focusing on mental health, then it behooves researchers to lay the groundwork that (a) leads sites to prioritize mental health, and (b) justifies district expenditures on mental health to the public eye.

Fourth, it would be worthwhile to attempt to parse the effects of each piece of the comprehensive array. It would be impossible to implement MetWest's model to scale in every major metropolitan area. In lieu of that, effectiveness research can be performed on pieces of the array to understand the protective factors most practical and meaningful to adopt.

Finally, one of the major incidental findings of this research was that students' future aspirations play a large role in informing students' resolve. Student A could not bring himself to respond despite the presence of the wide array due to his lack of plan and hope. It is plausible that the difference between academic survival and dropping out is the development of future aspirations and career goals. Focusing on developing these attitudes is a promising way to help students navigate secondary schooling and avoid dropping out.

This research sought to understand the process by which the most marginalized of traditionally-marginalized subpopulations became non-responders despite the most powerful array of interventions anywhere. Because most of the pENRs in this study graduated, we know several of the factors most able to reduce dropout. It is absolutely possible to design better approaches to help failing students in marginalized at-risk populations reverse their course towards dropout and ultimately graduate. 


\section{Bibliography}

Adams, S.D, Hazelwood, S., \& Hayden, B. Student affairs case management: Merging social work theory with student affairs practice. Journal of Student Affairs Research and Practice, 51(4), 446-458.

Allensworth, E.M., \& Easton J.Q., What Matters for Staying on Track and Graduating in Chicago Public High Schools. Retrieved from: consortium.uchicago.edu

Allensworth E.M. (2013). The use of ninth-grade early warning indicators to improve Chicago Schools. Journal of Education for Student's at Risk, 18, 68-83.

Balfanz, R., Bridgeland, J.M., Fox, J.H., Depaoli, J.L., Ingram E.S., \& Maushard M. (2014). Building a Grad Nation: Progress and Challenge in Ending the High School Dropout Epidemic.

Retrieved from: https://gradnation.americaspromise.org

Barrat, V.X., Berliner, B., Fong, A.B. (2012). When dropping out is not a permanent highschool outcome: Student characteristics, motivations, and reenrollment challenges. Journal of Education for Students Placed at Risk 17, 217-233. DOI:10.1080/10824669

Bartlett, L., Kupczynski, L., \& Holland G. (2011). Impact of school reform on dropout rates and test scores in an urban high school. Contemporary Issues in Education Research 4(11), 1-8. 
Bloom H.S., Thompson S.L., \& Unterman R. (2010). Transforming the High School Experience: How New York City's New Small Schools are Boosting Student Achievement, and Graduation Rates. Retrieved from: mdrc.org

Bowers, A.J., Sprott R., Why tenth graders fail to finish highschool: A dropout typology latent class analysis. Journal of Education for Students at Risk 17, 129-148. DOI: $10.1080 / 10842669.2012 .692071$

Bridgeland J.M. (2010) The new dropout challenge: Bridging gaps among students, parents, and teachers. New Directions for Youth Development 127, 101-110. DOI: $10.1002 / y d$

Bronfenbrenner, U. (1979). The Ecology of Human Development. Cambridge, Massachusetts: Harvard University Press.

Burzichelli C., Mackey P.E., \& Bausmith J. (2011). Dropout prevention programs in nine mid-Atlantic region school districts: Additions to a dropout prevention database. Retrieved from: files.eric.ed.gov/fulltext/ed516740.pdf

Castrechini, S., London, R.A. (2012). Positive Outcomes in Community Schools. Retrieved from: www.americanprogress.org

Chapman, C., Laird, J., Ifill, N., \& KewalRamani, A. (2011). Trends in High School Dropout and Completion Rates in the United States: 1972-2009.

Retrieved from: https://nces.ed.gov/

CIS Annual Report 2014. Retrieved from: https://www.communitiesinschools.org CIS Annual Report 2015. Retrieved from: https://www.communitiesinschools.org 
Communities In Schools National Evaluation Five Year Executive Summary. Retrieved from: https://www.communitiesinschools.org

Crosby, S.D., Day A.G., Baroni, B.A., \& Somers, C.L. (2015). School staff perspectives on the challenges, and solutions to working with court-involved students. Journal of School Health, 85, 347-354.

Darling-Hammond, L. (2010). The Flat World and Education: How America's commitment to Equity Will Determine Our Future, New York, NY: Teachers College Press.

Erickson, L.D., Mcdonald, S., \& Elder Jr., G.H. (2009). Informal mentors, and education: complementary, or compensatory resources? Sociology of Education, 82, 344367.

Evan, A., Huberman, M., Means, B., Mitchell, K., Shear, L., Shkolnik, J., ... Uekawa, K. (2006) Evaluation of the Bill \& Melinda Gates Foundation's High School Grants Initiative: 2001-2005 Final Report.

Retrieved from: http://www.air.org/publications/pubs_ehd_school_reform.aspx

Fantuzzo J., Leboeuf W., Rouse, H, \& Chen C. (2012). Academic achievement of African-American boys: A city-wide, community-based investigation of risk and resilience. Journal of School Psychology 50, 559-579.

Fehrer K., \& Leos-Urbel J. (2015). Oakland Unified School District Community Schools: Understanding Implementation Efforts to Support Students, Teachers, and Families. Retrieved from: https://gardnercenter.stanford.edu 
Felitti, V.J., Anda, R.F., Nordenburg, D., Williamson, D.F., Spitz, M.A., Edwards, V. Koss M.P., Marks, J.S. (1998). Relationship of childhood abuse and household dysfunction to many of the leading causes of death in adults. American Journal of Preventive Medicine, 14(4), 245-258.

Foltz R., Dang S., Daniels, B., Doyle H., Mcfee, S., \& Quisenberry C. (2013). When diagnostic labels mask trauma. Reclaiming Children, and Youth 22(2), 12-17.

Gase L.N., Defosset A., Perry R., \& Kuo T., (2016). Youth's perspectives on the reasons underlying school truancy and opportunities to improve school attendance. The Qualitative Report 21(2), 299-320.

Ginwright, S. (2004). Black in School; Afrocentric Reform, Urban Youth and the Promise of Hip-Hop Culture, New York, Teachers College Press, Columbia University.

Goodkind, J. R., LaNoue M.D., \& Milford, J. (2010). Adaption and implementation of cognitive behavioral intervention for trauma in schools with American Indian youth. Journal of Clinical Child \& Adolescent Psychology 39(6), 858-872. DOI: $10.1080 / 15374416.2010 .517166$.

Gregory, A., Skiba, R.J., and Noguera, P. A. (2010). The achievement gap and the discipline gap: Two sides of the same coin? Educational Reseracher, 39(1), 5968. 
Guterman J., Schreiber F., Matulis S., Schwartkopff L., Deppe J., \& Steil R. (2016) Psychological treatments for symptoms of posttraumatic stress disorder in children, adolescents, and young adults: A meta-analysis. Clinical Child Family Psychology Review 19, 77-93. DOI: 10.1007/s10567-016-0202-5.

Havik ,T., Bru, E., \& Ertesvag, S.K. (2015). School factors associated with school refusal- and truancy-related reasons for school non-attendance. Social Psychology of Education 18, 221-240.

Herrera, C., Dubois D. L., \& Grossman J. B. (2013). The Role of Risk: Mentoring Experiences and Outcomes for Youth with Varying Risk Profiles. Retrieved from: www.mdrc.org/publication/role-risk

Hodis, F.A., Meyere L.H., \& McClure J. (2011). A longitudinal investigation of motivation and secondary school achievement using growth mixture modeling. Journal of Education Psyhchology 103(2), 312-323. DOI: 10.1037/a0022547

Jaycox, L.H., Kataoka S.H., Stein, B.D., Langley, A.K., \& Wong, M. (2012). Cognitive intervention for trauma in schools. Journal of Applied School Psychology 28, 239255. DOI: $10.1080 / 15377903.2012 .695766$

Johnson, S.B., Pryce, J.M. (2013) Therapeutic mentoring: reducing the impact of trauma for foster youth. Child Welfare 92(3), 9-25. 
Kataoka S., Jaycox L.H., Wong, M., Nadeem E., Langley A., Tang L., \& Stein B.D. (2011). Effects on school outcomes in low-income minority youth: preliminary findings from a community-partnered study of a school trauma intervention. Ethnicity and Disease 21(3 01$), 1-12$.

Kataoka, S.H., Nadeem, E., Wong, M., Langley, A.K., Jaycox, L.H., Stein, B.D., \& Young, P. (2009). Improving disaster mental health care in schools: a communitypartnered approach. American Journal of Preventive Medicine, 37(6), 225-229.

Leonard J. (2011). Using Bronfenbrenner's Ecological Theory to understand community partnerships: a historical case study of one urban high school. Urban Education 46(5), 988-1010. DOI: 10.1177/0042085911400337.

Leithwood K., \& Jantzi D., A review of empirical evidence about school size effects: A policy perspective. Review of Educational Research. 79(1), 464-490.

DOI: $10.3102 / 0034654308326158$.

Little S.G., Akin-Little, A., \& Somerville M.P. (2011). Response to trauma in children: An examination of effective intervention and post-traumatic growth. School Psychology International 32(5), 448-463. DOI: 10.1177/0143034311402916.

Mac Iver, M.A. (2011). The challenge of improving urban high school graduation outcomes: Findings from a randomized study of dropout prevention efforts. Journal of Education for Students Placed at Risk 16, 167-184.

DOI: $10.1080 / 10824669.584497$ 
Maynard B.R., Mcrea K.T., Pigott T.D., \& Kelly M.S. (2012). Indicated Truancy Interventions: Effects on School Attendance Among Chronic Truant Students. Retrieved from: campbellcollaboration.org.

Maynard B.R., Kjellstrand E.K., \& Thompson A.M. (2014). Effects of check and connect on attendance, behavior, and academics: A randomized effectiveness trial. Research on Social Work Practice 24(3), 297-309.

Nadeem E., Jaycox L.H., \& Stein, B.D. (2011). Going to scale: Experiences implementing a school-based trauma intervention. School Psychology Review 40(4), 549-568.

Ngo V., Langley A., Kataoka S.H., Nadeem, E., Escudero P., \& Stein B.D. (2008). Providing evidence-based practice to ethnically diverse youths: Examples from the cognitive behavioral intervention for trauma in schools (CBITS) program. Journal of the American Academy of Child and Adolescent Psychiatry 47(8), 858862.

Nikulina, V., Widom, C.S., \& Czaja, S. (2011). The role of childhood neglect and childhood poverty in predicting mental health, academic achievement and crime in adulthood. American Journal of Community Psychology, 48(3-4), 309-321.

Nixon, R.D., Sterk J., \& Pearce A. (2012). A randomized trial of cognitive behavior therapy and cognitive therapy for children with posttraumatic stress disorder following single-incident trauma. Journal of Abnormal Child Psychology 40, 327337. DOI: $10.1007 / \mathrm{s} 10802-011-9566-7$ 
Parks- Yancy, R. (2012). Interactions into opportunities: career management for lowincome, first generation African American college students. Journal of College Development 53(4), 510-523.

Rodgers K. (2014). With liberty and justice for some: A philosophical argument in opposition to the small schools movement in New York City. Philosophical Studies in Education 45, 126-135.

Roksa, J., \& Potter, D. (2011). Parenting and academic achievement: intergenerational transmission of educational advantage. Sociology of Education 84(4), 299-321. DOI: $10.1177 / 0038040711417013$.

Rotermund, S. (2013). Big Picture Learning: High School Alumni Report Retrieved from: www.bigpicture.org

Shanks T.R., \& Robinson C. (2012). Assets, economic opportunity and stress: A framework for understanding child and educational outcomes. Economics of Education Review 33, 154-170.

Skiba, R. J., Michael, R. S., Nardo, A. C., and Peterson, R. L. (2002). The color of discipline: Sources of racial and gender disproportionality in school punishment. The Urban Review, 34(4), 317-342.

Stein, B.D., Jaycox L.H., Kataoka S.H., Wong M., Tu, W., Eliott, M.N., \& Fink, A. (2003). A mental health intervention for schoolchildren exposed to violence. Journal of American Medical Association 290(5), 603-611. 
Tanner-Smith E.E., \& Wilson S.J. (2013). A meta-analysis of the effects of dropout prevention programs on school absenteeism. Prevention Science 14, 468478. DOI: $10.1007 / \mathrm{s} 11121-012-0330-1$

Unterman, R. (2014). Headed to College: The Effects of New York City's Small High Schools of Choice on Postsecondary Enrollment. Retrieved From: www.mdrc.org

Valli L., Stefanski A., \& Jacobson R. (2014). Typologizing school-community partnerships: A framework for analysis and action. Urban Education 1-29. DOI: $10.1177 / 0042085914549366$.

Wadsworth, M.E., Raviv T., Reinhard C., Wolff B., Santiago, C.D., \& Einhorn L. (2008). An indirect effects model of the association between poverty and child functioning: The role of children's poverty-related stress. Journal of Loss and Trauma 13, 156-185. DOI: 10.1080/15325020701742185.

Wainer, H., \& Zwerling H.L. (2006). Evidence that smaller schools do not improve student achievement. The Phi Delta Kappa International 88(4), 300-303.

Wei, Y., Szumilas M., \& Kutcher S. (2010). Effectiveness on mental health of psychological debriefing for crisis intervention in schools. Educational Psychology Review 22, 339-347. DOI: 10.1007/s10648-010-9139-2

What Works Clearinghouse: https://ies.ed.gov/ncee/wwc/ 
Wilson S.J., Tanner-Smith, E.E., Lipsey M.W., Katarzyna S.F., \& Morrison, J. (2011). Dropout Prevention and Intervention Programs: Effects on School completion and Dropout Among School-Aged Children, and Youth. Retrieved from: campbellcollaboration.org

Wilson, W.J. (2009). More Than Just Race. Being Black and Poor in the Inner City. New York, NY: W.W. Norton. \& Co.

Wright, T. \& Ryan, S. (2014). Too scared to learn. Young Children, 69(5), 88-93. 
Appendix A: Permission to Perform Research at MetWest Oakland

To Whom It May Concern:

I am Charles Plant, Principal of MetWest High School in Oakland. I have been working with Josh Pong for several months now on developing a community-based mentor program for our school. He has been a pleasure to work with. He has developed into a positive presence and real asset for the school - especially for our students.

I have complete confidence in Josh, and he has permission to conduct research at our school. If I can be of any help to you, please let me know.

Charles Plant charlie.plant@metwest.org 401-741-8954 


\section{Appendix B: General Recruiting Script for Students}

Hello, my name is Joshua Pong. I am a doctoral student at SF state in Educational Leadership. I have been working with the Principal, Charlie, here at MetWest to perform research on school improvement. I am inviting you to participate in this research because we believe that you can provide MetWest with some insight as to what else they should provide for you to succeed here. The steps we would like you to participate in are:

1. Three 30-minute interviews that will happen at your convenience.

2. Three 15-minute clarifying sessions that will occur post-analysis, also at your convenience.

The first and second interviews will ask about your current world and circumstances. The third will ask about what you believe you need or want to see happen.

Your participation in this study is purely voluntary; you may withdraw at any time, regardless of what stage in the research project you are at. If you have any questions or would like to participate in the research, I can be reached at. 


\section{Appendix B2: General Recruiting Script for Staff Members}

Hello, my name is Joshua Pong. I am a doctoral student at SF state in Educational Leadership. I have been working with the Principal, Charlie, here at MetWest to perform research on school improvement. I am inviting you to participate in this research because we believe that you can provide MetWest with some insight as to what your student(s) might need in order to succeed here. The steps we would like you to participate in are:

1. Two 30-minute interviews that will happen at your convenience.

2. Two 15-minute clarifying sessions that will occur post-analysis, also at your convenience.

The first interview will ask about your perceptions and beliefs about your student.The second interview will ask about your perceptions and beliefs regarding your practice and school policy/structures.

Your participation in this study is purely voluntary; you may withdraw at any time, regardless of what stage in the research project you are at. If you have any questions or would like to participate in the research, I can be reached at ioshuapong@.gmail.com. 


\section{Appendix C: Assent Form for Students \\ SAN FRANCISCO STATE UNIVERSITY \\ Assent to Participate in a Research Study \\ Interviews for Student Needs Assessment}

\section{PURPOSE AND BACKGROUND}

My name is Joshua Pong. I am a graduate student at San Francisco State University and I am conducting a research study about what MetWest can do to help meet your needs. I am inviting you to take part in the research because your advisory teachers believe that you are the best source for insights and understanding regarding this particular area.

\section{PROCEDURES}

If you agree to participate in this research study, the following will occur:

- I will interview you three times for up to 30 minutes at a time and place convenient to you. The first and second interviews will ask about your current world and circumstances. The third will ask about what you believe you need or want to see happen.

- You will be contacted post-analysis to clarify your answers. Each session will be about 15 minutes long.

- I will audiotape the interview to be sure I record your thoughts correctly.

\section{RISKS}

There is a risk of loss of privacy. However, the researcher will not use your name or any other identifying information in any published reports of the research. The research material will be kept in a secure location, and only the researcher will have access to the data. After one year, the researcher will destroy all audio recordings of your interview, will remove all identifying information from the transcripts, and will keep the data in a locked cabinet or office.

There is a risk of discomfort or anxiety because of the personal nature of the questions. You may choose not to answer any question without penalty. If you feel you need it, a list of counseling resources is provided. 


\section{DIRECT BENEFITS}

There are no direct benefits to you for participating in this research.

\section{COSTS}

There will be no cost to you for participating in this research.

\section{COMPENSATION}

Student will receive a $\$ 50$ gift certificate to a place of their choosing, or their first semester college textbooks to a maximum of $\$ 150$.

\section{ALTERNATIVES}

The alternative is to not participate in this research. OUESTIONS

You have spoken with Joshua Pong about this study and have had your questions answered. If you have any further questions about the study, you may contact the researcher by email at Joshuapong@,gmail or you may contact Professor Pogrow, the researcher's advisor, at stanpogrow@att.net. You may also ask questions about your rights as a research participant, or send any comments or complaints about the study, to Human and Animal Protections at San Francisco State University at 415: 338-1093 or protocol@,sfsu.edu.

Participation in research is voluntary. You do not have to participate, and you may stop participating at any time, or at any point in the project, without any penalty to yourself.

\section{ASSENT}

You have been given a copy of this assent form to keep.

I understand the purpose and the procedures of the research as stated above, and agree to participate.

Participant's Name (print)

Signature

$$
\text { Research Participant }
$$

Signature
Date:

Date:

\section{Researcher}




\section{Appendix C2: Consent Form for Staff Members SAN FRANCISCO STATE UNIVERSITY \\ Assent to Participate in a Research Study \\ Interviews for Student Needs Assessment}

\section{PURPOSE AND BACKGROUND}

My name is Joshua Pong. I am a graduate student at San Francisco State University and I am conducting a research study about what MetWest can do to help meet the needs of it's at-risk students. I am inviting you to take part in the research because as a staff member who works closely with the student research participants, I believe that you are an excellent source for insights and understanding regarding the students and environmental context surrounding them.

\section{PROCEDURES}

If you agree to participate in this research study, the following will occur:

- I will interview twice for up to 30 minutes at a time and place convenient to you. The first interview will ask about your perceptions and beliefs about your student. The second interview will ask about your perceptions and beliefs regarding your practice and school policy/structures.

- You will be contacted within a week of each interview to clarify your answers. Each session will be about 15 minutes long.

- I will audiotape the interview to be sure I record your thoughts correctly.

\section{RISKS}

There is a risk of loss of privacy. However, the researcher will not use your name or any other identifying information in any published reports of the research. The research material will be kept in a secure location, and only the researcher will have access to the data. After one year, the researcher will destroy all audio recordings of your interview, will remove all identifying information from the transcripts, and will keep the data in a locked cabinet or office.

There is a risk of discomfort or anxiety because of the personal nature of the questions. You may choose not to answer any question without penalty. If you feel you need it, a list of counseling resources is provided. 
DIRECT BENEFITS

There are no direct benefits to you for participating in this research.

\section{COSTS}

There will be no cost to you for participating in this research.

\section{COMPENSATION}

There will be no compensation for participating in this research.

\section{ALTERNATIVES}

The alternative is to not participate in this research.

\section{OUESTIONS}

You have spoken with Joshua Pong about this study and have had your questions answered. If you have any further questions about the study, you may contact the researcher by email at Joshuapong@gmail or you may contact Professor Pogrow, the researcher's advisor, at stanpogrow@att.net. You may also ask questions about your rights as a research participant, or send any comments or complaints about the study, to Human and Animal Protections at San Francisco State University at 415: 338-1093 or protocol@,sfsu.edu.

Participation in research is voluntary. You do not have to participate, and you may stop participating at any time, or at any point in the project, without any penalty to yourself.

\section{CONSENT}

You have been given a copy of this consent form to keep.

I understand the purpose and the procedures of the research as stated above, and agree to participate.

Participant's Name (print)

Signature

Date:

$$
\text { Research Participant }
$$

Signature

Date:

$$
\text { Researcher }
$$




\title{
Appendix D: Parent/Guardian Permission Form
}

\author{
San Francisco State University \\ Parent/Guardian Permission for a Minor to Participate in a Research Study \\ Interviews for Student Needs Assessment
}

\section{A. PURPOSE AND BACKGROUND}

My name is Joshua Pong. I am a doctoral student at San Francisco State University conducting research to understand the needs of students who are failing despite existing supports at MetWest. This research is meant to help the school know how best to serve your child as they attend MetWest. The research will involve data gathering, analyzing interview transcripts and collaborating with your child on the research data.

I am inviting your child to participate in this research because we believe that your child can provide MetWest with some insight as to what else they should provide for your child to succeed.

\section{B. PROCEDURES}

If your child agrees to participate in this research study, this is what will happen:

1. Your child will be interviewed three times at 30 minutes for each interview

- Your child will be recorded on a digital audio recorder.

- Your child will be interviewed on school grounds or at a nearby food establishment at your convenience.

- The researcher may contact your child later for around 15 minutes so your child may clarify data

2. The total time commitment to interacting with the researcher, 2.25 hours or less.

\section{RISKS}

Your child risks a loss of privacy. However, the name will be replaced with a pseudonym, and no identifiable data will be used in published reports on the research. Only the researcher (Joshua Pong) will have access to the research data. There may be some discomfort at being asked some of the questions; your child will be provided a list of counseling resources. Your child may choose not to answer any of the questions asked 
and may leave the research project at any time, without penalty. Whatever data has been collected up to that point will only be used with your child's assent. If they do not assent to its use, all data collected up to the point of withdrawal will be destroyed.

\section{CONFIDENTIALITY}

All research data will be stored in my faculty advisor's office, $\mathrm{BH} 248$, to which only this researcher has access. All research data will be stored in a device with full disk encryption and password-protection. Data will be stored for three years upon completion of the study.

\section{E. DIRECT BENEFITS}

There are no direct benefits. However, student participants might improve on their academic progress. Reflecting on their experiences may help them better understand themselves, such as what they need in order to academically succeed, now and in the future.

\section{F. COSTS}

There is no cost to the student for participating in this research.

\section{G. COMPENSATION}

Student will receive a $\$ 50$ gift certificate to a place of their choosing, or their first semester college textbooks to a maximum of $\$ 150$.

\section{H. ALTERNATIVES}

The alternative is to not participate in the research.

\section{OUESTIONS}

All questions from student participants or parents should be answered personally and verbally in discussion with the researcher prior to receiving this assent form. For any further questions regarding the study, you may contact me by email at joshuapong@gmail.com, or speak to me over telephone at (510) 931-3622.

Questions about your rights as a study participant, comments, or complaints about the study may be address to the Office for the Protection of Human Subjects at (415) 338-1093 or protocol@sfsu.edu.

\section{J. CONSENT}

You will be given a copy of this assent form to keep. Participation in this research is voluntary. By signing below, you agree to your child being a part of this research study. You also acknowledge that your child is free to leave the research at any point in the 
study with no penalty to their personal and academic well-being. Declining to participate, or withdrawing, will have no effect on your child's present or future status as a student at MetWest High School or San Francisco State University.

Student Name

Parent/Guardian Name

Researcher Name
Student Signature

Date

Parent/Guardian Signature

Date

Researcher Signature

Date

Page 3 of 3 


\section{Appendix E1: Semi-Structured Interview Protocols for Students}

\section{Interview 1}

1. What are some of the things that you enjoy about life?

2. What are some of the more important things (or persons) in your life? What makes them important?

3. What is something you've accomplished that you are proud of?

4. What is something about you that you are most proud of?

\section{Interview 2}

1. What are some of your biggest challenges?

2. How do you deal or cope with those things?

3. What is a typical day for you like?

4. If you had to describe your relationship with your family members in 5 words, what would those words be, and why?

\section{Interview 3}

1. What are your plans after you finish high school?

2. What do you believe MetWest has done very well for you?

3. What do you believe MetWest needs to do better?

4. What do you feel MetWest lacks that you would like to see?

\section{Appendix E2: Semi-Structured Interview Protocols for Staff}

\section{Interview 1}

1. What do you believe hinders or helps [student's name] academic progress?

2. What do you believe [student's name] finds joy and pride in?

3. What is a typical day with [student's name] like?

4. What are you most proud of for [student's name]?

5. What are you most fearful of for [student's name]?

\section{Interview 2}

1. What do you believe are your best practices for your students?

2. What do you believe you could do better for your students?

3. In what areas do you believe you could use some extra support in?

4. How do you envision that extra support being implemented?

5. How well do you believe the present school model is working? 


\section{Counseling Referrals (Appendix F)}

MetWest Restorative Justice Office

Malik Edwards: Restorative Practice Coordinator

Anne Brown: Restorative Practice Coordinator

\section{Strengthofus.org}

"StrengthofUs is an online community designed to inspire young adults impacted by mental health issues to think positive, stay strong and achieve their goals through peer support and resource sharing... Everything here has been developed and created by and for young adults with you specifically in mind. We hope every time you visit, you find hope, encouragement and support."

Teen Line - (800) TLC-TEEN [toll free in CA] / (310) 855-HOPE

Can also text "TEEN" to 839863 at standard msg/data rates, or use email and message boards at teenlineonline.org.

"TEEN LINE is a confidential telephone helpline for teenage callers. It operates every evening from 6:00pm to 10:00pm PST and is toll-free from anywhere in California. If you have a problem or just want to talk with another teen who understands, then this is the right place for you!"

Boys Town National Hotline - (800) 448-3000

Can also text VOICE to 20121 for free text messaging on most major carriers.

Live chat and email can be found at www.yourlifeyourvoice.org, a website affiliated with Boys Town National Hotline.

California Coalition for Youth - (800) 843-5200

"California Coalition for Youth offers support, encouragement, and referrals to youth needing assistance or in crisis situations."

Youth America Hotline - (877) 968-8454

"YAH is the first and only toll free, peer to peer hotline network linking callers to community based peer counseling hotlines in the nation."

National Suicide Prevention Lifeline - (800) 273-TALK

"The National Suicide Prevention Lifeline is a 24-hour, toll-free, confidential suicide prevention hotline available to anyone in suicidal crisis or emotional distress... The Lifeline's national network of local crisis centers provides crisis counseling and mental health referrals day and night." 


\section{Crisis Support Services of Alameda - (800) 309-2131}

"Founded in 1966, Crisis Support Services offers a broad range of counseling, education and prevention services in a safe environment. CSS' 24-hour crisis hotline responds to more than 60,000 calls each year. Services include on-going therapy groups, schoolbased counseling, supportive services for seniors, suicide prevention for youth; and community education." 